University of Redlands

\title{
Dam Burst Model Prototype
}

A Major Individual Project submitted in partial satisfaction of the requirements for the degree of Master of Science in Geographic Information Systems

\author{
By \\ Dean Erpenbach
}

Committee in charge:

Mark Kumler, Ph.D., Chair

Karen K. Kemp, Ph.D.

David Lovell 
Dam Burst Model Prototype

Copyright (C) July 2005

by

Dean Erpenbach 
The report of Dean Erpenbach is approved.
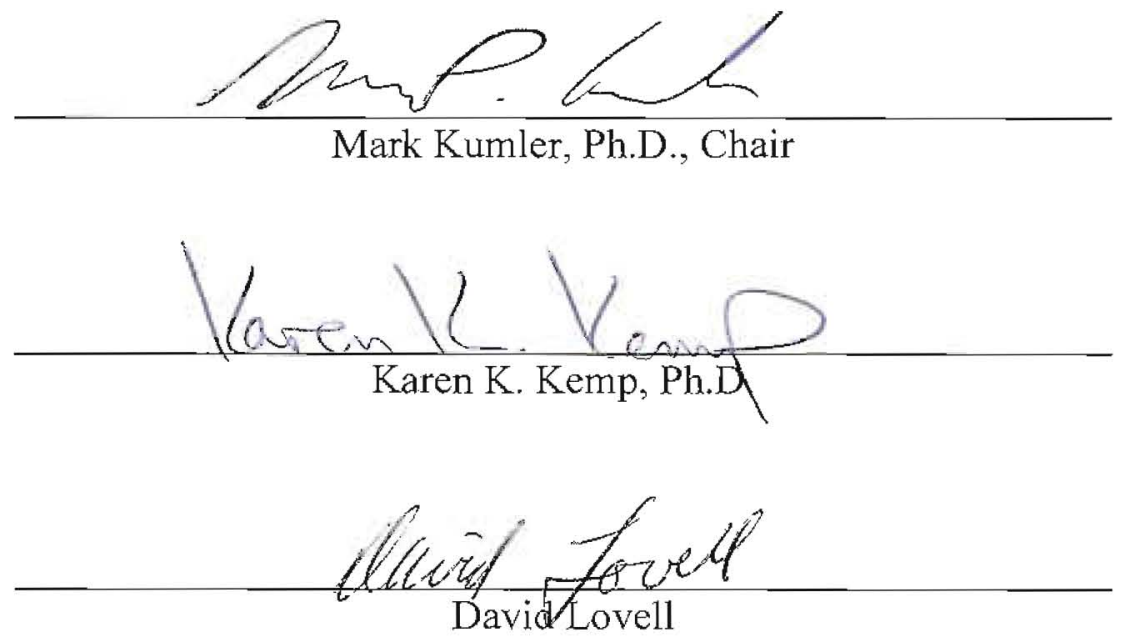

July 2005 



\section{ACKNOWLEDGEMENTS}

I would like to acknowledge my wife, Karen, and children, Hannah and Hayden, for accepting my absence the last eleven months.

I would like to acknowledge my client, David Lovell, for his advice, support and associations with the County of San Bernardino Flood Control District.

I would also like to acknowledge Dr. Dean Djokic for his assistance with technical problems. 



\author{
ABSTRACT \\ Dam Burst Model Prototype \\ By \\ Dean Erpenbach
}

The analyst has created a model using ESRI model builder software, spatial analyst, and 3D extensions, to create a simulated dam burst for analysis purposes. The main software packages utilized were ESRI's ArcGIS 9.0, Leica's Erdas Imagine, and the United States Army Corps of Engineer's (USACE) Hydrologic Engineering Center River Stream Analysis (HEC-RAS). The analyst has also included the ESRI HEC-GeoRAS extension and the ESRI Arc Hydro extension in the analysis. Many processes were automated using ESRI's model builder toolset; however the model could be interrupted whenever human decision-making was required. The main intention of the model was to automate many of the more computationally intensive processes to allow the analyst more efficient use of their time. The final output desired was a polygon shapefile of the potential flooded area. This polygon was used for further analysis of critical infrastructure data sets affected.

The analysis included three different methods. The first method showed the resulting graphics using HEC-RAS. The second method used the ESRI HEC-GeoRAS extension in ArcGIS 8.3. The third method tried to emulate HEC-RAS software results using ArcGIS 9.0 with the Spatial Analyst and Arc Hydro extensions. The results were compared graphically and dramatic differences were evident.

This model is suitable for use by the National Geospatial-Intelligence Agency (NGA) and the Department of Homeland Security (DHS) for analysis relating to a possible terrorist-induced event involving a dam burst. Since most processes will be automated, the training involved for new analysts will be minimal. The analyst's employer, NGA, has an extremely large database which lends itself well to use in a working model. The analyst intends to use the newly created model on other critical infrastructure data sets, such as chemical plants, oil refineries, and nuclear facilities. 



\section{Table of Contents}

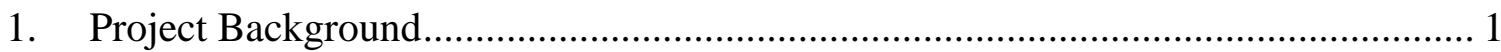

1.1. Fact Sheet on Silverwood ...................................................................... 1

2. Data Acquisition and Preparation ................................................................................ 3

2.1. Project Development Focusing on Data Preparation and Acquisition................. 3

2.2. Data Acquisition ........................................................................................ 3

2.3. Data Preparation.............................................................................. 5

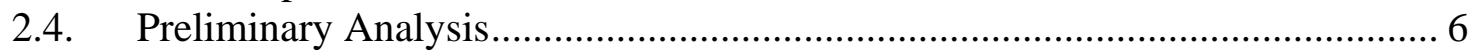

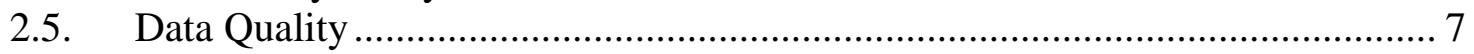

2.6. Build Model .................................................................................................. 7

3. Project Development with Extensive Emphasis on HEC-RAS .................................. 13

3.1. Selecting XS Cutlines and River Reaches ....................................................... 13

3.2. Problems Encountered During HEC-RAS Software Usage ............................. 16

4. Visualizing Flooded Area with ArcGIS 8.3 and HEC-GeoRAS ................................ 31

5. Emulating HEC-RAS with ArcGIS 9.0, ArcHydro and Spatial Analyst Extensions 43

6. Comparison of Results and Conclusions .............................................................. 57

Appendix A: Tuttle Creek Dam Safety Exercise .............................................................. 67

Appendix B: Cost Summary of MIP in terms of hours ................................................. 70

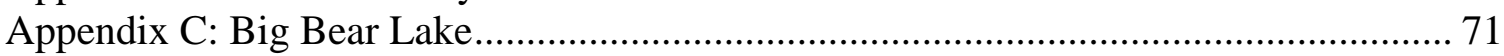

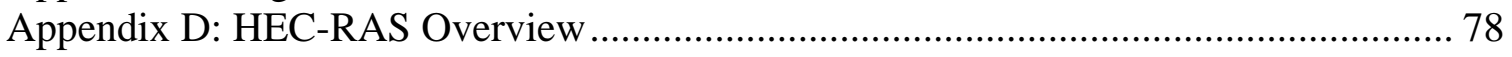

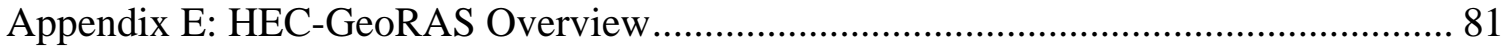




\section{List of Figures}

Figure 2-1 Silverwood Lake Reference Map.............................................................. 4

Figure 2-2 Terrain Visualization Model ....................................................................... 8

Figure 2-3 Raw DEM (the main input of the model) and Silverwood Lake ................ 9

Figure 2-4 Shaded relief image created from DEM and Spatial Analyst extension... 10

Figure 2-5 Slope Depiction of Silverwood Lake area ................................................ 11

Figure 3-1 Example of poorly generated XS cutlines by the automatic process........ 15

Figure 3-2 Perspective plot with left-to-right view (HEC-RAS results) ..................... 18

Figure 3-3 Perspective view looking upstream (HEC-RAS results) ........................... 19

Figure 3-4 Profile view of one of the XS cutlines (HEC-RAS results)...................... 20

Figure 3-5 First XS cutline with water surface displayed ........................................... 20

Figure 3-6 Sample XS cutline with water surface displayed....................................... 21

Figure 3-7 Sample XS cutline with water surface displayed....................................... 21

Figure 3-8 Profile plot of stream centerline (HEC-RAS results) ................................ 22

Figure 3-9 Profile plot of stream centerline and elevation (HEC-RAS results) ......... 22

Figure 3-10 HEC-RAS plot of geometry created in HEC-GeoRAS extension of

ArcGIS 9.0 ............................................................................................... 23

Figure 3-11 Profile view looking down from Silverwood Dam (HEC-RAS results)... 24

Figure 3-12 Perspective view using the fly-through tool in HEC-RAS ........................ 27

Figure 4-1 HEC-GeoRAS TIN created from XS cutlines ........................................... 32

Figure 4-2 HEC-GeoRAS Bounding polygon and Depth polygon ............................... 33

Figure 4-3 HEC-GeoRAS Bounding polygon and Flooded polygon.......................... 34

Figure 4-4 TIN elevations created in HEC-GeoRAS extension of ArcGIS 8.3 ......... 35

Figure 4-5 TIN and Depth polygon of intermediate floodplain .................................. 36

Figure 4-6 Bounding polygon of XS cutlines and Floodplain polygon ...................... 37

Figure 4-7 TIN elevations created in HEC-GeoRAS extension of ArcGIS 8.3 ......... 39

Figure 4-8 TIN and Depth polygon of full extent floodplain ...................................... 40

Figure 4-9 Bounding polygon of XS cutlines and Floodplain polygon ...................... 41

Figure 4-10 Floodplain with transparency enhanced................................................... 42

Figure 5-1 Flooded area depiction using ArcGIS 9.0 ………...................................... 44

Figure 5-2 Three-Dimensional view of DEM and Silverwood Lake .......................... 45

Figure 5-3 Higher angle 3D view of DEM and Silverwood Lake............................... 45

Figure 5-4 Large scale 3D view of XS cutlines...................................................... 46

Figure 5-5 Three-Dimensional view from behind Silverwood Lake........................... 46

Figure 5-6 Three-Dimensional view of the area of concern with transportation

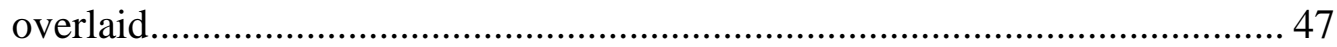

Figure 5-7 The processed DEM and overlaid hillshade featuring Silverwood Lake . 48

Figure 5-8 Area of interest showing parcels affected (highlighted in turquoise) ....... 49

Figure 5-9 DEM and hillshade with 1000 meter buffers of the intersection

of flooded area and buffers, which can be used as a time-series depiction

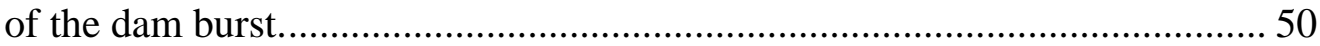

Figure 5-10 Depiction of the flooded area using ArcGIS 9.0...................................... 51

Figure 5-11 XS cutlines created in ArcGIS using the same two reference data sets.... 52

Figure 5-12 The XS cutlines converted to 3D feature class are here. .......................... 53 
Figure 5-13 This graphic shows the DEM along with Silverwood Lake for reference.54

Figure 5-14 Silverwood Lake with surrounding transportation network .................... 55

Figure 5-15 Poster display of Silverwood Lake ........................................................ 56

Figure 6-1 HEC-RAS geometry plot of XS cutlines and stream centerline ............... 58

Figure 6-2 Profile view looking down from Silverwood Dam (HEC-RAS results)... 59

Figure 6-3 Perspective view using the fly-through tool in HEC-RAS 3.1.3 .............. 59

Figure 6-4 HEC-GeoRAS Initial Bounding polygon and Floodplain polygon .......... 60

Figure 6-5 Bounding polygon of XS cutlines and intermediate Floodplain polygon. 61

Figure 6-6 Fully extended Floodplain polygon with transparency enhanced.............. 62

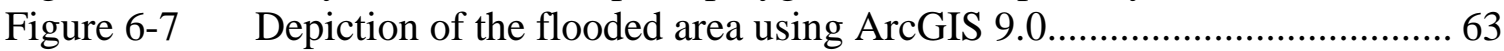

Figure 6-8 Time buffer flooded area depiction using ArcGIS 9.0 ........................... 64

\section{List of Tables}

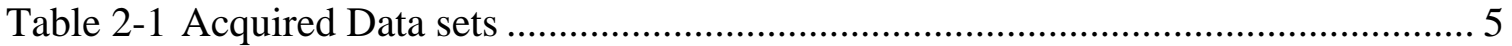

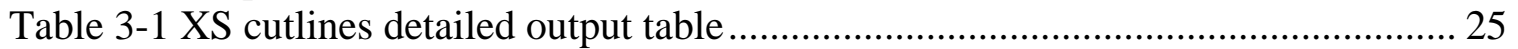

Table 3-2 Detailed Output table of the first three XS cutlines profiles ............................ 26

Table 3-3 Values used in first flooded area polygon trial.............................................. 29

Table 3-4 Values used in second flooded area polygon trial ........................................ 30

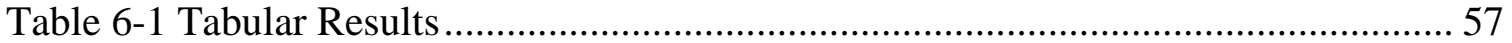

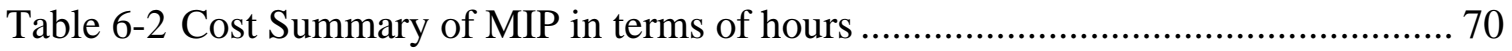

\section{Acronyms and Abbreviations}

$\begin{array}{ll}\text { ASCII } & \text { American Standard Code for Information Interchange } \\ \text { CRADA } & \text { Cooperative Research and Development Agreement } \\ \text { DEM } & \text { Digital Elevation Model } \\ \text { DHS } & \text { Department of Homeland Security } \\ \text { DOQQ } & \text { Digital Ortho Quarter Quadrangle } \\ \text { DRG } & \text { Digital Raster Graphics } \\ \text { ESRI } & \text { Environmental Systems Research Institute } \\ \text { HSIP } & \text { Homeland Security Infrastructure Program } \\ \text { GIMS } & \text { Geographic Information Management System } \\ \text { GIS } & \text { Geographic Information System } \\ \text { HEC } & \text { Hydrologic Engineering Center } \\ \text { HEC-RAS } & \text { Hydrologic Engineering Center- River Analysis System } \\ \text { mdb } & \text { Personal Geodatabase } \\ \text { MIP } & \text { Major Individual Project } \\ \text { MSGIS } & \text { Masters of Science in Geographic Information Systems } \\ \text { NGA } & \text { National Geospatial-Intelligence Agency } \\ \text { SA } & \text { Spatial Analyst } \\ \text { TIN } & \text { Triangulated Irregular Network } \\ \text { U of R } & \text { University of Redlands } \\ \text { USACE } & \text { United States Army Corps of Engineers } \\ \text { XML } & \text { eXtensible Markup Language } \\ \text { XS } & \text { Cross Sections }\end{array}$





\section{Project Background}

The analyst works for the National Geospatial-Intelligence Agency (NGA). One of the main projects the analyst will be using in his employment is the Homeland Security Infrastructure Program (HSIP). The HSIP contains all of the data sets deemed critical to our nation's security. The analyst will also work indirectly with the Department of Homeland Security (DHS). This dam burst prototype model can subsequently be used by the DHS. The analyst intends to expand on this dam burst model idea beyond the span of dams, to include other vital infrastructure data sets, such as chemical plants, petroleum refineries, and nuclear facilities.

The analyst has extensive experience providing geospatial support while working with military and civilian disaster response exercises and special events, such as major sporting events. Since the infamous events of September $11^{\text {th }}, 2001$, the practice of emergency response has become extremely prevalent. An especially appropriate example of such an exercise involves the Tuttle Creek Dam Project outside Manhattan, Kansas. The United States Army Corps of Engineers (USACE), Kansas City District, held an exercise to test emergency response on October 20, 2004 (U.S. Army Corps of Engineers, 2005). The exercise tested the Tuttle Creek Dam Failure Warning System activated in the occurrence of an earthquake. The exercise involved over one hundred people from across the country at the city, county, state, and federal government level. Although this exercise considered the possibility of an earthquake disaster, many similarities can be drawn to a terrorist event, which makes this exercise very interesting to the analyst. The complete article is found in Appendix A.

\subsection{Fact Sheet on Silverwood}

The analyst chose the Silverwood Dam in San Bernardino County, CA, for his prototype example. Silverwood Dam was selected because of its close proximity to the University of Redlands (U of R). The following paragraphs from the California Parks webpage give a brief description of the lake.

"Silverwood Lake was formed by the 249-foot Cedar Springs Dam. At 3,350 feet, it is the highest reservoir in the State Water Project. The park features hiking trails, swimming beaches and designated areas for boating, water-skiing and fishing. The lake has trout, large-mouth bass, catfish and bluegill. There is a marina with a launching ramp, boat and equipment rentals, and a store. The park has picnic areas, including three that can only be reached by boat. The lake attracts waterfowl, raptors and songbirds. Canada Geese and an occasional bald eagle can be seen in the area.

On October 29, 2003, forest fires that swept through Southern California damaged much of Silverwood Lake and the surrounding forests. Emergency cleanup and preparation for winter rains are now taking place. There are many damaged facilities and hazards that prevent safe camping, day-use, and boating. Vehicle access to Cedar Springs Dam is limited due to 9/11 security measures." 
The lake was formed by the 204 foot high Mojave Dam, which was built in 1971 for flood control. The maximum capacity of Silverwood Lake is 157,000 acre-feet.

Silverwood Lake is a local haven for boating, canoeing, jet skiing, hiking and camping. It is also an excellent lake for fishing. The catch includes perch, trout catfish, blue gill, bass and salmon. Silverwood Lake area offers excellent camping opportunities. It offers 136 developed camp sites. With an elevation of 3350, feet it is especially appealing as an escape from the scorching 'high desert' temperatures in the summer months.

The mention of 9/11 security measures ties in with the topic of what the analyst intends to help substantiate. On June $17^{\text {th }}$, 2005, the analyst was able to drive to within 50 feet of the dam, where the restrictions turned to foot traffic only. Prior to 9/11, the public could drive up to the Cedar Springs Dam.

The analyst has developed a working prototype model using ArcGIS 9.0 software that will automate most of the processes. The specific objectives of this project are to automate many GIS processes, which will afford GIS professionals the latest tools, saved in the structure of a model, and to gain valuable time for analysis. The project will combine multiple GIS tasks within the model. The deliverable will be a working model which can be shared among GIS professionals. The model will expedite processing, freeing the analyst from some of the more time consuming processing tasks. The analyst can then spend time on other analytical steps that can not be automated. The analyst will be able to use this model on any dam (assuming that the data sets involved would be similar) by simply changing the computer path names and re-running the model. 


\section{Data Acquisition and Preparation}

\subsection{Project Development Focusing on Data Preparation and Acquisition}

The data preparation and acquisition phase of the analyst's MIP began as soon as his idea was accepted by the faculty at the University of Redlands ( $U$ of R). The U of R staff, composed of Dr. Karen Kemp and Dr. Mark Kumler, approved the analyst's MIP idea of developing a dam burst prototype model. Once the MIP idea was accepted, the analyst then concentrated on the datasets deemed necessary to complete his MIP. This list included various raster and vector datasets.

The analyst chose the ESRI ArcMap software program and the Hydrologic Engineering Center River Analysis System (HEC-RAS) software program as the two main software programs for his MIP development. The HEC-RAS software is available free of charge from the United States Army Corps of Engineers (USACE) website. A

detailed explanation of the HEC-RAS software and the HEC-GeoRAS extension used in ArcGIS and their differences is warranted. The HEC-GeoRAS is the extension developed by ESRI for use with ArcGIS 8.3. The HEC-GeoRAS extension is being developed under a Cooperative Research and Development Agreement (CRADA) by the Hydrologic Engineering Center (HEC) and ESRI. Since this is a CRADA, it becomes lower priority for development, compared to a paying contract. The HEC-GeoRAS extension is named as such because it incorporates geographic coordinates into the HECRAS software. To alleviate the confusion between the very similar terms, note that there are only two software programs being used. HEC-RAS is a completely separate software program. HEC-GeoRAS is an extension to the ArcGIS software that is being developed by ESRI. It is important to note that when the 'HEC-RAS' term is used, it is referring to the software program used by the United States Army Corps of Engineers (USACE), and when the 'HEC-GeoRAS' term is used, it is referring to the extension to ESRI's ArcGIS 8.3 version (currently being updated for version 9.0). To further clarify this: When the term "Geo" is used, the (ESRI) software is being discussed, and when the term "Geo" is not used, the analyst is referring to the USACE software.

The ESRI HEC-GeoRAS extension is used to create Geometric Data that can be input into HEC-RAS. This data is imported into HEC-RAS as a feature class in ASCII (sdf) format. The HEC-RAS software is used to perform calculations on the Geometric Data. This HEC-RAS output data is then exported in both an ASCII (sdf) and extensible markup language (XML) format. The ASCII and XML formats are both imported into ArcGIS 8.3 for analysis using the HEC-GeoRAS extension. The HEC-RAS (USACE) software operates in the two-dimensional mode, whereas the HEC-Geo RAS (ESRI) software allows the analyst to explore in the three-dimensional mode. This is the main advantage of using the HEC-GeoRAS (ESRI) software over the HEC-RAS (USACE) software program.

\subsection{Data Acquisition}

The major web sites for data used by the analyst were the California Spatial Information Library (www.gis.ca.gov), MapMart.com, and the Utah Automated 
Geographic Reference Center (AGRC). A complete list of data sites is included in Table 2-1, shown later in this chapter. The analyst initially selected a dam location in the state of Utah. A decision was later made to select a local dam. The dam chosen was Silverwood Dam, in San Bernardino County, California. See Figure 2-1.

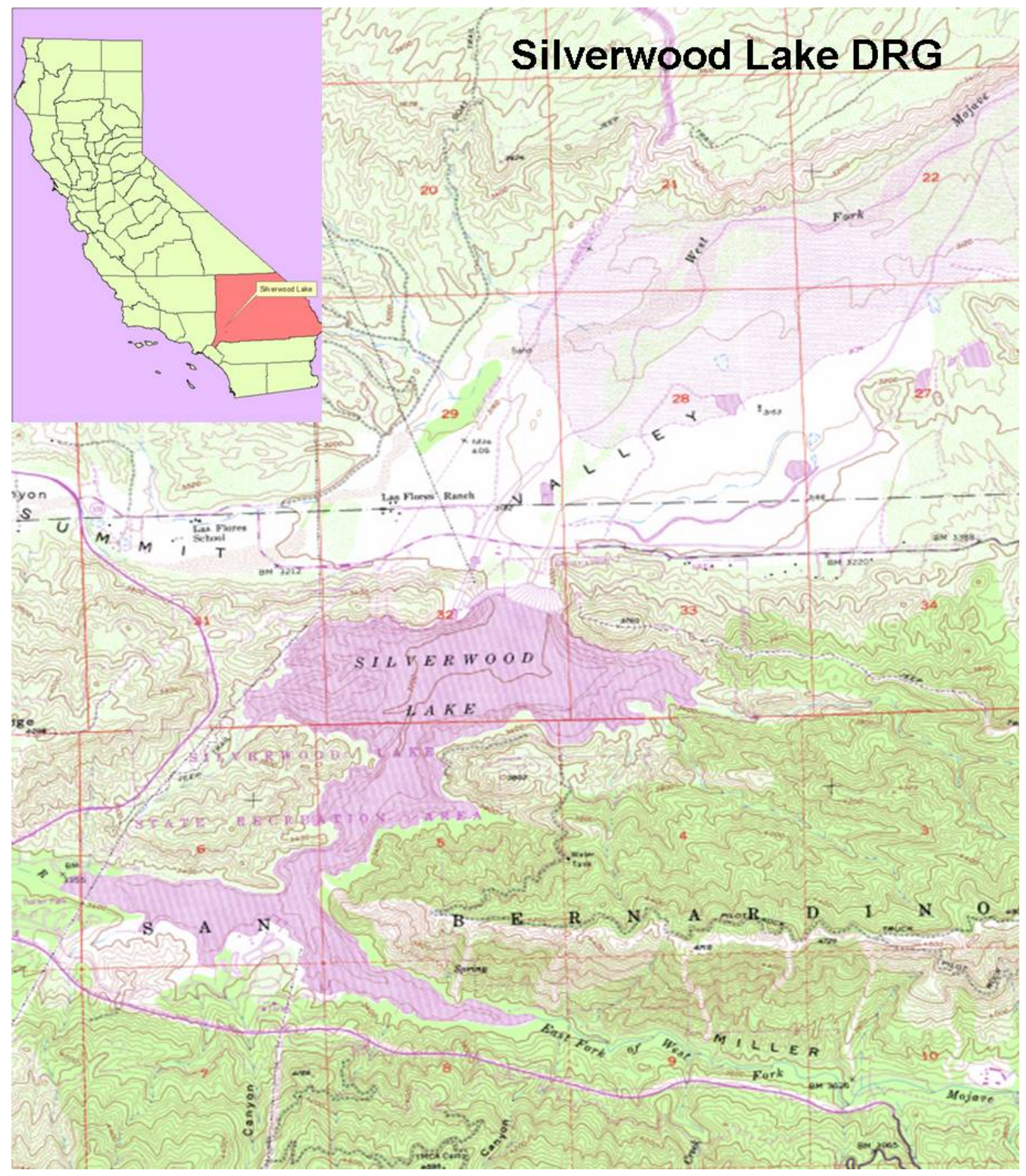

Figure 2-1. Silverwood Lake Reference Map

The analyst also received parcel data from Mr. Brent Rolf, Geographic Information Management System (GIMS) Manager, County of San Bernardino, Information Services Department, Emerging Technologies Division, Office of the CIO. See Table 2-1 below for a complete listing of data sets acquired. 
Table 2-1. Acquired Data sets

\begin{tabular}{|l|l|l|}
\hline Data Set Name & Data Type & Source \\
\hline Administrative & vector & www.gis.ca.gov \\
\hline Airports & vector & www.gis.ca.gov \\
\hline Census data & vector & www.gis.ca.gov \\
\hline Dams & vector & www.gis.ca.gov \\
\hline DEM & raster & www.MapMart.com \\
\hline DOQQ & raster & www.gis.ca.gov \\
\hline DRG & raster & www.gis.ca.gov \\
\hline Fire Stations & vector & www.gis.ca.gov \\
\hline Hospital & vector & www.gis.ca.gov \\
\hline Hydrology & vector & www.gis.ca.gov \\
\hline Imagery & raster & www.gis.ca.gov \\
\hline Lakes & vector & www.gis.ca.gov \\
\hline Parcels & vector & GIMS, San Bernardino \\
\hline Police Stations & vector & www.gis.ca.gov \\
\hline Rivers & vector & www.gis.ca.gov \\
\hline Soils & vector & www.gis.ca.gov \\
\hline Transportation & vector & www.gis.ca.gov \\
\hline Utilities & vector & www.gis.ca.gov \\
\hline
\end{tabular}

\subsection{Data Preparation}

The data preparation consisted of various steps for the different data sets. The Digital Ortho Quarter Quadrangles (DOQQs) were mosaicked into a single file. Mosaicking is the process of combining several small raster files into one larger raster file. The single raster file gives the user a seamless view that is much easier to view in various software programs. The method of creating a virtual mosaic (where multiple rasters can be viewed seamlessly, but are broken into separate pieces to reduce display time) can also be used. The analyst chose a one-piece mosaick, but limited the geographic extent. The spatial extent of the workspace was limited to the local analysis area to expedite the processing and maximize storage capacity. The spatial extent was set in ArcGIS to be the smallest geographic area needed to correctly portray the dam burst area being analyzed with the "model". This was accomplished by subsetting the mosaicked imagery to the area of immediate interest. Subsetting is defined as "breaking out a portion of a large file into one or more smaller files”. (Erdas Imagine Document, 1999)

A set of ten 10-meter digital elevation models (DEMs) were acquired through www.MapMart.com. These were subsequently mosaicked in Erdas Imagine to create a continuous elevation surface. The mosaics were then subset in Erdas Imagine to limit the extent to the area of analysis. This served a dual purpose by reducing processing time due to limiting the spatial extent, and also reducing storage required.

The DEM for the area of interest was converted to an ESRI grid for use in ArcGIS 9.0. The ESRI grid was used as the main input to the model. The following procedures were run on the ESRI grid and its associated output files: aspect, slope, hillshade, flow 
direction, flow accumulation, sink, and contour. This set of tools gave the analyst a good visual perspective of the area of interest. They are discussed in detail in section 2.4.

Since the prototype dam selected was so close to the $U$ of $R$, the analyst was able to drive to Silverwood Dam and physically validate the portrayal of the elevations by the DEM. The actual area of interest appeared just as its GIS portrayal in ArcGIS. Traveling to the site will rarely be the case, since the model is designed to be used on any dam in the nation. The idea of traveling to the site is somewhat contradictory to the main function of the working model, which is to automate processes to save time.

The analyst performed a series of procedures in the HEC-RAS software program used by the United States Army Corps of Engineers and the HEC-GeoRAS extension being developed by ESRI. A comprehensive explanation of these procedures is presented in Chapters 3, 4, and 5.

\subsection{Preliminary Analysis}

The following gives a more detailed description of the analyst's terrain visualization work using Erdas Imagine and ESRI's Spatial Analyst and 3D Analyst extensions. These steps were critical to determining the study area extent, as well as selecting cross-section lines in the initial analysis with HEC-RAS.

A total of ten 10-meter Digital Elevation Models (DEM) were downloaded from www.MapMart.com. Their spatial reference was Universal Transverse Mercator (UTM) Projection (Zone 11), in the Clarke 1866 Spheroid and the North American Datum 1927 (NAD27). The DEMs had a ddf file extension in the Spatial Data Transfer Standard (SDTS) format. They were imported into Erdas Imagine and then exported as .img files. The DEMs were displayed as 8-bit monochromatic raster images with the lowest elevation being displayed as black, the highest elevation as white and intermediate elevations as shades of gray.

The analyst mosaicked the DEMs using the Erdas Imagine software program. The files were then subset into smaller raster files to expedite processing time. The analyst included four of the DEMs in the analysis area for the dam burst prototype of Silverwood Lake.

The DEM was then brought into ArcMap. The following GIS tools, from the Spatial Analyst extension, were selected for model input:

Aspect - the direction of a raster surface

Sink - identifies sinks or areas of internal drainage

Flow Direction - creates a raster based on the surrounding Z (elevation) values

Flow Accumulation - creates a raster using the flow direction raster as input

Slope - identifies the slope or change in the $\mathrm{Z}$ value, from raster cell to surrounding raster cells

Slope over 30 degrees - similar to slope above, except that it identifies areas of steep slope 
Hillshade - creates a hillshade view of a raster considering illumination angles and shadows

Contour - generates contour lines from the DEM values

\subsection{Data Quality}

The analyst performed several checks to verify the validity of the data. Of great importance was the accuracy of the Digital Elevation Model (DEM). The analyst had already taken a major step toward guaranteeing high accuracy by acquiring a 10-meter DEM. Many DEMs available are 30-meter pixel size (standard download pixel size from United States Geological Survey), so a 10-meter pixel size DEM has nine times as many pixels as the 30-meter DEM covering the same geographic extent. The analyst used all the visual graphics produced from the 'surface analysis model' discussed in the next section. These graphic outputs include hillshade, contours, slope and aspect. If there were blunders in the DEM, they may not be obvious by viewing the DEM in its raw.dt1 format, but would most likely be exposed by one of these graphic outputs.

Since the study area was within driving distance of the University of Redlands, the analyst was able to drive to Silverwood Lake, to verify the accuracy of the DEM. This is the exception, rather than the rule, so an analyst has to trust the accuracy of the data being used. The analyst looked at the metadata included with the 10-meter DEM for relative and vertical accuracy numbers. There was no accuracy data available in the metadata or the Read-me Word Document provided. Thus, the analyst was relying on exposure of any blunders by viewing the graphic outputs of the 'surface analysis model'. To further reinforce the accuracy of the DEM, the analyst did some research on the internet to include, but not limited to the MapMart website. This research revealed basic data quality information, so again the analyst relied on the model, and trusted in the MapMart Company's quality products.

The other main data set that had to be verified for accuracy was the hydrology (stream) dataset. The analyst verified the stream dataset by viewing the metadata accuracies, by comparing it to standard atlas maps, and also comparing it to Digitized Raster Graphics (DRG). The stream dataset compared very closely to all three ancillary datasets. The stream dataset was used in the HEC-GeoRAS portion of this project, for reference only, since the analyst delineated the stream centerline based on the visual appearance of the land portrayed by the hillshade graphic.

\subsection{Build Model}

The analyst created a model in ArcGIS 9.0 for the purpose of automating many of the steps in the Dam Burst Model Prototype. The model consists of eight processes in its current form.

A major advantage of using a model is that it can be used on other datasets with only a change in the working directory's path name. The analyst intends to expand this model beyond dams to include other types of critical infrastructure, such as chemical plants and nuclear facilities. It really is difficult to replace a human mind with a computer for analysis purposes. The analyst will use a series of working models that have to be broken when the "human factor" comes into play. A diagram of the initial stages of a surface analysis model appears below in Figure 2-2. 


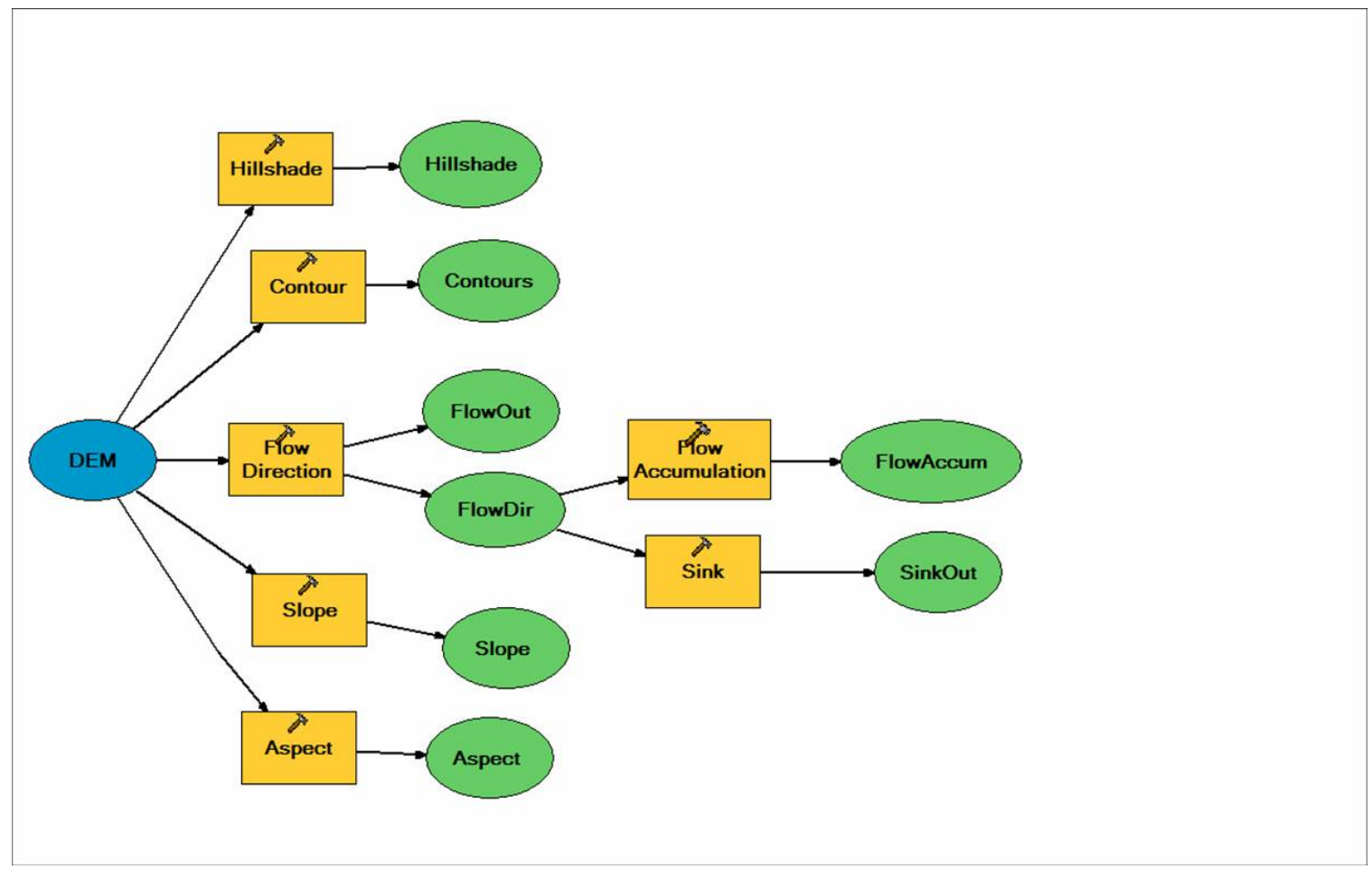

Figure 2-2. Terrain Visualization Model

The analyst initially ran the model on Silverwood Lake. Figure 2-3 through Figure 2-5 illustrate three of the products from the DEM pre-processing. 


\section{DEM GRID}

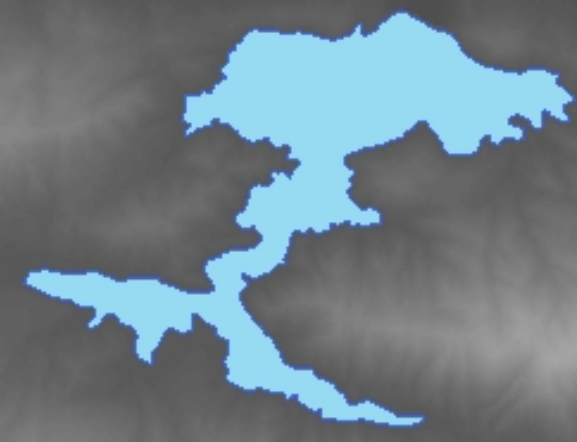

DEM GRID

Meters

High : 1968.3

\begin{tabular}{llllll}
0 & 0.25 & 0.5 & 1 & 1.5 & 2 \\
\hline
\end{tabular}

Low : 335.4

Figure 2-3. Raw DEM (the main input of the model) and Silverwood Lake 


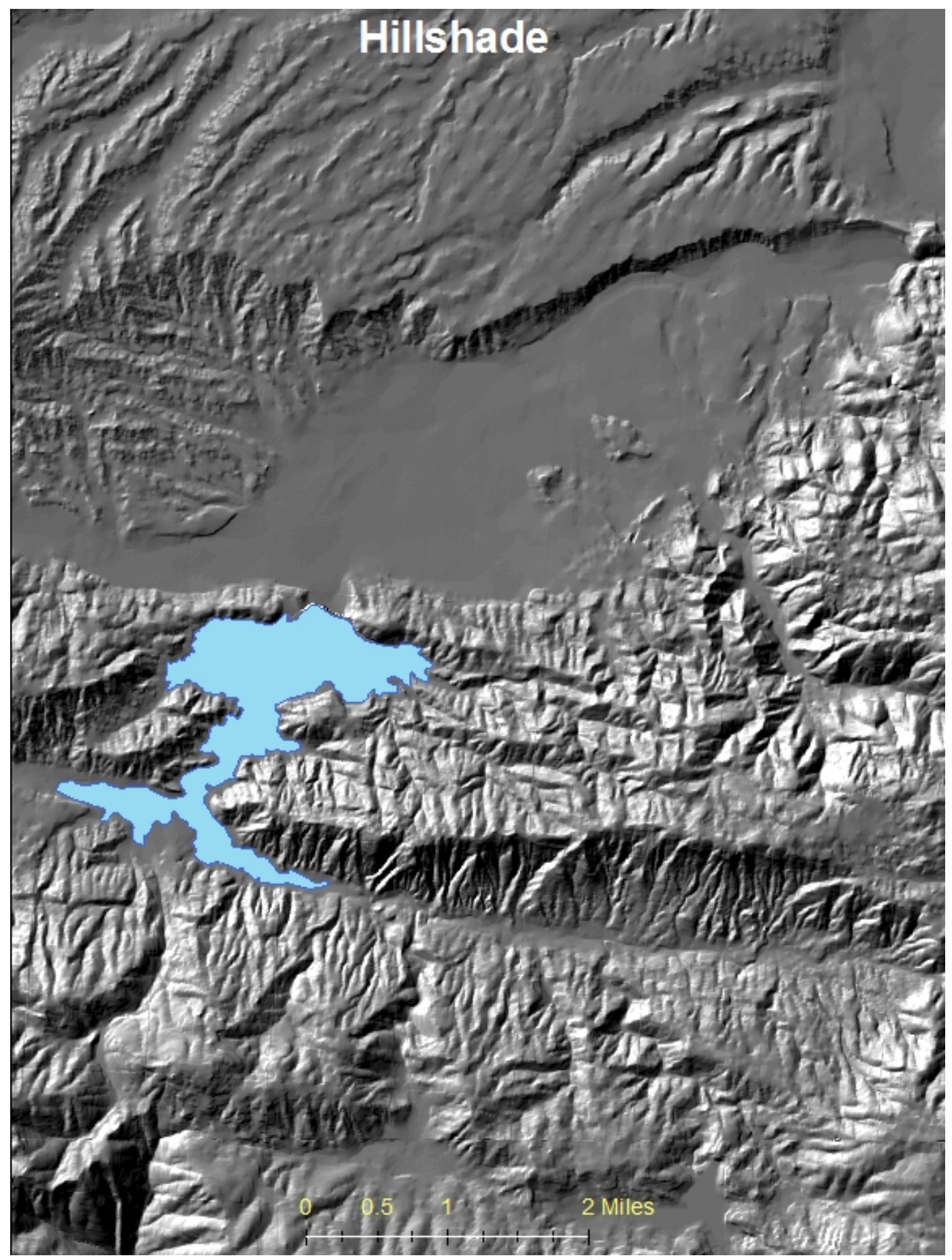

Figure 2-4. Shaded relief image created from DEM and Spatial Analyst extension 


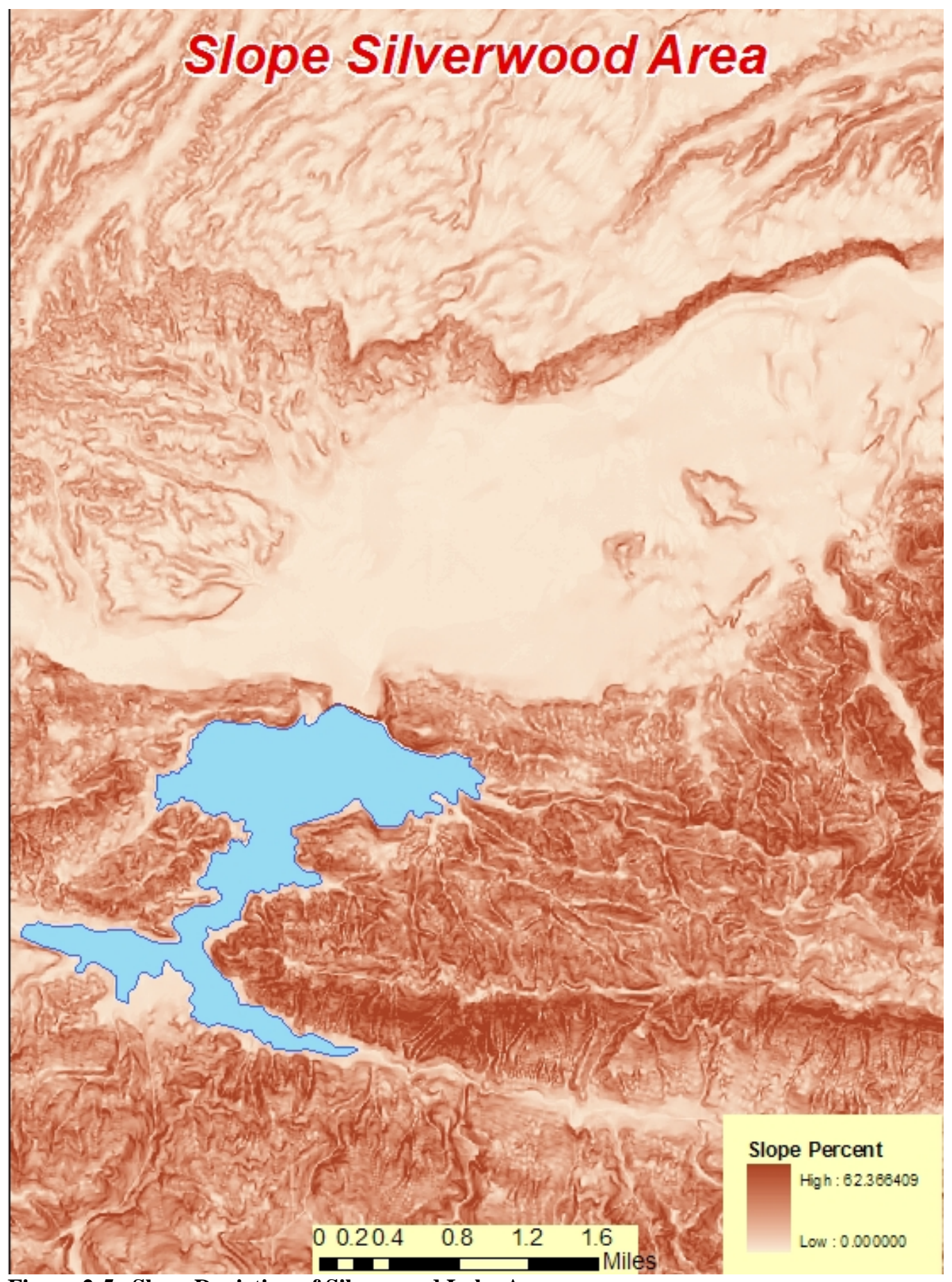

Figure 2-5. Slope Depiction of Silverwood Lake Area

The analyst's MIP proposal was intended to test the model on a second lake. These graphics are included in Appendix C. 



\section{Project development with extensive emphasis on HEC-RAS}

The first set of GIS tools used to create the surface analysis products were combined into the first working model in the MIP. While a working model that requires no intervention is the ideal situation, it is virtually impossible to eliminate the analyst from the interpretation process. The analyst has a natural break in the model here because of the use of the Hydrologic Engineering Center River Analysis System (HECRAS) software.

The analyst incorporated the HEC-RAS software into the MIP because of the extensive research that was put into the software program's development, and the close detail relating to hydrologic systems. The current version is 4.0 Beta. With 4.0 Beta only being compatible with ArcGIS 8.3, the analyst had to locate a computer with ArcGIS 8.3, versus ArcGIS 9.0, which was loaded to his computer. This situation lends itself to a natural break in the model, since the Beta version required the analyst to switch computers. This problem will be fixed once the 4.0 Beta version is compatible with ArcGIS 9.0. Another reason for this natural break in the model is because of the 'hands on' work required from the analyst when selecting Cross Section (XS) cutlines while in the HEC-GeoRAS extension of ArcGIS 8.3. The HEC-GeoRAS extension has a function for selecting XS cutlines automatically, but the on-line help highly recommends the XS cutlines be selected manually. An example of XS cutlines being selected automatically by HEC-GeoRAS is included in the next section. It is important to note again: To alleviate the confusion between the very similar terms, note that there are only two software programs being used. HEC-RAS is a completely separate software program. HEC-GeoRAS is an extension being developed by ESRI. So, it is important to note that when the term "HEC-RAS" is used, it is referring to the software program used by the United States Army Corps of Engineers (USACE), and when the term "HEC-GeoRAS" is used, it is referring to the extension to ESRI's ArcGIS 8.3 version (currently being updated for version 9.0).

The ESRI HEC-GeoRAS extension is used to create Geometric Data that can be input into (HEC-RAS). This data is imported into HEC-RAS as a feature class in ASCII (sdf) format. The HEC-RAS software is used to perform calculations on the Geometric

Data. This HEC-RAS output data is then exported in both an ASCII (sdf) and extensible markup language (XML) format. The ASCII and XML formats are both imported into ArcGIS 8.3 for analysis using the HEC-GeoRAS extension.

\subsection{Selecting XS Cutlines and River Reaches}

The first step performed by the analyst was to create a new ArcMap document with the following layers:

DEM
Hillshade
Streams
Lakes
Dams
Transportation network


Subsequently, the analyst manually created a stream centerline, using the hillshade and streams layers for reference. The hillshade derived from the Digital Elevation Model (DEM) provides the necessary information to visualize the potential flooded area.

The selection of XS cutlines in the HEC-RAS software program plays a crucial part in many of the calculations. Great attention to detail was practiced in the selection of the XS cutlines. The more XS cutlines delineated, the more accurate were the statistics. This is analogous to a 10-meter DEM being more accurate than a 30-meter DEM. There is a point of diminishing return however, where too many XS cutlines would not improve the results, just as there is a point of diminishing return on a high resolution DEM. At some point the processing time and storage requirements offset the increased accuracy of the data. An example of XS cutlines being selected automatically by HEC-GeoRAS is shown in Figure 3-1. 


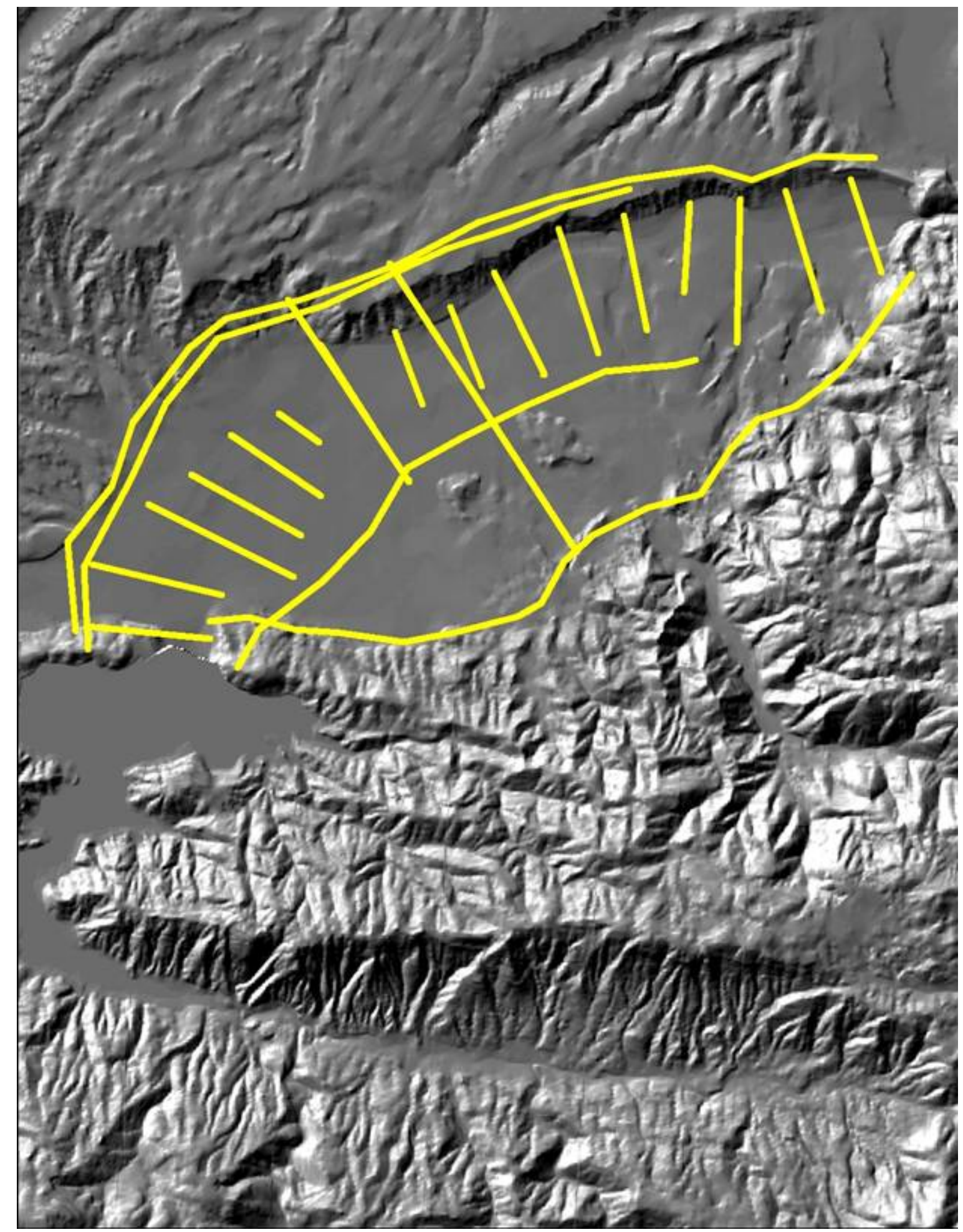

Figure 3-1. Example of poorly generated XS cutlines by the automatic process

The analyst delineated 32 evenly spaced XS cutlines. These were delineated from the left bank to the right bank, while looking downstream. The analyst used the DEM for elevation retrieval and overlaid the hillshade in order to visualize the relief of the area of 
interest. The area of interest was greatly magnified to ensure the best visualization, and the utmost accuracy. These newly created feature classes were delineated using the ArcGIS 8.3 Editor Toolbar.

The ESRI HEC-GeoRAS extension is used to create Geometric Data that can be input into (HEC-RAS). This data is imported into HEC-RAS as a feature class in ASCII (sdf) format. The HEC-RAS software is used to perform calculations on the Geometric Data. This HEC-RAS output data is then exported in both an ASCII (sdf) and extensible markup language (XML) format. The ASCII and XML formats are both imported into ArcGIS 8.3 for analysis using the HEC-GeoRAS extension.

\subsection{Problems encountered during HEC-RAS software usage}

The analyst encountered a few problems using this new software and new extension. The HEC-GeoRAS extension in ArcGIS 9.0 was utilized for a portion of this project. The extension is still in the beta development phase. While the extension has been tested more thoroughly in ArcGIS 8.3 than ArcGIS 9.0, it is still being developed for both. The HEC-GeoRAS extension is not as widely available as other ESRI extensions. The extension is only available through Dr. Dean Djokic's office at ESRI, since his office is working on it as part of a Cooperative Research and Development Agreement (CRADA) with the USACE. The latest updates are only available from the ESRI ftp site, and are password protected. The Read-Me Word Document mentioned that there may be problems using this extension in ArcGIS 9.0, as it has not yet been tested in this version. There were problems. The initial download of the software was the first problem. It did not work at all in 9.0. The analyst ended up using ArcGIS 8.3 for this portion of the analysis, as the extension had been tested there. This caused a definite break in the building of the model, as previously mentioned. Anytime that analyst intervention is needed, the model has to be broken. The fact that the analyst had to switch from ArcGIS 9.0 to ArcGIS 8.3 isn't the only cause for the break in the model. The ESRI HEC-GeoRAS extension highly recommends the analyst delineates the stream centerline and the XS cutlines, instead of letting the program delineate them automatically.

Another problem encountered was the familiarity of working with ArcGIS 9.0 and having to revert to ArcGIS 8.3. Although they are basically the same programs, there are quite a few differences between them. This reversal also became a factor since ArcGIS 8.3 mostly uses shapefiles and ArcGIS 9.0 primarily uses feature classes and feature datasets, which are stored in personal geodatabases (mdb). The ArcGIS Toolbox, used to perform over 400 GIS functions, is more user friendly in ArcGIS 9.0.

The analyst required more knowledge about hydrology to perform a legitimate dam burst model. The analyst attended the "Hydrologic and Hydraulic Analyses Using ArcGIS” course taught by Dr. Dean Djokic, of ESRI. The analyst also spent numerous hours studying the material. The course and materials proved invaluable in completing the work. The analyst corresponded with Dr. Djokic numerous times concerning project development.

The analyst wanted to obtain some technical advice on the intricacies of the HECRAS software. His client, Mr. David Lovell, arranged a meeting with San Bernardino 
County employees: Mr. Hany F. Peters, P. E., Chief Planning Section, Water Resources Division, and Mr. Reza Fatemi, Federal Projects, Flood Control District. Their insight proved invaluable to the analyst for the completion of the HEC-RAS portion of the analyst's MIP, allowing him to complete the HEC-RAS portion of his plan. The analyst exported an ASCII file of HEC-RAS output to bring into ArcGIS 8.3. The analyst used the rate of flow in Cubic Feet per Second ("Q" value) as the dam break value, at the suggestion of Mr. Fatemi and Mr. Peters. The analyst also used a set value for the Downstream River Reach Lengths (R) as suggested by Mr. Fatemi and Mr. Peters. The analyst used one final suggestion from Mr. Fatemi and Mr. Peters for the Manning's N coefficient of roughness, deciding on a value of 0.35 . Two books frequently used by HEC-RAS experts are Handbook of Applied Hydrology (Chow, 1964) and Kings Handbook of Hydraulics (Brater, et. al., 1996). These reference books allow insight for the GIS analyst who is not an engineer.

The analyst exported the HEC-RAS geometric output to an sdf (ASCII) file. This ASCII file was imported into the HEC-GeoRAS extension. The extension creates an extensible markup language (XML) file and the outputs are stored in a personal geodatabase (mdb) created by the user. The XML file can be used to manually limit the extent of the HEC-RAS resulting feature classes. A Triangulated Irregular Network (TIN) was created from the XS cutlines and the DEM. The following output feature classes are created in the HEC-GeoRAS extension: bounding polygon (of the XS cutlines) floodplain polygon (based on the water depth at the XS cutlines from the HECRAS software program), and depth polygon. The mdb can then be imported into ArcMap just as any other feature dataset. The spatial reference of the mdb is set to the same as the DEM. Sample graphics from HEC-RAS are displayed in Figures 3-2 through Figure 311 below. 


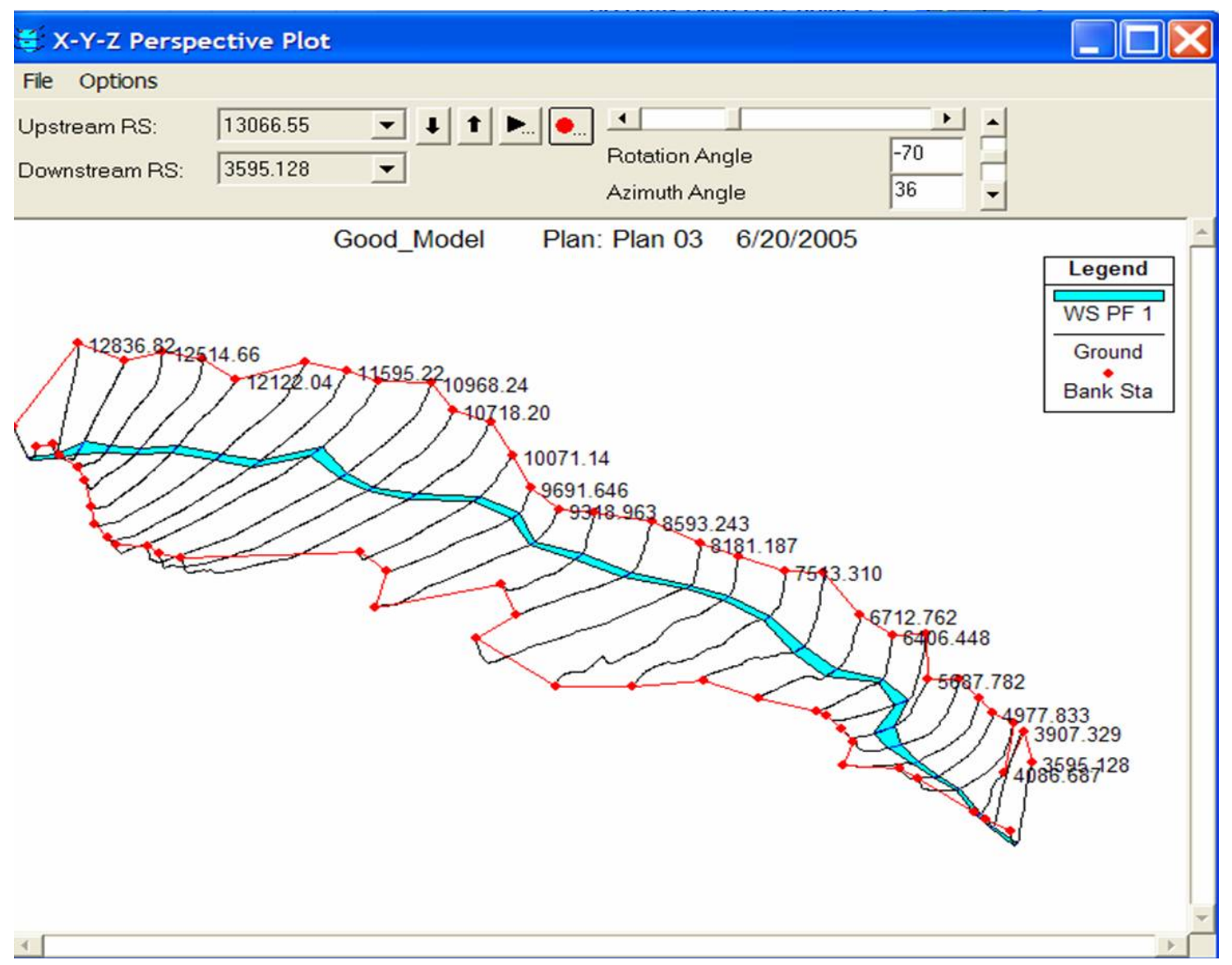

Figure 3-2. Perspective plot with left to right view (HEC-RAS results) 


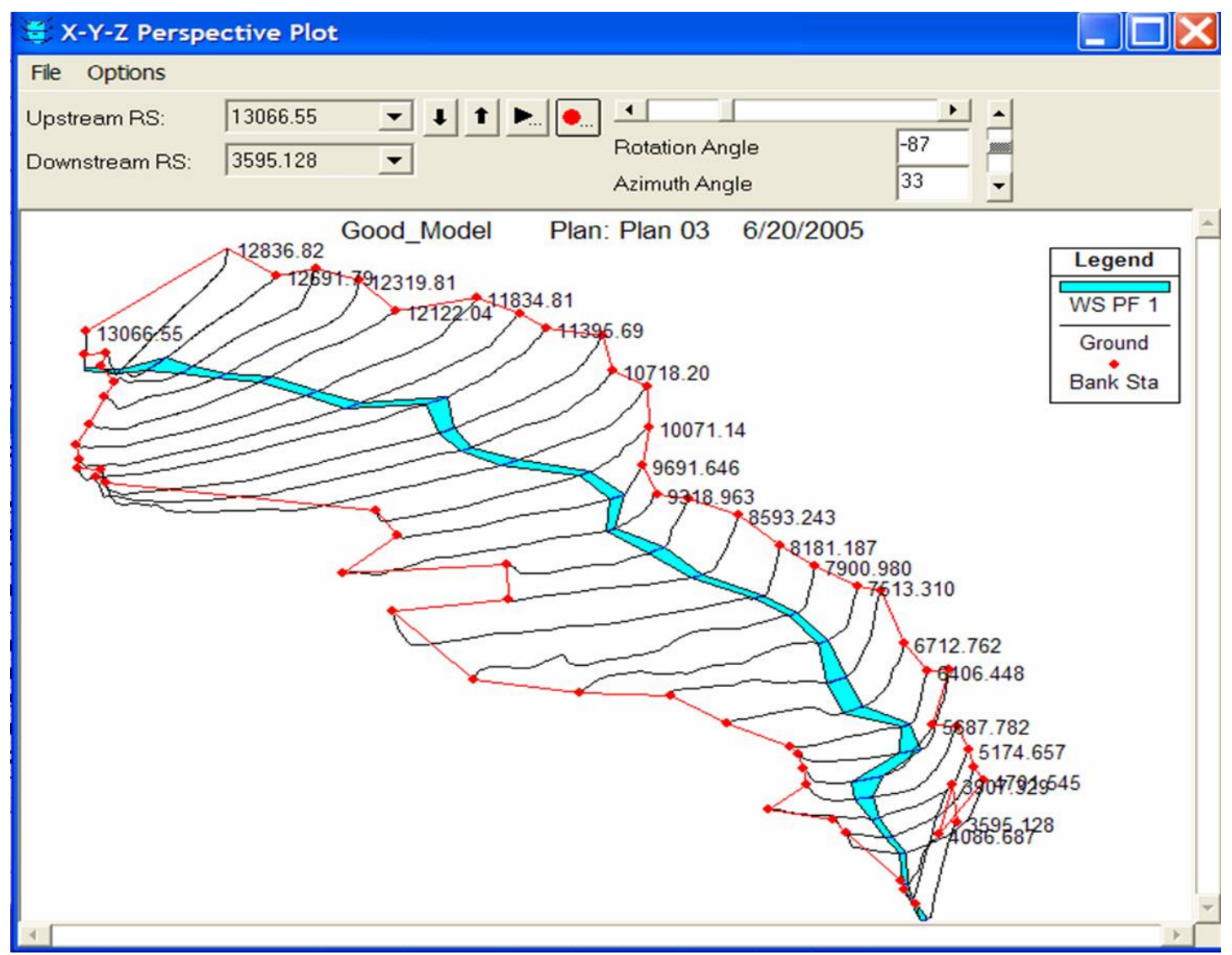

Figure 3-3. Perspective view looking upstream (HEC-RAS results) 


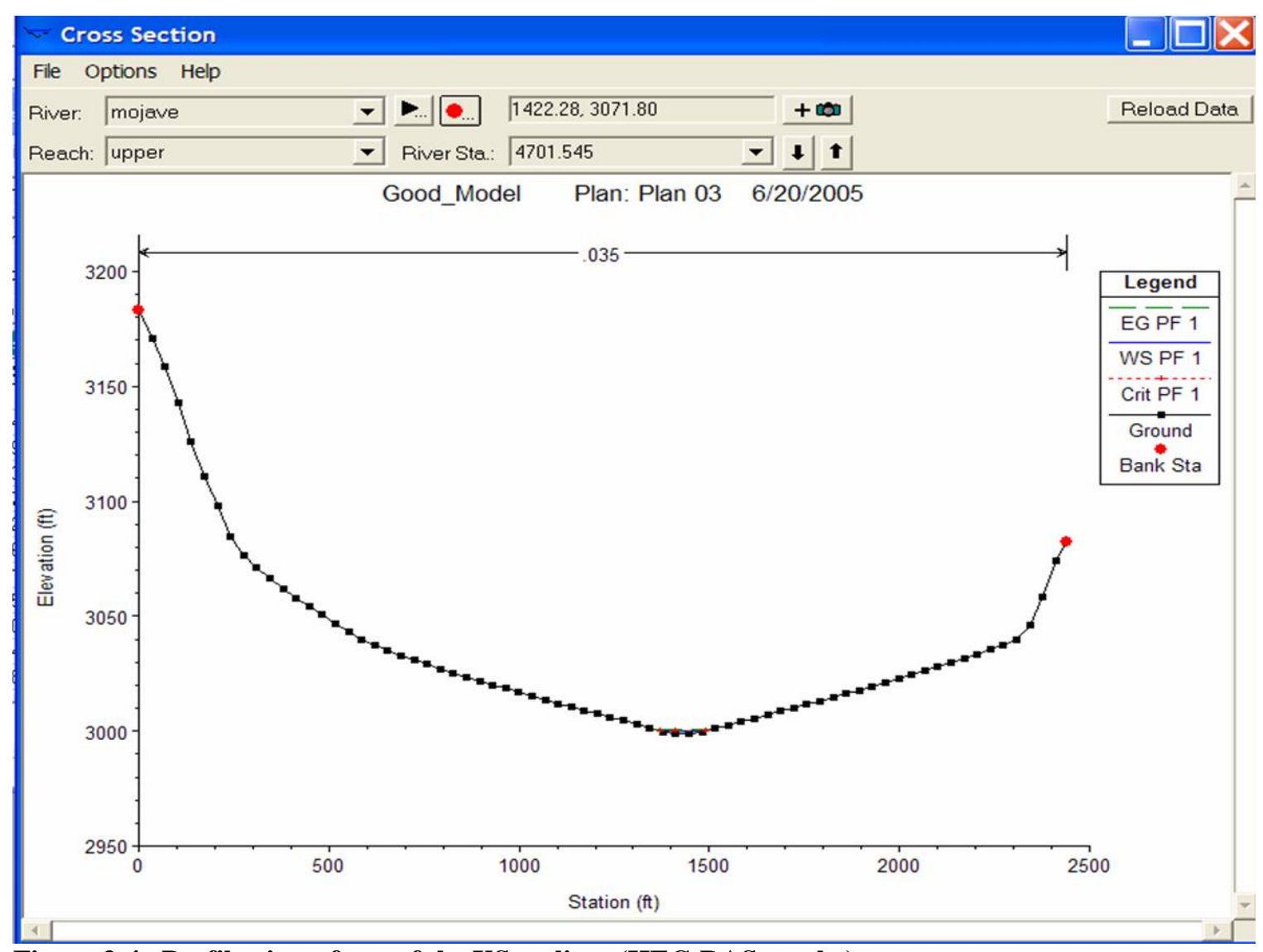

Figure 3-4. Profile view of one of the XS cutlines (HEC-RAS results)

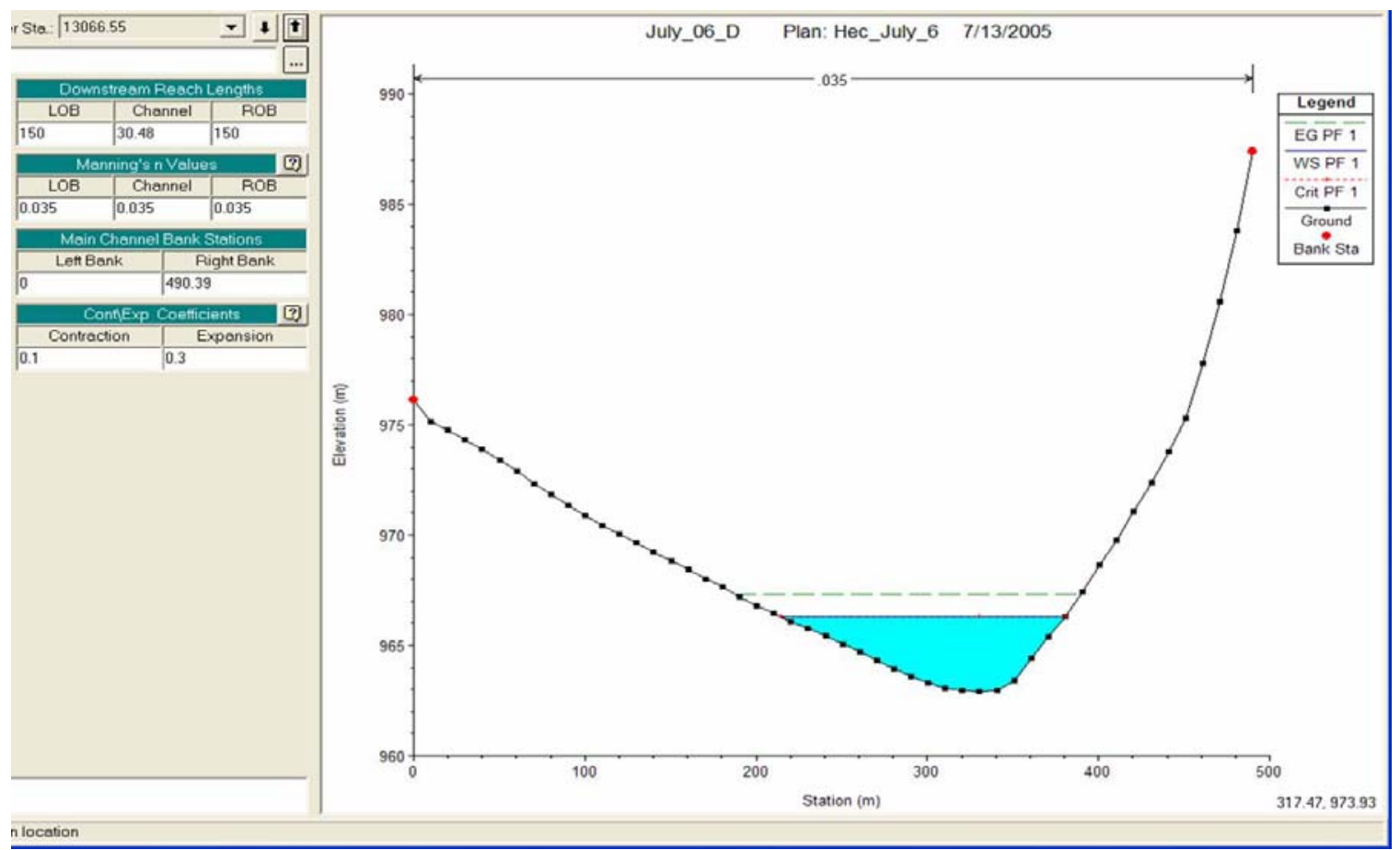

Figure 3-5. First XS cutline with water surface displayed 

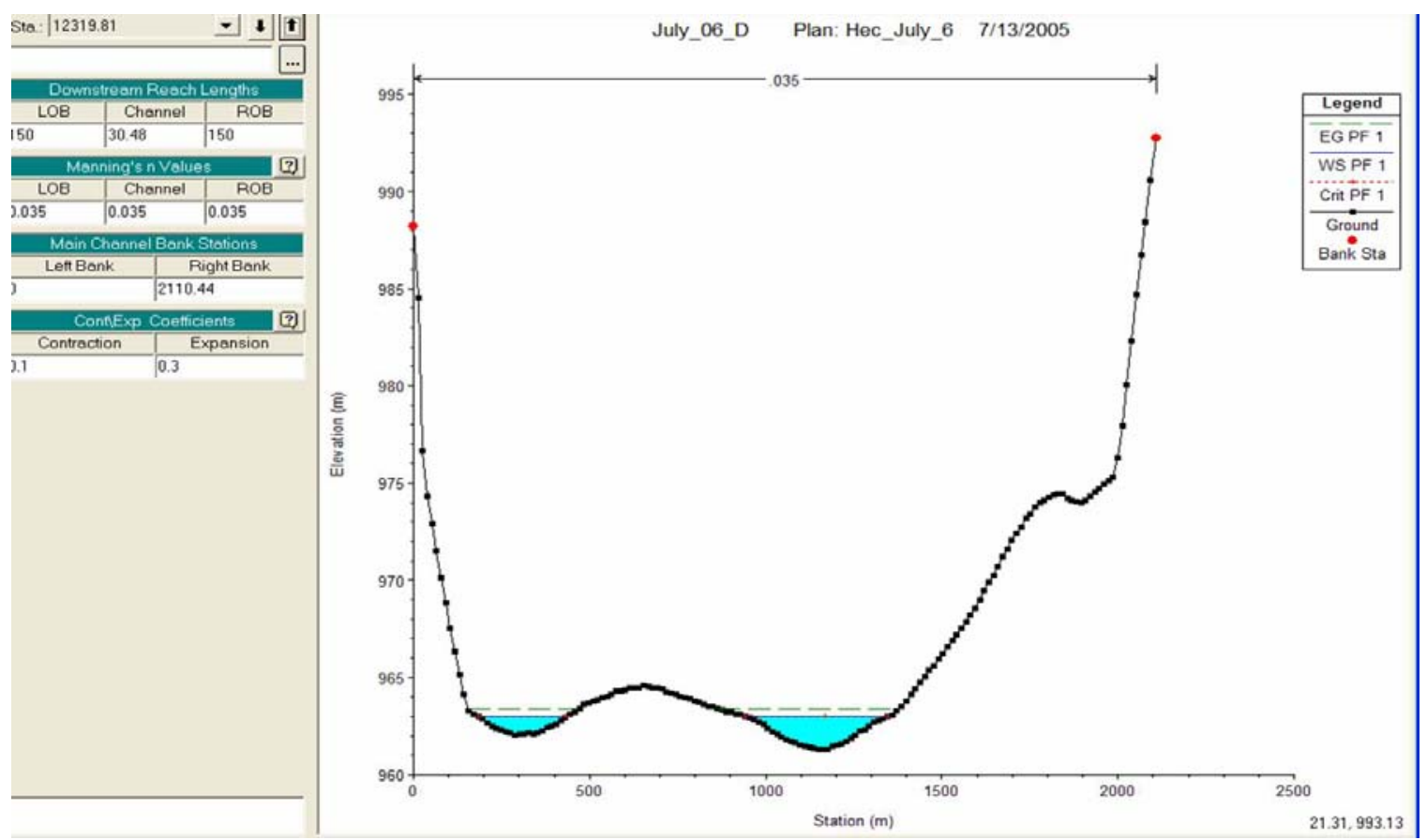

Figure 3-6. Sample XS cutline with water surface displayed
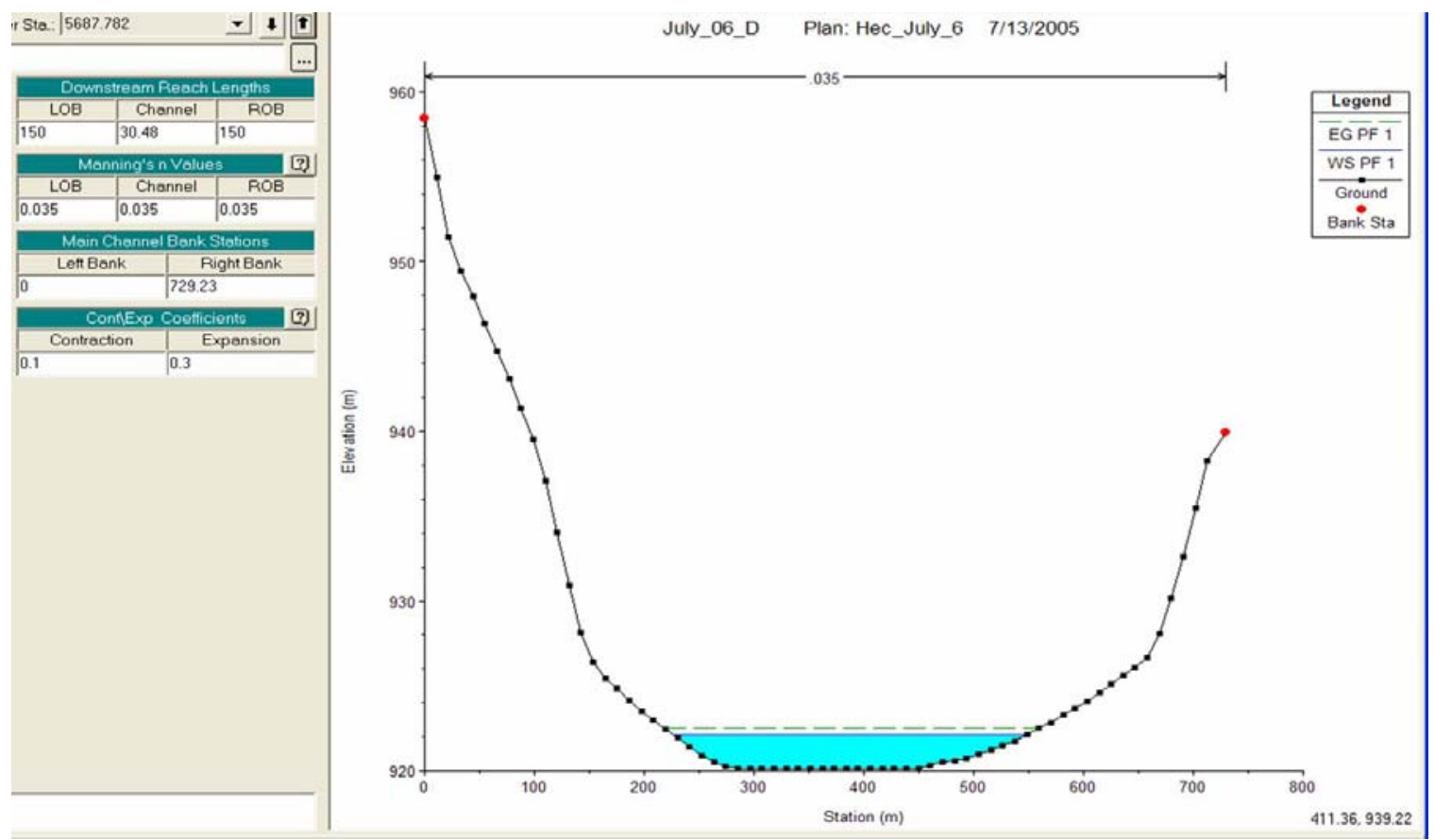

Figure 3-7. Sample XS cutline with water surface displayed 


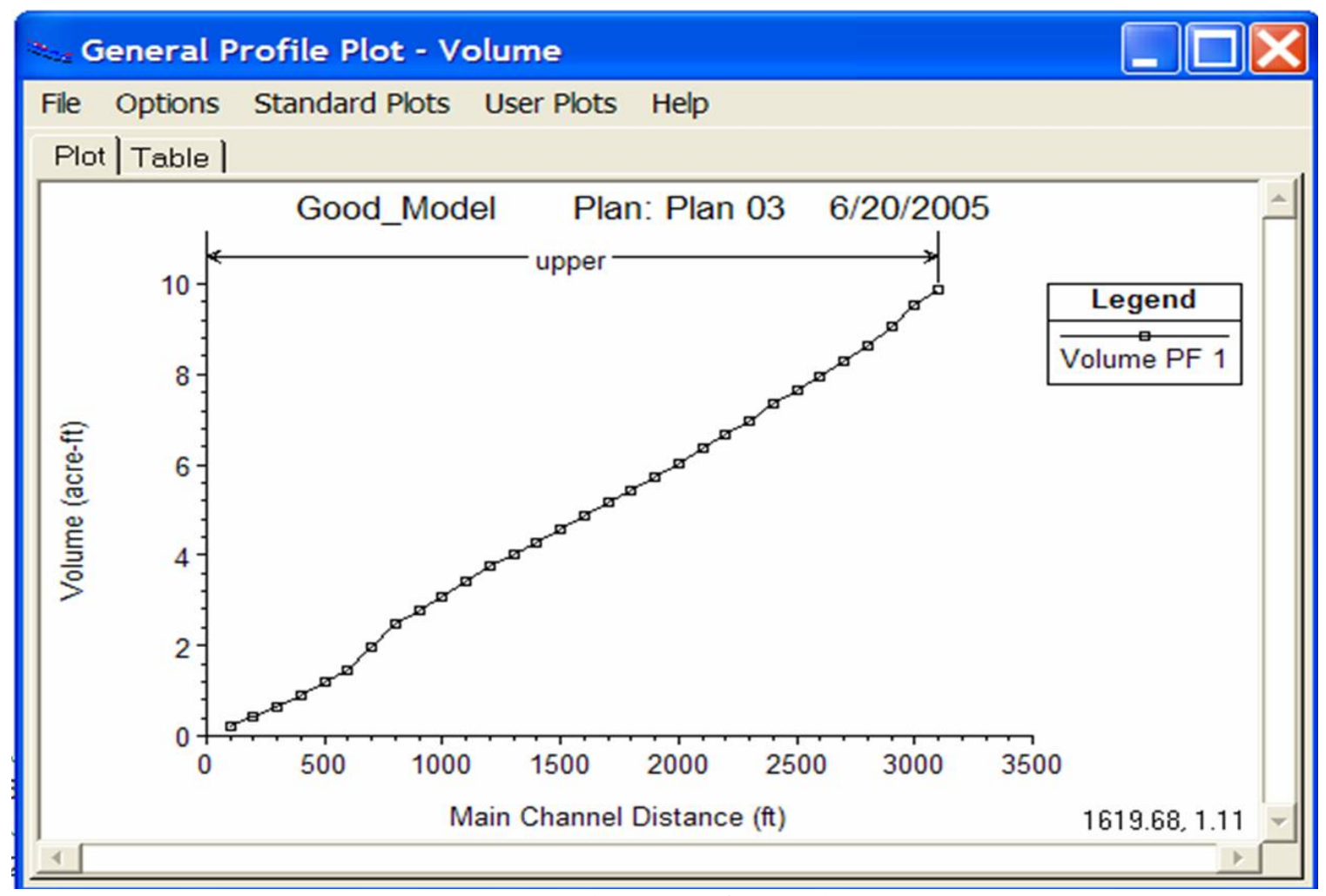

Figure 3-8. Profile plot of stream centerline (HEC-RAS results)

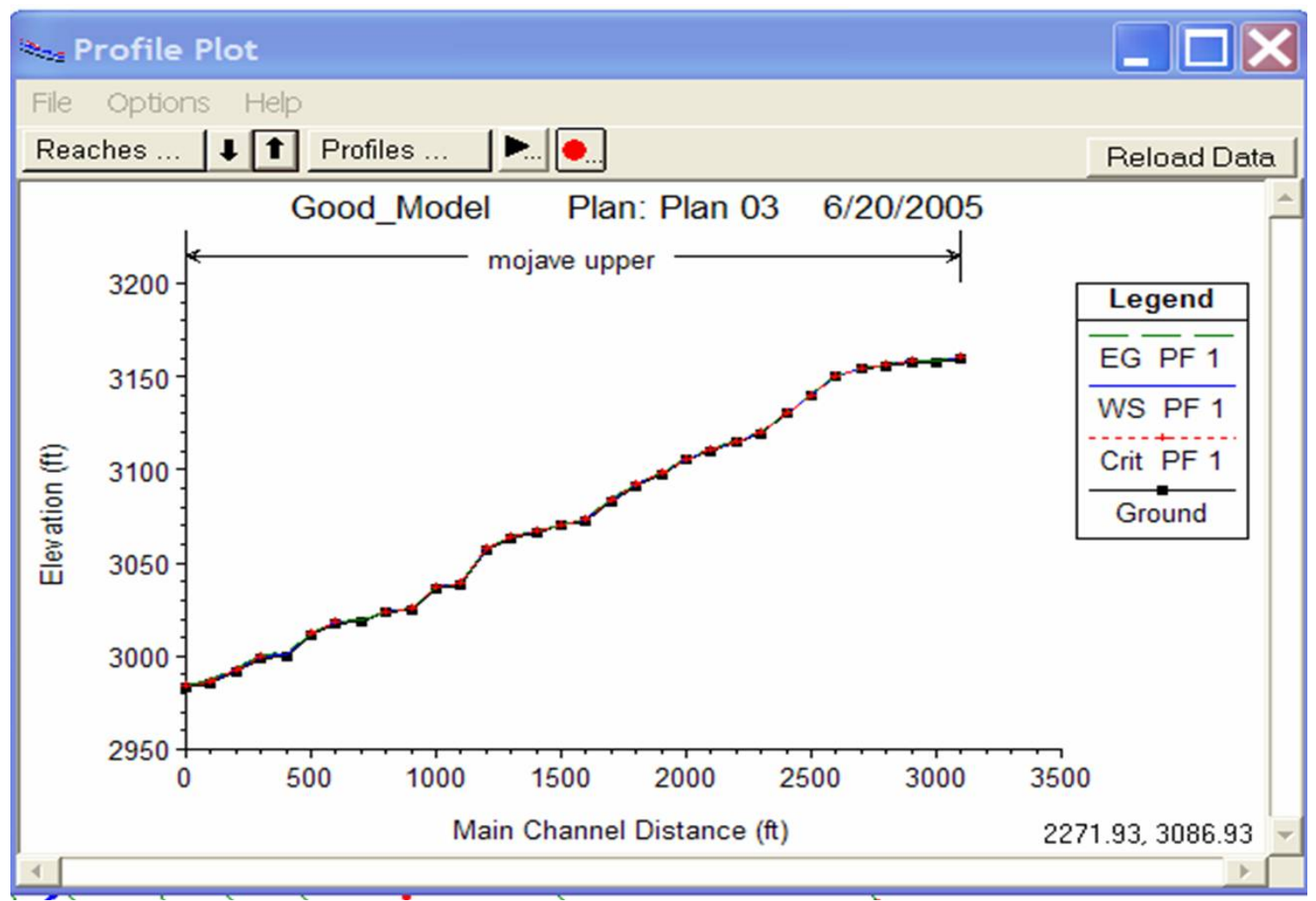

Figure 3-9. Profile plot of stream centerline and elevation (HEC-RAS results) 


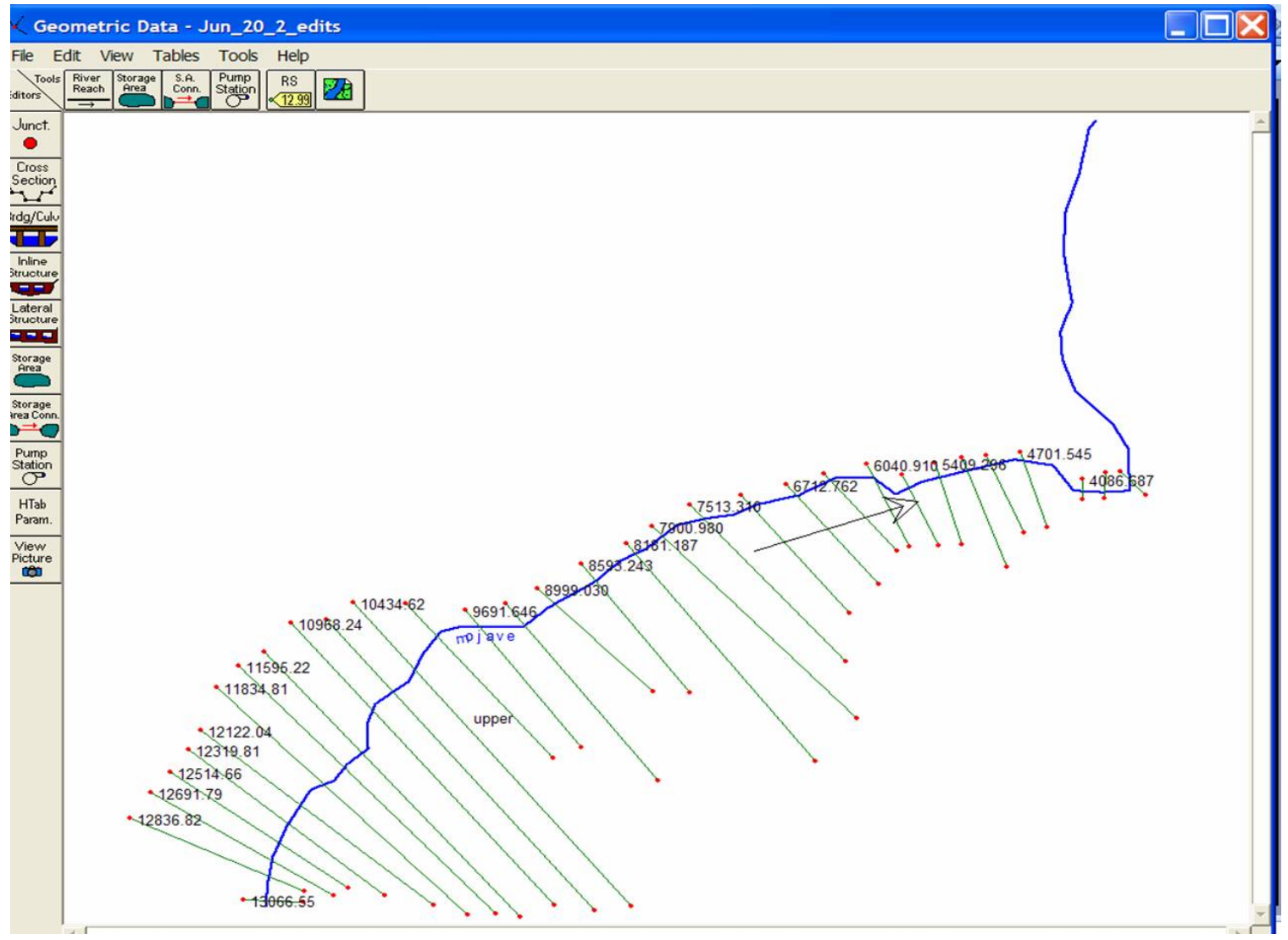

Figure 3-10. HEC-RAS plot of geometry created in HEC-GeoRAS extension of ArcGIS 9.0

The same geometry can be created in the HEC-RAS program, but it would not have the spatial attributes. 


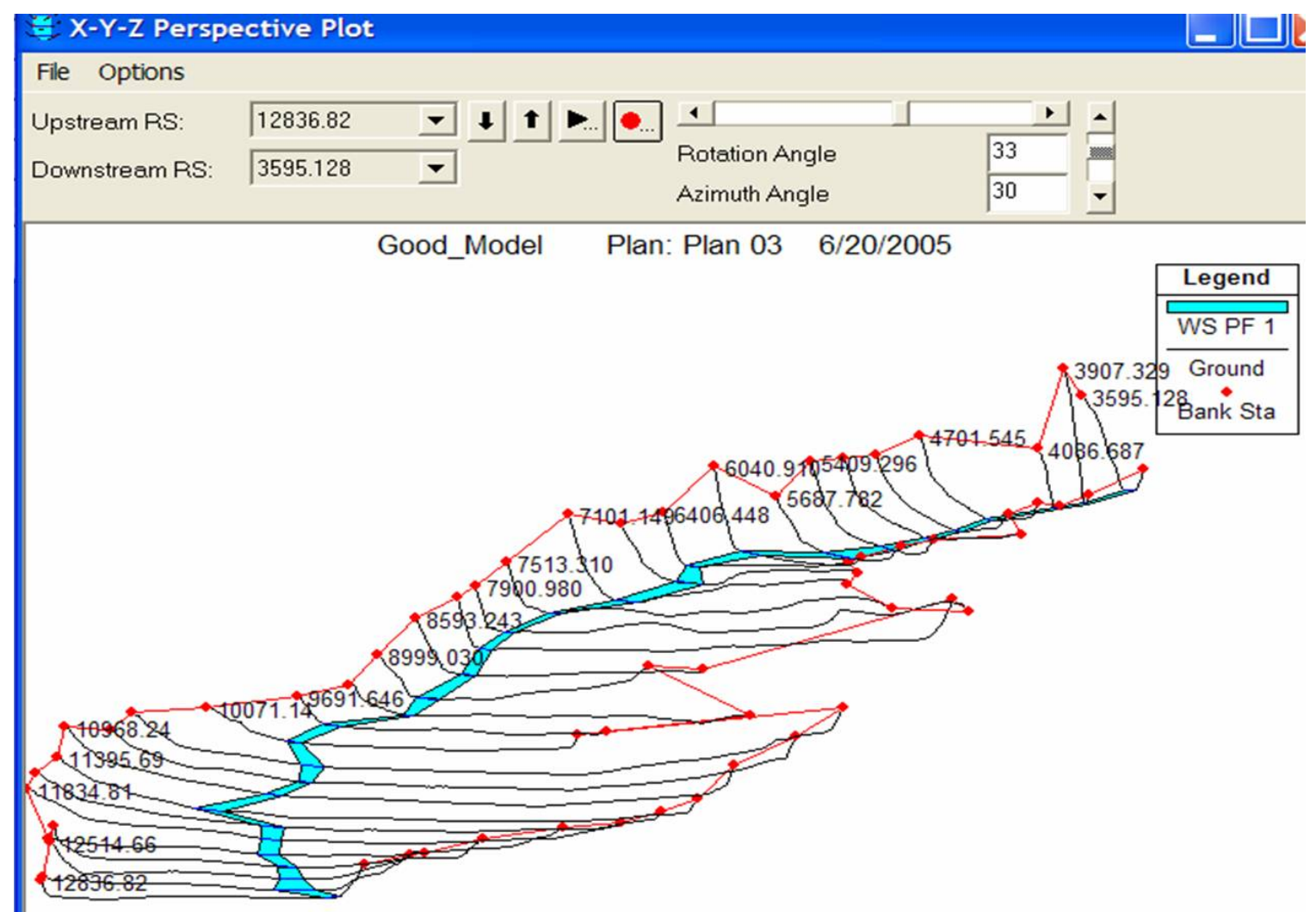

Figure 3-11. Profile view looking down from Silverwood Dam (HEC-RAS results) 
Table 3-1. XS cutlines detailed output table

Profile Output Table - Standard Table 1

Fle Options Std. Tables Locations Help

HEC-FAS Plan Plan 03 River mojave Reach: upper Profile:PF

\begin{tabular}{|c|c|c|c|c|c|c|c|c|c|c|c|c|}
\hline Reach & River Sta & Profile & OTotal & Min ChEl & W.S. Elev & CritW.S. & E.G. Elev & E.G. Slope & Vel Chnl & Flow Area & Top Width & Froude $\#$ ChI \\
\hline & & & (cds) & (ii) & (ti) & (it) & (it) & $(t / t \pi)$ & $(\mathrm{t} / \mathrm{s})$ & $(s q \mathrm{ft})$ & (it) & \\
\hline upper & 13066.55 & PF 1 & 500.00 & 3159.12 & 3160.17 & 3160.17 & 3160.54 & 0.020306 & 4.88 & 102.36 & 141.06 & 1.01 \\
\hline upper & 12836.82 & PF1 & 500.00 & 3157.81 & 3158.86 & & 3158.96 & 0.004753 & 2.53 & 197.55 & 245.66 & 0.50 \\
\hline upper & 12691.79 & PF1 & 500.00 & 3157.58 & 3158.16 & 3158.08 & 3158.24 & 0.012299 & 2.26 & 221.28 & 665.57 & 0.69 \\
\hline upper & 12514.66 & $\overline{\text { PF1 }}$ & 500.00 & 3155.91 & 3156.64 & 3156.59 & 3156.80 & 0.016976 & 3.16 & 158.02 & 365.27 & 0.85 \\
\hline upper & 12319.81 & PF 1 & 500.00 & 3153.87 & 3154.56 & 3154.56 & 3154.77 & 0.024375 & 3.72 & 134.46 & 319.99 & 1.01 \\
\hline upper & 12122.04 & PF 1 & 500.00 & 3149.87 & 3150.44 & 3150.44 & 3150.64 & 0.024302 & 3.59 & 139.27 & 348.60 & 1.00 \\
\hline upper & 11834.81 & PF 1 & 500.00 & 3139.44 & 3140.15 & 3140.15 & 3140.36 & 0.024680 & 3.73 & 134.18 & 321.28 & 1.02 \\
\hline upper & 11595.22 & PF1 & 500.00 & 3130.25 & 3130.76 & 3130.76 & 3130.95 & 0.024936 & 3.51 & 142.49 & 376.28 & 1.00 \\
\hline upper & \begin{tabular}{|l|}
1395.69 \\
\end{tabular} & $\overline{F F 1}$ & 500.00 & 3119.13 & 3119.77 & 3119.77 & 3119.93 & 0.026296 & 3.16 & 158.45 & 510.57 & 1.00 \\
\hline upper & 10968.24 & PF 1 & 500.00 & 3114.73 & 3115.43 & 3115.43 & 3115.64 & 0.024093 & 3.65 & 137.02 & 332.52 & 1.00 \\
\hline upper & \begin{tabular}{|l|}
10718.20 \\
\end{tabular} & PF1 & 500.00 & 3109.91 & 3110.88 & 3110.88 & 3111.14 & 0.022920 & 4.11 & 121.73 & 238.27 & 1.01 \\
\hline upper & 10434.62 & $\mathrm{PF} 1$ & 500.00 & 3105.18 & 3105.94 & 3105.94 & 3106.13 & 0.025344 & 3.49 & 143.07 & 384.80 & 1.01 \\
\hline upper & 10071.14 & PF1 & 500.00 & 3097.44 & 3098.40 & 3098.40 & 3098.66 & 0.023060 & 4.07 & 122.85 & 244.92 & 1.01 \\
\hline upper & 9691.646 & PF1 & 500.00 & 3091.27 & 3092.08 & 3092.08 & 3092.30 & 0.024797 & 3.74 & 133.57 & 318.76 & 1.02 \\
\hline upper & 9318.963 & PF 1 & 500.00 & 3083.14 & 3084.12 & 3084.12 & 3084.45 & 0.021128 & 4.58 & 109.26 & 171.08 & 1.01 \\
\hline upper & 8999.030 & PF 1 & 500.00 & 3072.83 & 3073.47 & 3073.47 & 3073.66 & 0.024461 & 3.47 & 144.14 & 381.73 & 0.99 \\
\hline upper & 8593.243 & $\mathrm{PF} 1$ & 500.00 & 3069.88 & 3070.57 & 3070.57 & 3070.81 & 0.023095 & 3.98 & 125.74 & 259.85 & 1.01 \\
\hline upper & 8181.187 & PF1 & 500.00 & 3066.60 & 3067.37 & 3067.37 & 3067.66 & 0.021639 & 4.33 & 115.61 & 200.58 & 1.00 \\
\hline upper & 7900.980 & PF1 & 500.00 & 3062.99 & 3063.87 & 3063.87 & 3064.18 & 0.021134 & 4.42 & 113.01 & 186.19 & 1.00 \\
\hline upper & 7513.310 & PF 1 & 500.00 & 3056.73 & 3058.00 & 3058.00 & 3058.27 & 0.022176 & 4.19 & 119.30 & 220.97 & 1.01 \\
\hline upper & 7101.149 & PF 1 & 500.00 & 3038.39 & 3038.86 & 3038.78 & 3038.98 & 0.014095 & 2.83 & 176.37 & 418.12 & 0.77 \\
\hline upper & 6712.762 & PF1 & 500.00 & 3036.12 & 3036.94 & 3036.94 & 3037.16 & 0.023788 & 3.75 & 133.17 & 306.69 & 1.00 \\
\hline upper & 6406.448 & PF1 & 500.00 & 3024.97 & 3025.93 & 3025.89 & 3026.18 & 0.017391 & 4.04 & 123.78 & 201.97 & 0.91 \\
\hline upper & 6040.910 & PF 1 & 500.00 & 3023.29 & 3023.89 & 3023.89 & 3024.08 & 0.025629 & 3.50 & 143.01 & 387.62 & 1.01 \\
\hline upper & 5687.782 & PF 1 & 500.00 & 3018.70 & 3019.25 & & 3019.29 & 0.003823 & 1.66 & 301.83 & 602.03 & 0.41 \\
\hline upper & 5409.296 & PF 1 & 500.00 & 3017.72 & 3018.28 & 3018.28 & 3018.49 & 0.024494 & 3.73 & 134.15 & 319.30 & 1.01 \\
\hline upper & 5174.657 & $\overline{\mathrm{PF} 1}$ & 500.00 & 3010.83 & 3011.77 & 3011.77 & 3012.12 & 0.020666 & 4.79 & 104.37 & 150.07 & 1.01 \\
\hline upper & 4977.833 & PF1 & 500.00 & 2999.48 & 3001.30 & & 3001.50 & 0.006690 & 3.58 & 139.77 & 133.61 & 0.62 \\
\hline upper & 4701.545 & PF1 & 500.00 & 2998.82 & 3000.02 & 3000.02 & 3000.43 & 0.019390 & 5.10 & 97.99 & 122.15 & 1.00 \\
\hline upper & 4086.687 & PF 1 & 500.00 & 2991.44 & 2992.91 & 2992.91 & 2993.42 & 0.018102 & 5.71 & 87.58 & 87.58 & 1.01 \\
\hline upper & 3907.329 & PF 1 & 500.00 & 2985.01 & 2986.66 & 2986.66 & 2987.22 & 0.017757 & 6.01 & 83.19 & 75.80 & 1.01 \\
\hline upper & 3595.128 & PF 1 & 500.00 & 2983.20 & 2984.08 & 2984.08 & 2984.41 & 0.020421 & 4.65 & 107.60 & 160.45 & 1.00 \\
\hline
\end{tabular}


Table 3-2. Detailed Output table of the first three XS cutlines profiles

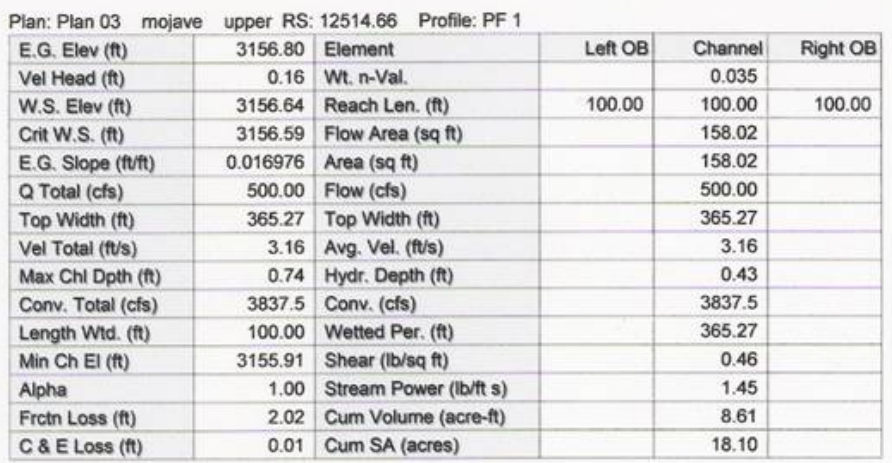

\begin{tabular}{|c|c|c|c|c|c|}
\hline \multirow{2}{*}{\begin{tabular}{|l|} 
Plan: Plan 03 \\
E.G. Elev (ft)
\end{tabular}} & \multicolumn{2}{|c|}{ upper RS: 12319.81 Profile: PF 1} & \multirow[b]{2}{*}{ Left $O B$} & \multirow[b]{2}{*}{ Channel } & \multirow[b]{2}{*}{ Right $\mathrm{OB}$} \\
\hline & 3154.77 & Element & & & \\
\hline Vel Head $(t)$ & 0.21 & Wh. n-Val. & & 0.035 & \\
\hline W.S. Elev (ft) & 3154.56 & Reach Len. ( $\mathrm{t}$ ) & 100.00 & 100.00 & 100.00 \\
\hline Crit W.S. (ft) & 3154.56 & Flow Area (sq ft) & & 134.46 & \\
\hline E.G. Slope (fUtt) & 0.024375 & Area (sq ft) & & 134.46 & \\
\hline Q Total (cfs) & 500.00 & Flow (cfs) & & 500.00 & \\
\hline Top Width $(f t)$ & 319.99 & Top Width (ti) & & 319.99 & \\
\hline Vel Total (ft/s) & 3.72 & Avg. Vel. (t/s) & & 3.72 & \\
\hline Max Chl Dpth (ft) & 0.68 & Hydr. Depth (ft) & & 0.42 & \\
\hline Conv. Total (cfs) & 3202.6 & Conv. (cfs) & & 3202.6 & \\
\hline Length Wid. (ft) & 100.00 & Wetted Per. (ft) & & 319.99 & \\
\hline Min Ch El (tt) & 3153.87 & Shear (lb/sq ft) & & 0.64 & \\
\hline Alpha & 1.00 & Stream Power (lb/tt s) & & 2.38 & \\
\hline Fretn Loss (n) & 2.43 & Cum Volume (acre-ft) & & 8.28 & \\
\hline C\& E Loss (ft) & 0.00 & Cum SA (acres) & & 17.31 & \\
\hline
\end{tabular}

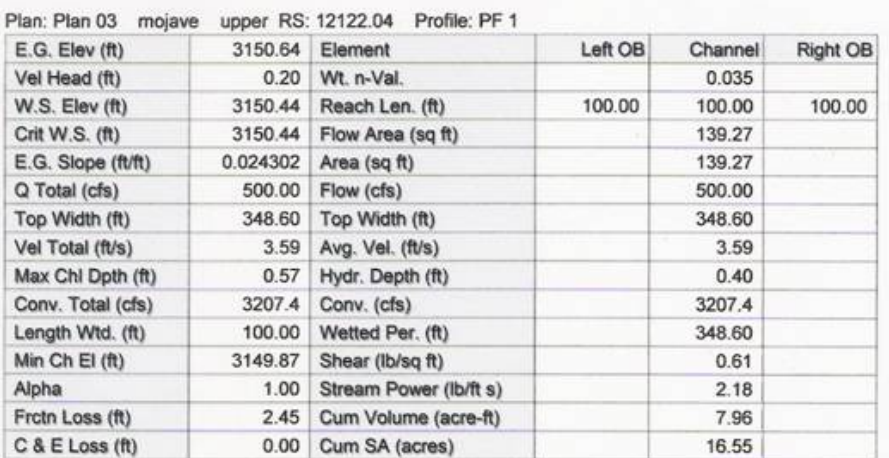

There are 13 pages of XS cutline information available on the CD for this MIP. They are not included in this document for the purpose of space reduction, and to avoid redundancy.

There is also a new beta version of a $3 \mathrm{D}$ viewer in the latest version of HEC-RAS (HEC 3.1.3). This allows the user to do a fly-through over the geometry created or imported in HEC-RAS. A still shot from the 3D viewer is shown below in Figure 3-12. 


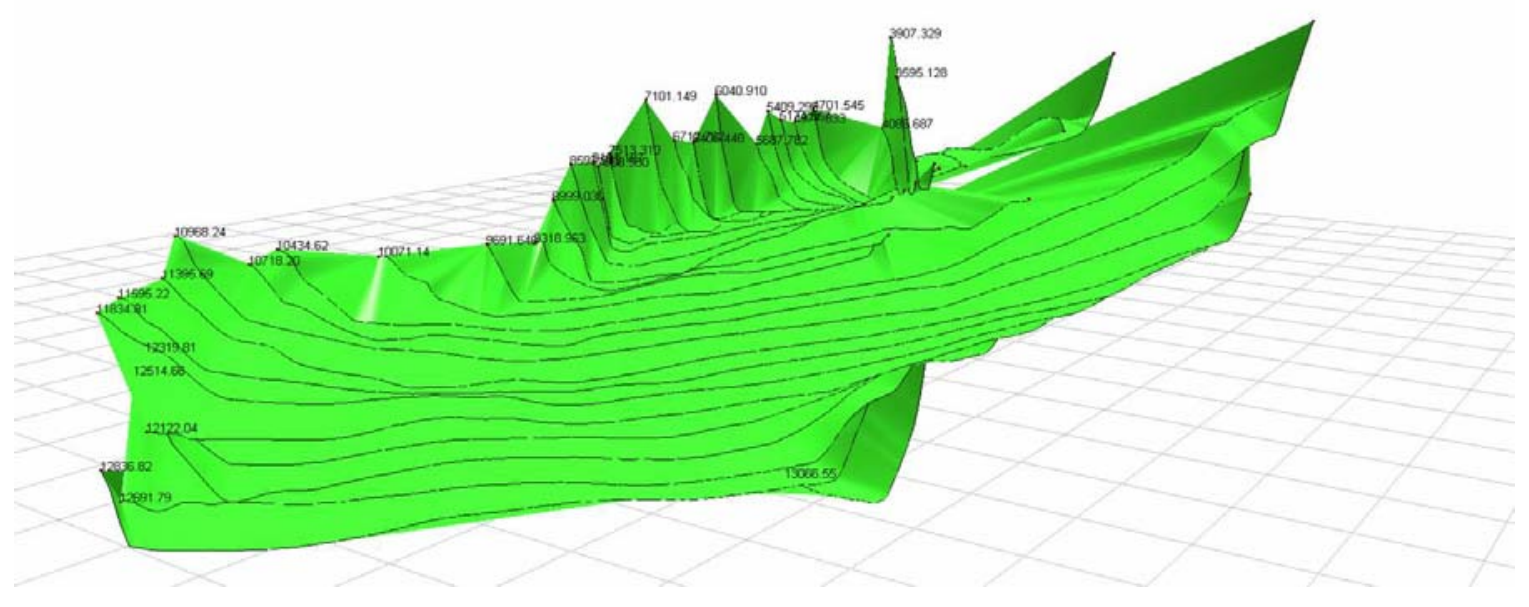

Figure 3-12. Perspective view using the fly-through tool in HEC-RAS 
The initial results did not prove logical to the analyst. The analyst experimented with different Cubic Feet per Second (Q) values, and Downstream River Reach Lengths (R) to obtain a more realistic result. Extensive research into the HEC-RAS program, along with the previously mentioned reference books used by HEC-RAS experts, Handbook of Applied Hydrology and Kings Handbook of Hydraulics, will be incorporated in future results. The analyst ultimately relied on the advice of the experts, Mr. Hany F. Peters, P. E., and Mr. Reza Fatemi, for the initial results. The input figures can be seen in Table 3-3 below. 
Table 3-3. Values used in first flooded area polygon trial

\begin{tabular}{|l|l|l|}
\hline Trial & $\begin{array}{l}\text { Q Value (Cubic Feet } \\
\text { per Second) }\end{array}$ & $\begin{array}{l}\text { R Value (Downstream River Reach } \\
\text { Lengths) Meters }\end{array}$ \\
\hline 1 & 500 & 100 \\
\hline 2 & 1000 & 100 \\
\hline 3 & 1500 & 100 \\
\hline 4 & 2000 & 100 \\
\hline 5 & 500 & 200 \\
\hline 6 & 1000 & 200 \\
\hline 7 & 1500 & 200 \\
\hline 8 & 2000 & 200 \\
\hline 9 & 500 & 300 \\
\hline 10 & 1000 & 300 \\
\hline 11 & 1500 & 300 \\
\hline 12 & 2000 & 300 \\
\hline
\end{tabular}

The analyst ran a series of 12 tests, varying the Cubic Feet per Second and Downstream River Reach Lengths. The number of tests set at 12 gave the analyst a large enough sample to analyze. The results selected by the analyst were 1000 Cubic Feet per Second and 200 meters for Downstream River Reach Lengths highlighted in table above.

Further analysis of the second set of results conveyed that the potentially flooded area covered the extent of the XS cutlines. The analyst wanted an intermediate portrayal of the potentially flooded area polygon. The analyst performed multiple iterations by adjusting the previously mentioned Downstream River Reach Lengths (R) and Cubic Feet per Second $(\mathrm{Q})$ values. The $\mathrm{Q}$ value had the most emphasis on the size of the potentially flooded area. The analyst performed these iterations one at a time. The resulting ASCII file was brought into the ESRI HEC-GeoRAS extension. The analyst then documented and compared the area (in square meters) of the resulting flooded polygon. The iteration values are listed in Table 3-4. 
Table 3-4. Values used in second flooded area polygon trial

\begin{tabular}{|c|c|c|}
\hline Second series of trials & $\begin{array}{l}\text { Q Value (Cubic Feet per } \\
\text { Second) }\end{array}$ & $\begin{array}{l}\text { R Value (Downstream } \\
\text { River Reach Lengths) } \\
\text { Meters }\end{array}$ \\
\hline 1 & 600 & 120 \\
\hline 2 & 700 & 120 \\
\hline 3 & 800 & 120 \\
\hline 4 & 900 & 120 \\
\hline 5 & 1000 & 120 \\
\hline 6 & 600 & 150 \\
\hline 7 & 700 & 150 \\
\hline 8 & 800 & 150 \\
\hline 9 & 900 & 150 \\
\hline 10 & 1000 & 150 \\
\hline 11 & 1100 & 150 \\
\hline 12 & 1200 & 150 \\
\hline 13 & 1300 & 150 \\
\hline 14 & 1400 & 150 \\
\hline 15 & 1500 & 150 \\
\hline
\end{tabular}

The analyst was not completely satisfied with the results from the initial polygon generation using the figures of 1000 feet per second and 200 meter river reach length. The analyst further refined the testing using Cubic Feet per Second values, incrementing by 100 , and comparing to River Reach Lengths varying by 30 meters. The analyst selected three different floodplain polygon extents to display graphically. The graphics of the three resulting potentially flooded area polygons, produced from HEC-GeoRAS extension, are shown in Chapter 6. 


\section{Visualizing Flooded Area with ArcGIS 8.3 and HEC-GeoRAS}

The results of the 27 iterations (two trials) were exported from HEC-RAS in ASCII (sdf) format. The resulting ASCII files were transferred to the server, so that they may be accessed by the lone computer with ArcGIS 8.3 loaded. The analyst created an ArcMap document for each of the iterations. Many of the results from the first set of trials produced similar potentially flooded area polygons. For this reason, the R and Q inputs for the second set of trials were more refined.

The HEC-GeoRAS extension creates four data sets of interest. First, a Triangulated Irregular Network (TIN) is created from the XS cutlines. The resulting TIN will be the same for all iterations, since it is based on the XS cutlines, which didn't change. Second, a Bounding polygon is created from the XS cutlines. It will also be the same for all iterations since it is based on the XS cutlines. The last two feature data sets created are a Depth polygon and a Floodplain boundary. The Depth polygon and Floodplain boundary polygon may vary since they are based on the input. The sample graphics in Figure 4-1 through Figure 4-3 below are from the initial results. 


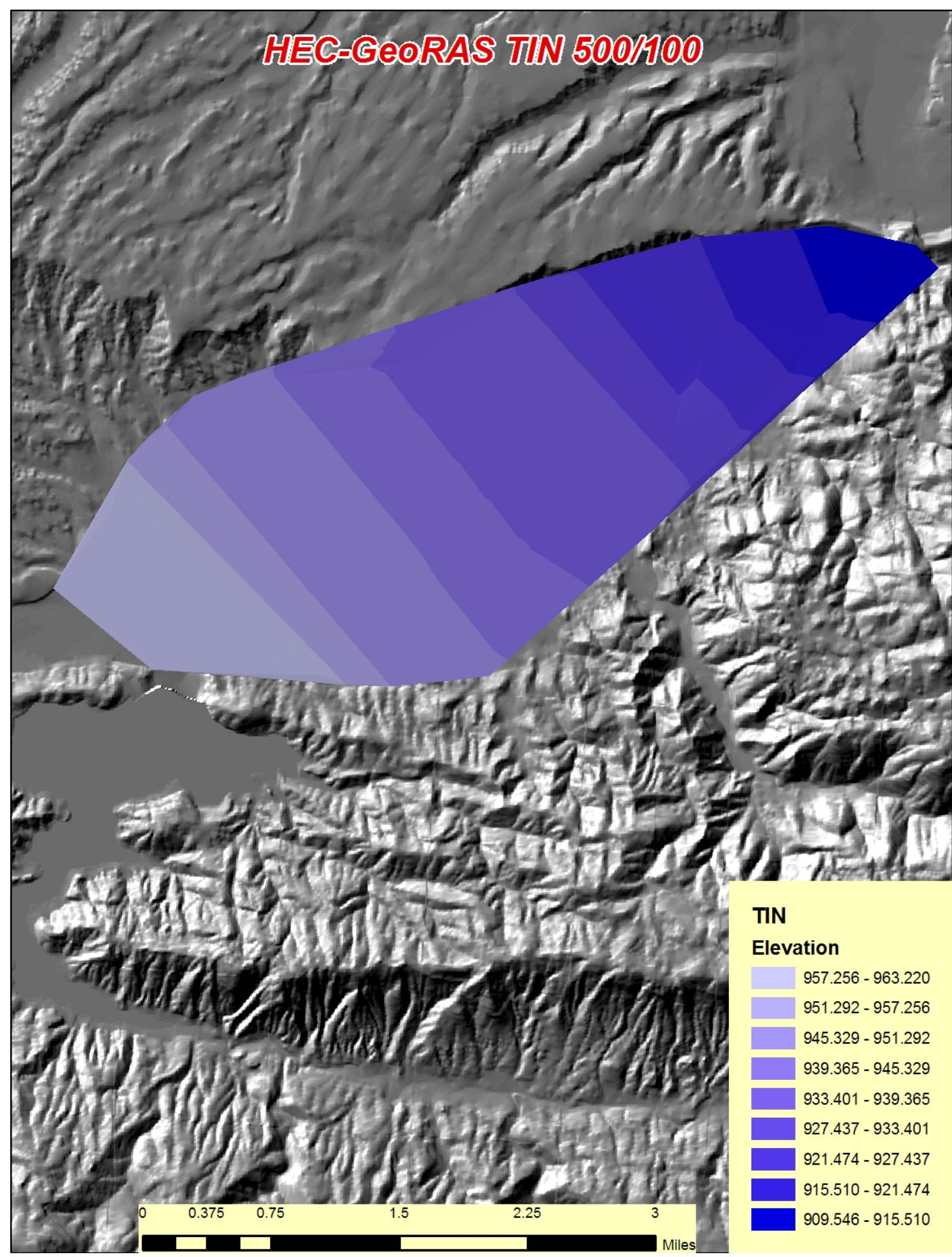

Figure 4-1. HEC-GeoRAS TIN created from XS cutlines 


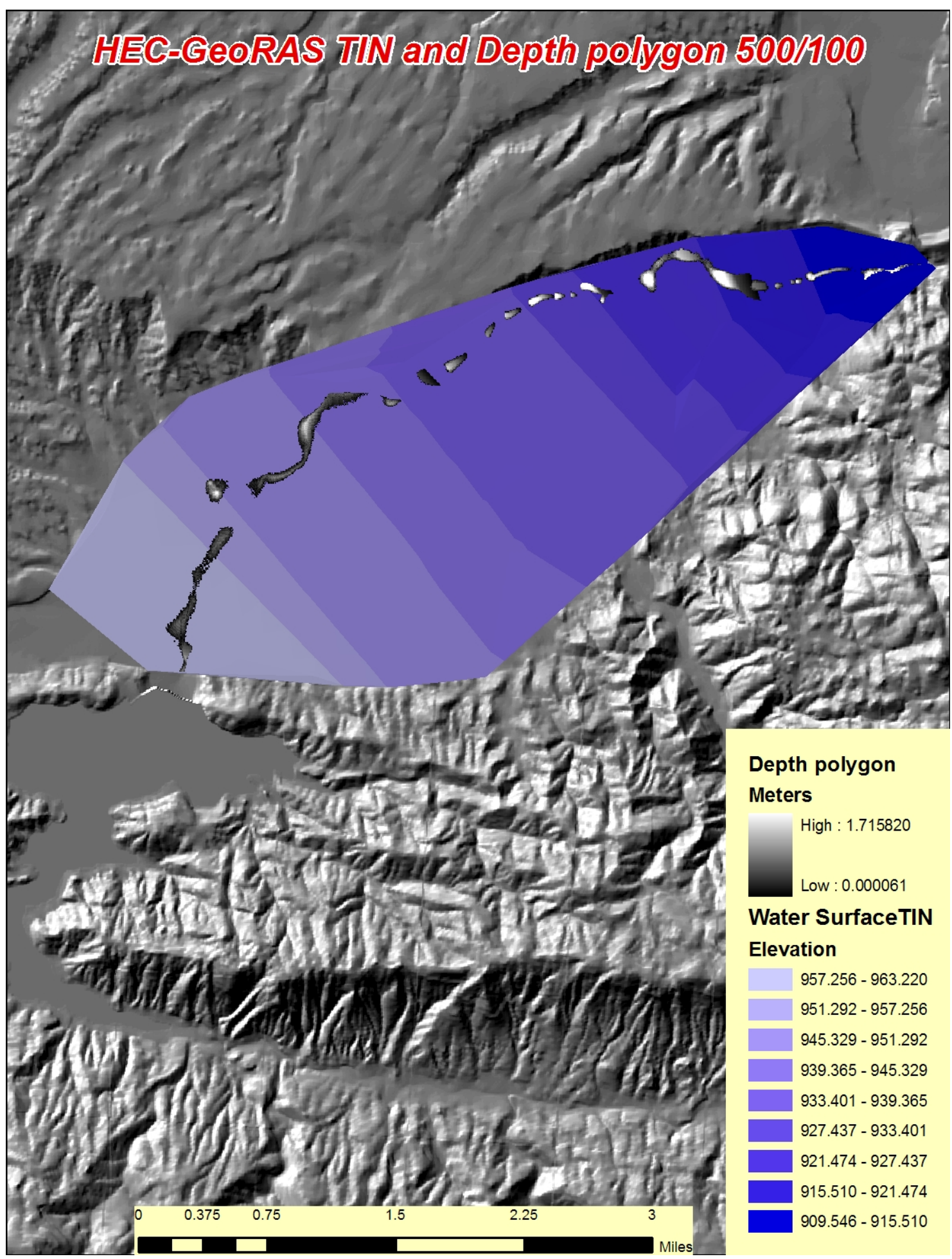

Figure 4-2. HEC-GeoRAS Bounding polygon and Depth polygon 


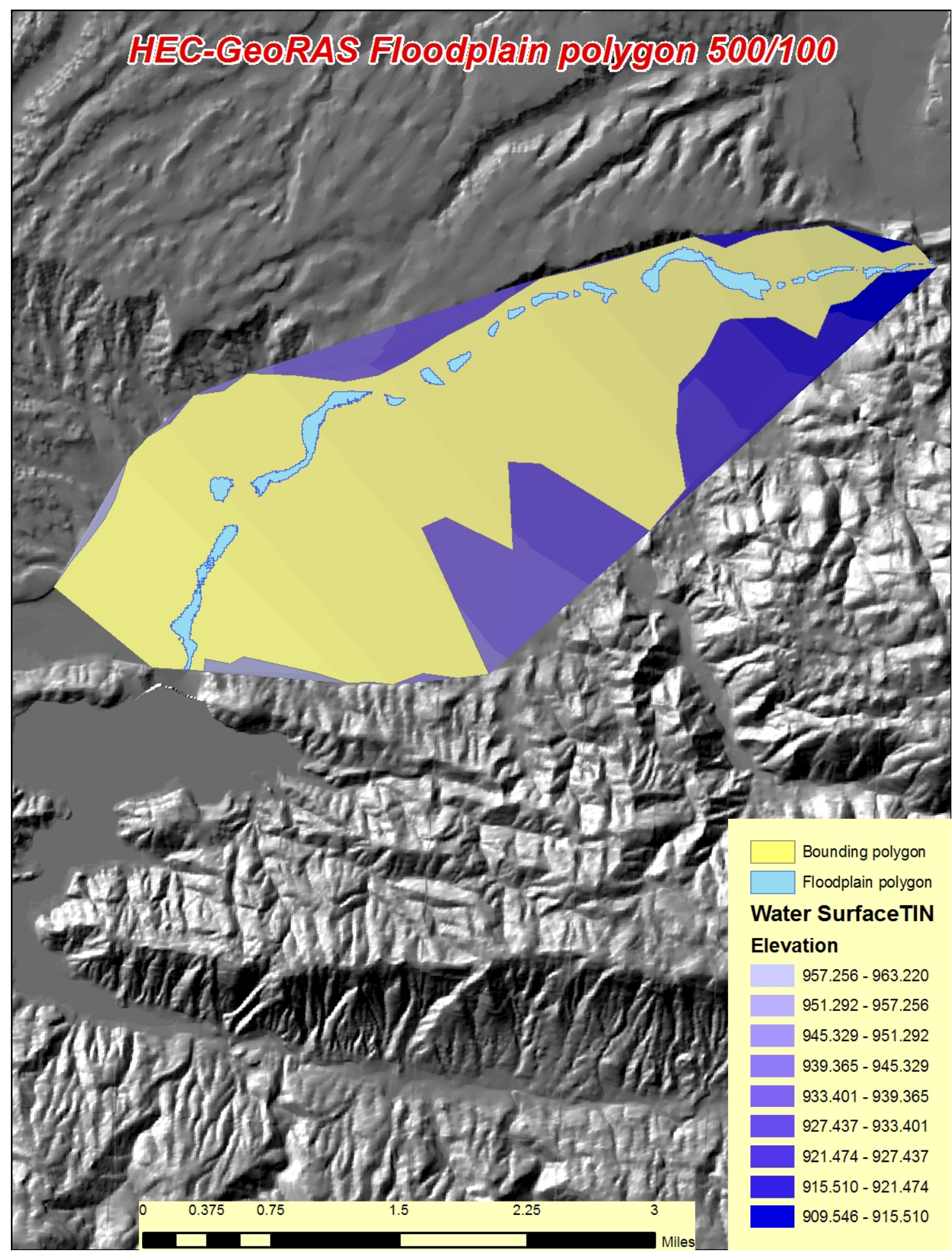

Figure 4-3. HEC-GeoRAS Bounding polygon and Flooded polygon

The analyst settled on the variables for Q and R to be 1200 and 150, respectively. This demonstrated the floodplain polygon at an intermediate level. The Manning's $\mathrm{N}$ coefficient of roughness remained at 0.35 throughout the testing. This is represented on a 
scale of 0.0 being completely smooth to 1.0 being extremely rough. The graphics in Figures 4-4 through Figures 4-6 represent the intermediate floodplain delineation.

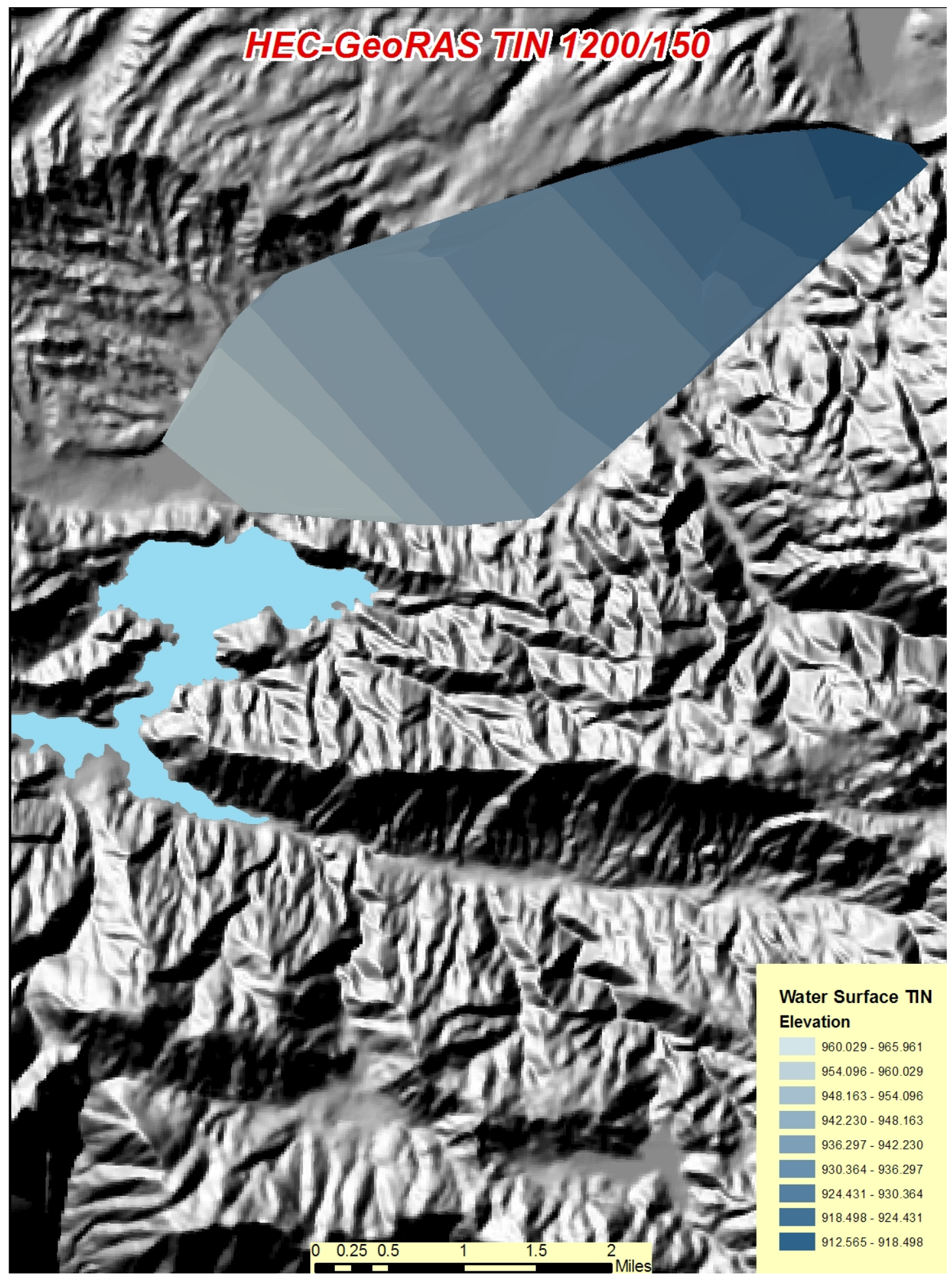

Figure 4-4. TIN elevations created in HEC-GeoRAS extension of ArcGIS 8.3 


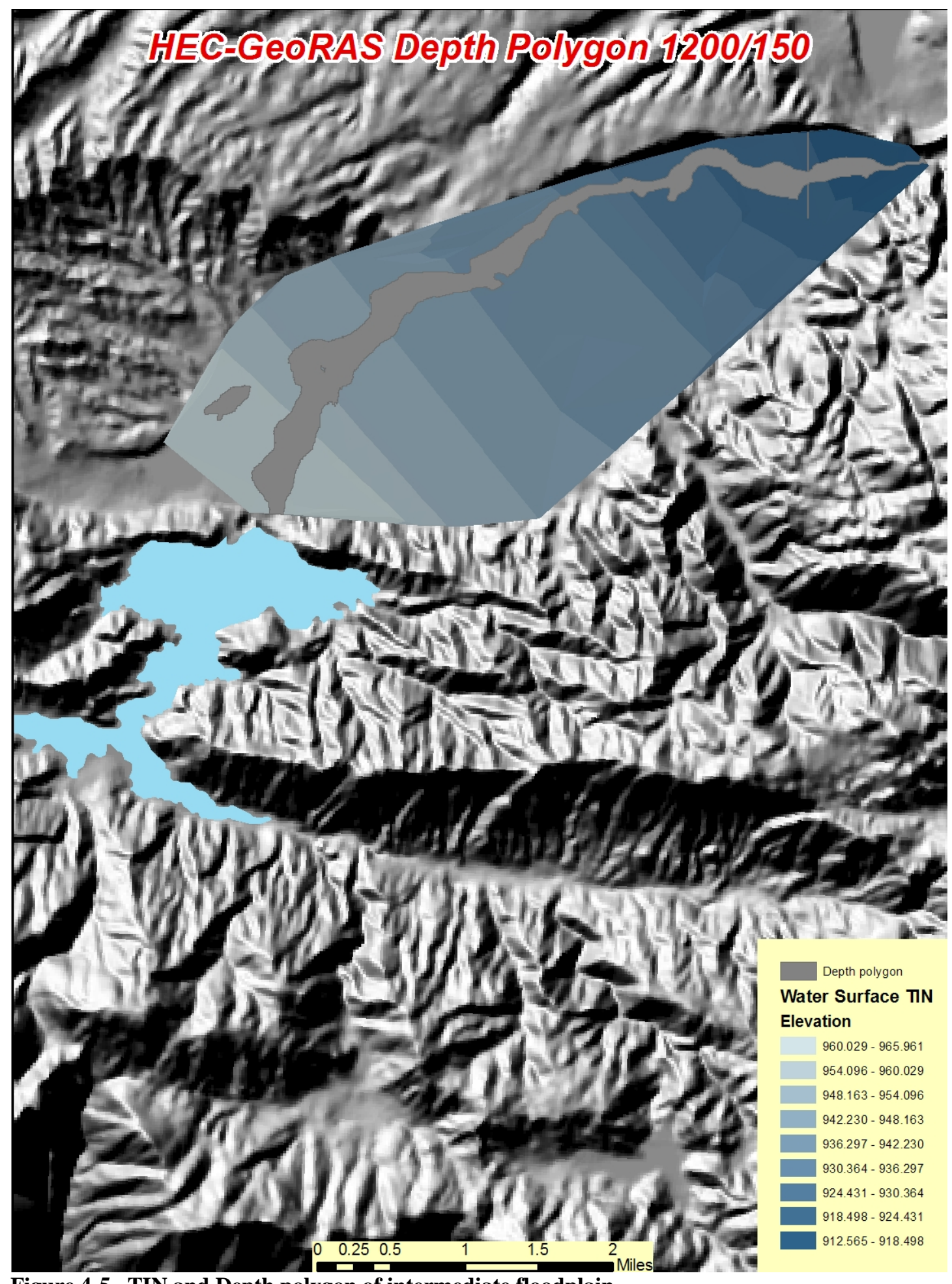

Figure 4-5. TIN and Depth polygon of intermediate floodplain 


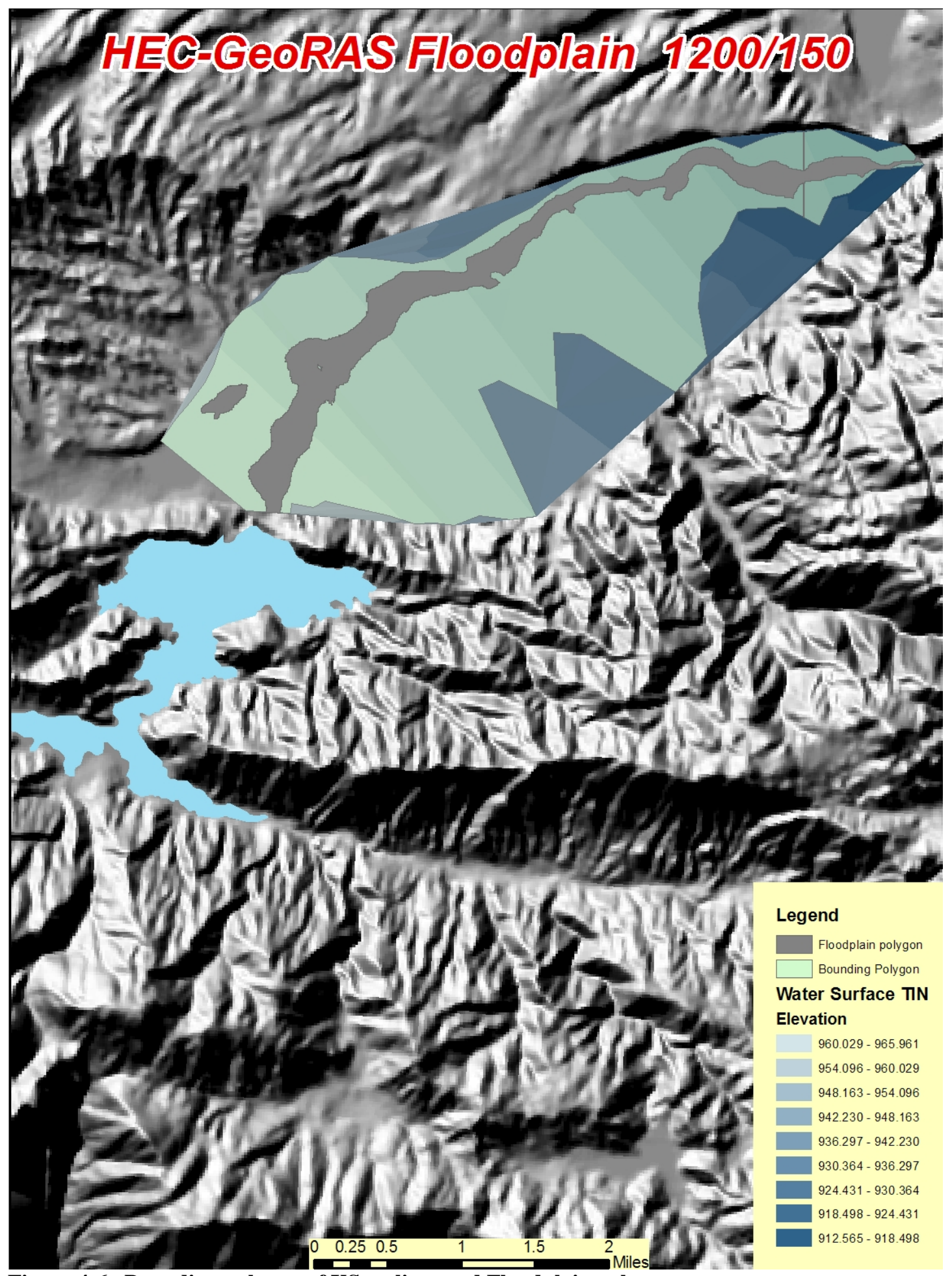

Figure 4-6. Bounding polygon of XS cutlines and Floodplain polygon

The following graphics were created with the Cubic Feet per Second variable Q set to 1000 and the Downstream River Reach Length variable R set to 200 meters. These variables produced a floodplain that encompassed the entire Bounding polygon. These variables produced the maximum flooded area. In this case the Bounding polygon, 
Floodplain polygon, and Depth polygon, are all the same size. This was one of the reasons the analyst sought an intermediate Floodplain polygon. Otherwise the Floodplain polygon would fully encompass the extents of the XS cutlines. This is the maximum extent of the floodplain based on the $\mathrm{Q}$ and $\mathrm{R}$ variables along with the XS cutlines. The format and sequential order of the graphics are the same as the two previous sets of graphics in this chapter. One additional graphic is included that has been enhanced with the ESRI Effects Toolbar. See Figures 4-7 through Figures 4-10 below. You will note that the symbology of the TIN appears differently as it was left at the default symbology called Elevation \#1, in the ESRI standard symbology. 


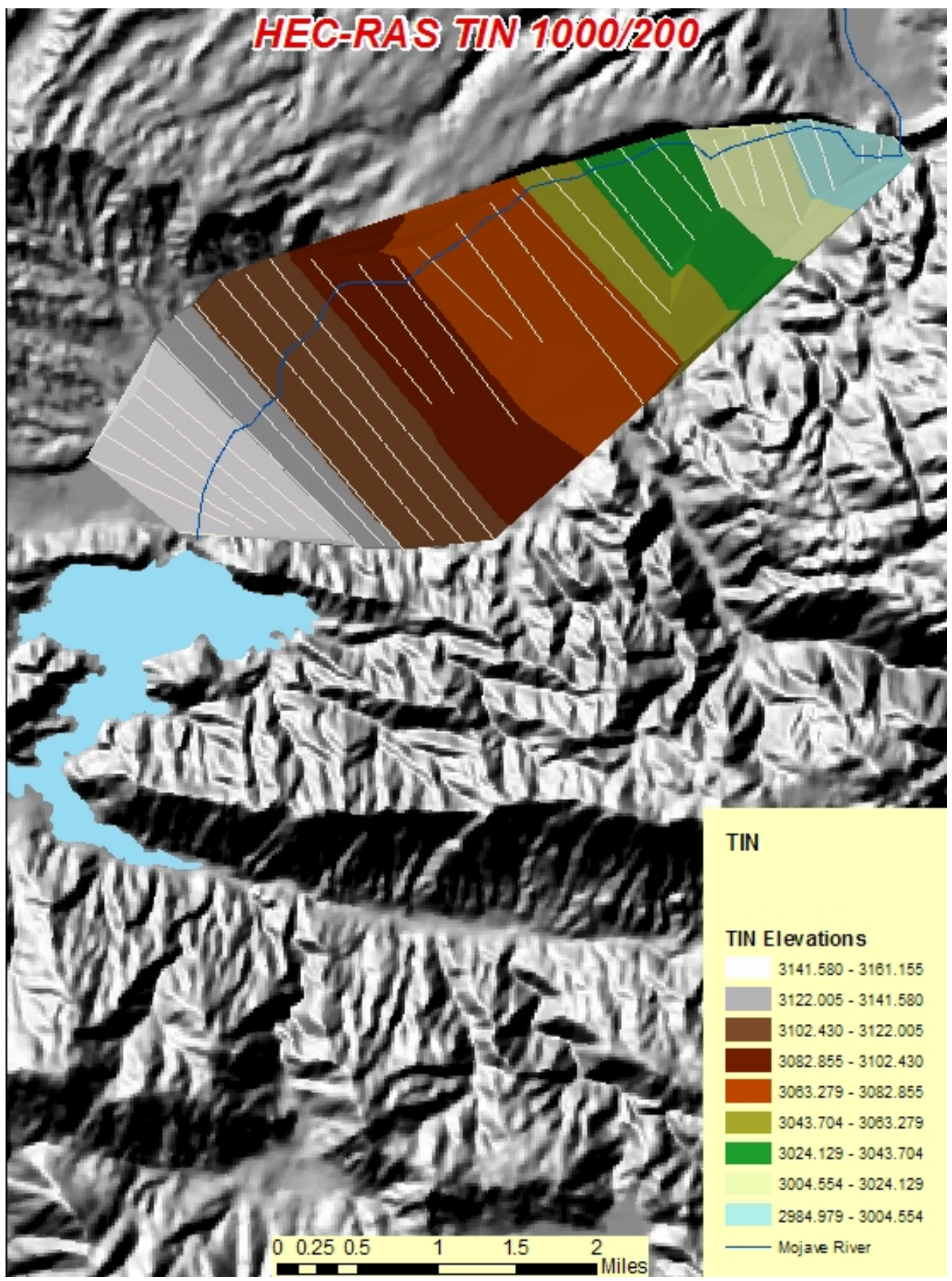

Figure 4-7. TIN elevations created in HEC-GeoRAS extension of ArcGIS 8.3 


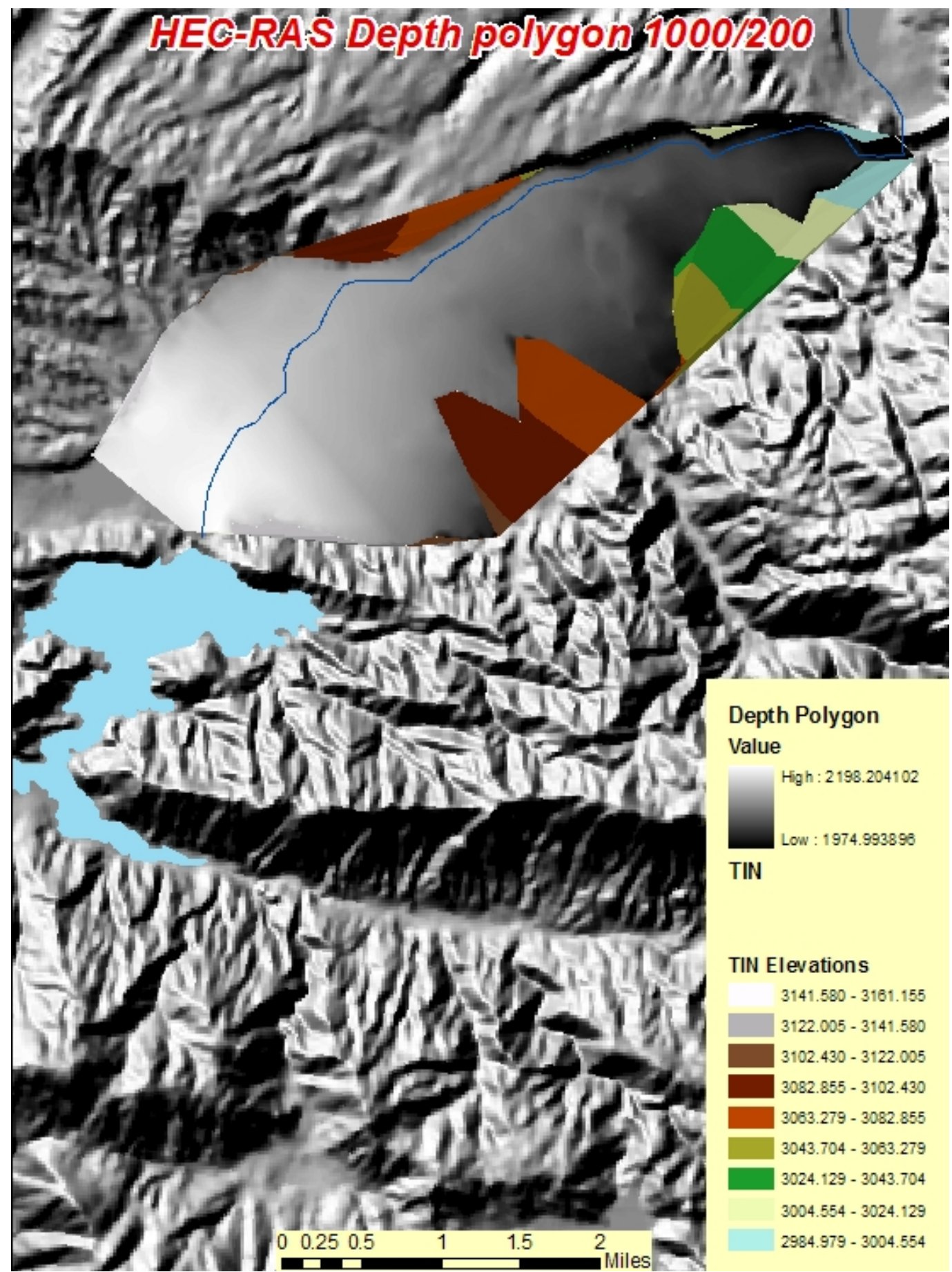

Figure 4-8. TIN and Depth polygon of full extent floodplain 


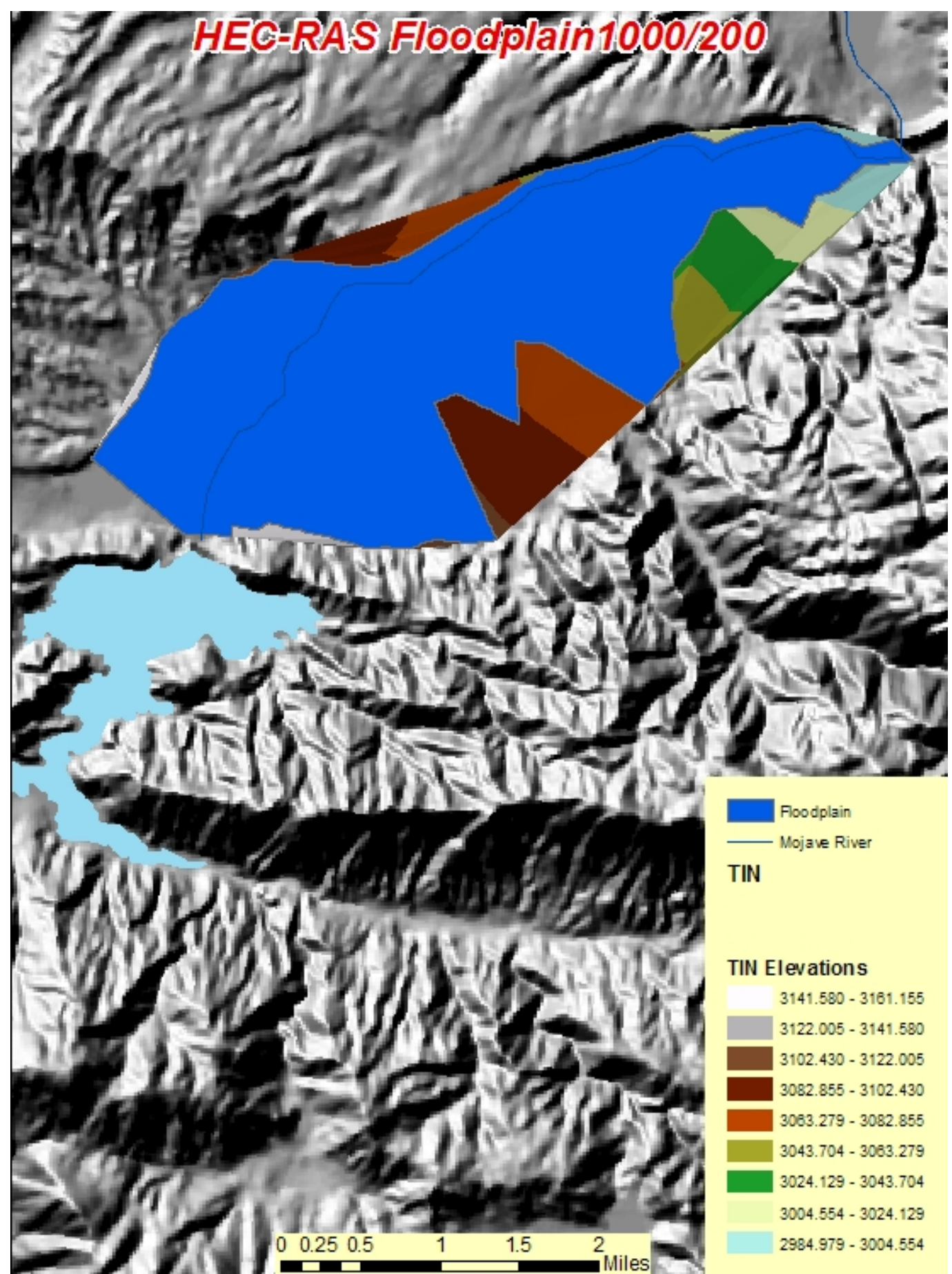

Figure 4-9. Bounding polygon of XS cutlines and Floodplain polygon 


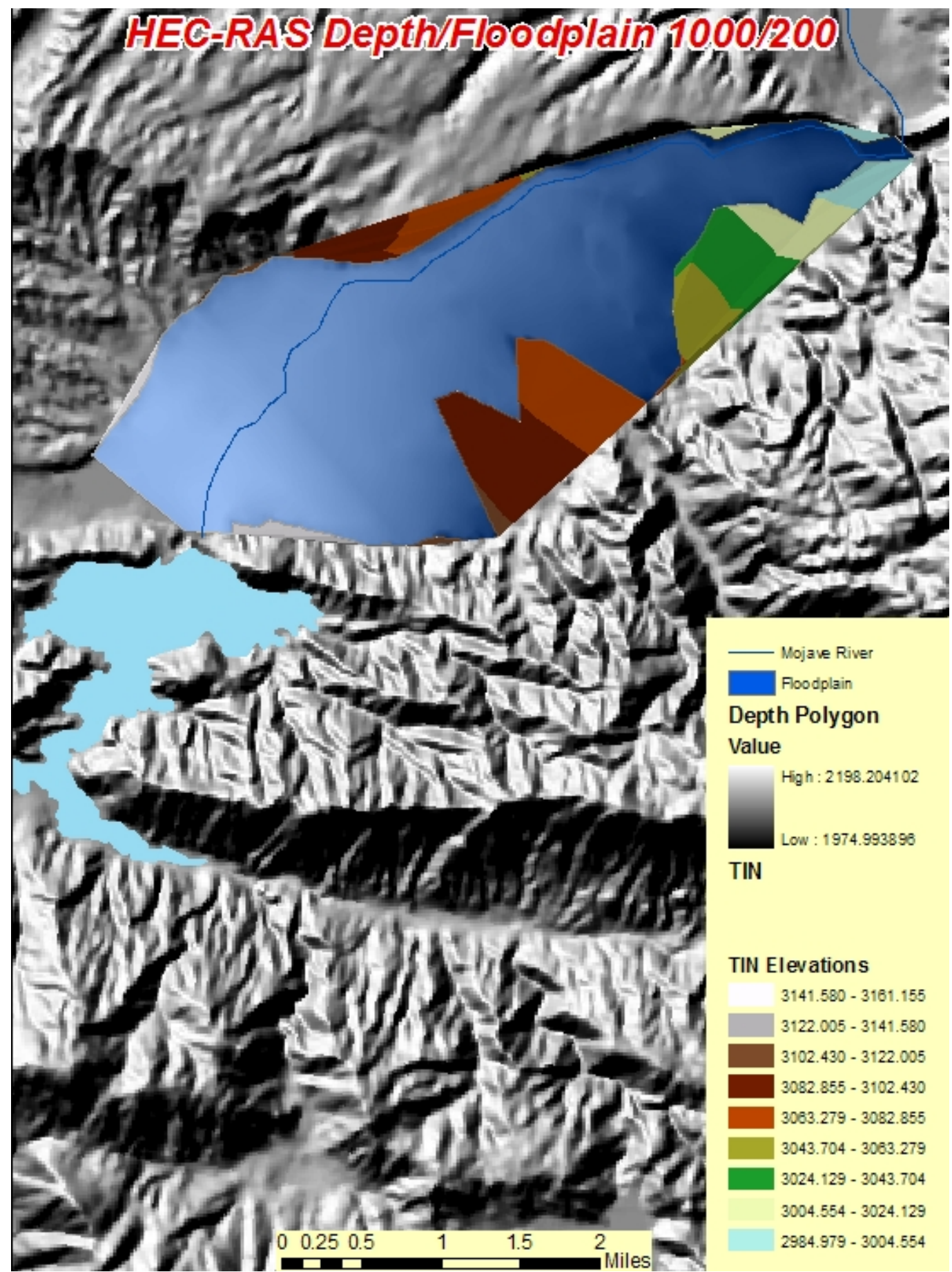

Figure 4-10. Floodplain with transparency enhanced 


\section{Emulating HEC-RAS with ArcGIS 9.0, ArcHydro and Spatial Analyst extensions}

The analyst completed many hours of HEC-RAS research during the MIP development. The analyst tried to emulate HEC-RAS output with ArcGIS 9.0 software, for the purpose of automating more of the analytical processes.

The analyst created XS cutlines in ArcGIS 9.0 using the same two reference data sets of rivers and hillshade. The XS cutlines were then converted to a 3D feature class. These were brought into ArcScene for visualization of the area of interest. While the analyst was able to emulate the procedure, the resulting flooded area polygon looked dramatically different. (See Figure 5-1.) This can be attributed to the mathematical calculations being performed using the HEC-RAS software. Comparison graphics of the flooded area are shown in Chapter 6. 


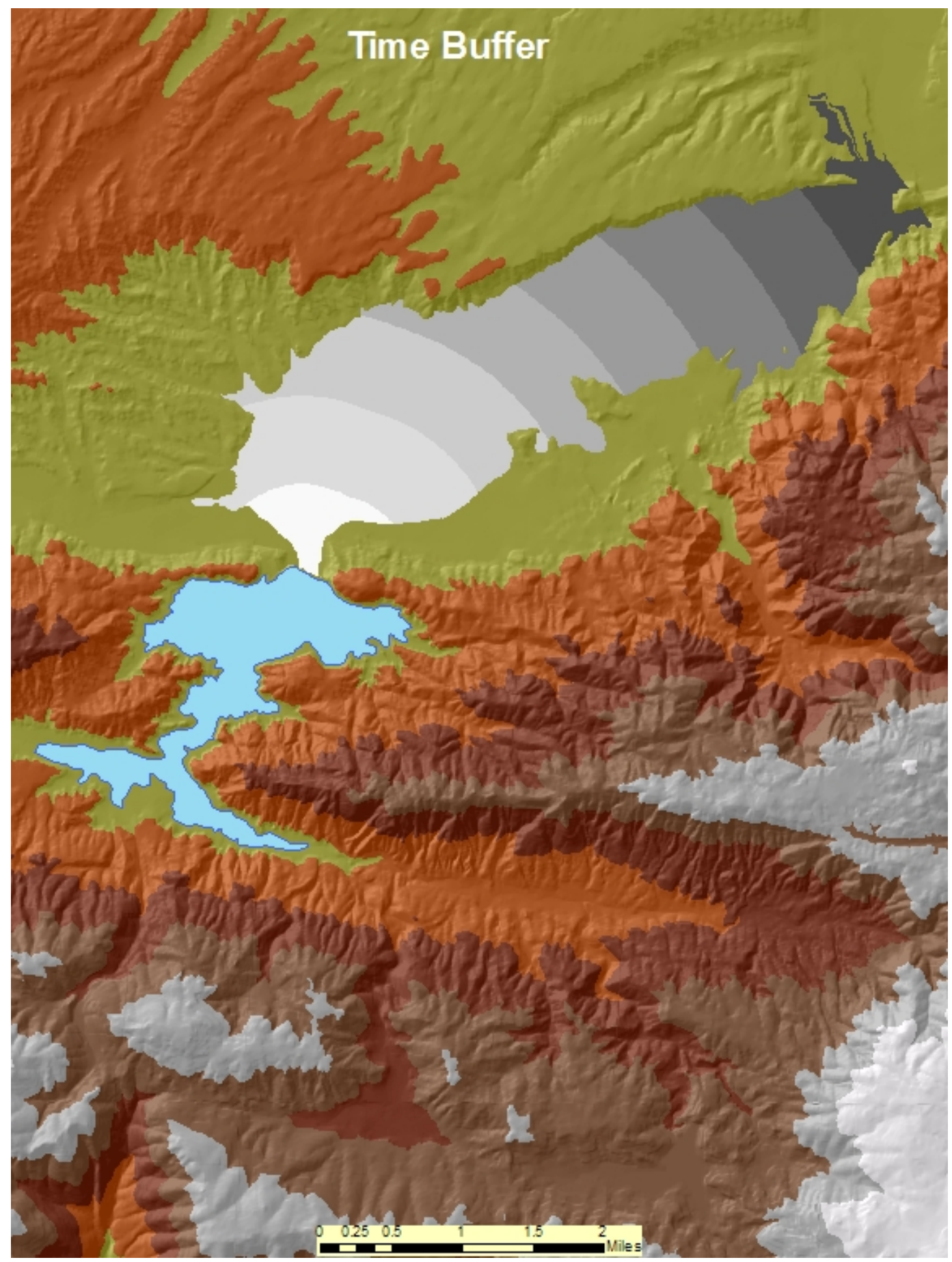

Figure 5-1. Flooded area depiction using ArcGIS 9.0

This shows the potential flooded area with time series buffers (minutes) applied.

As mentioned above, the analyst brought the feature classes that were created by using ArcGIS 9.0 only, into ESRI's ArcScene software. Several graphics from different scales and perspective views are presented in Figures 5-2 through 5-6. 


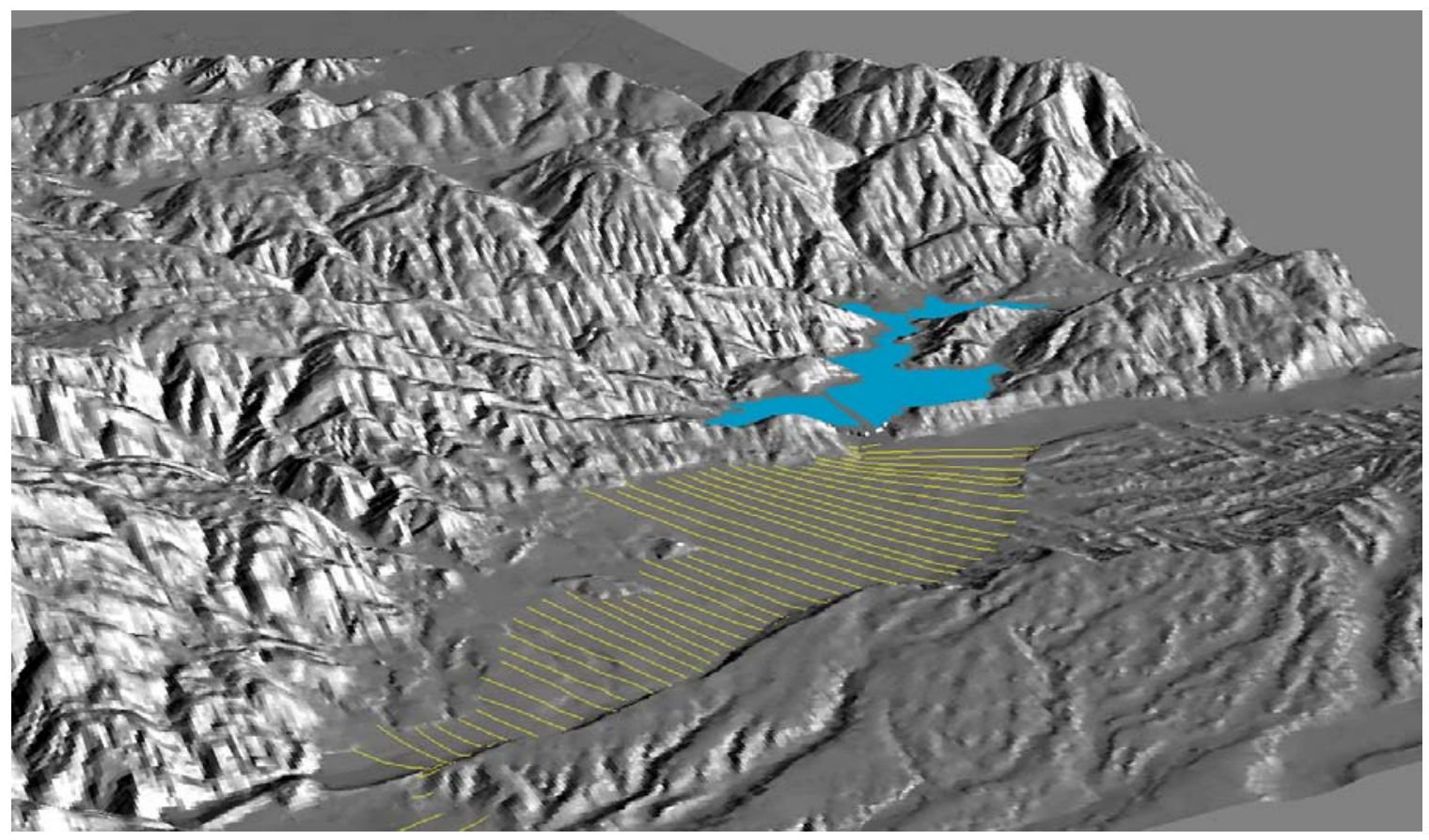

Figure 5-2. Three-Dimensional view of DEM and Silverwood Lake

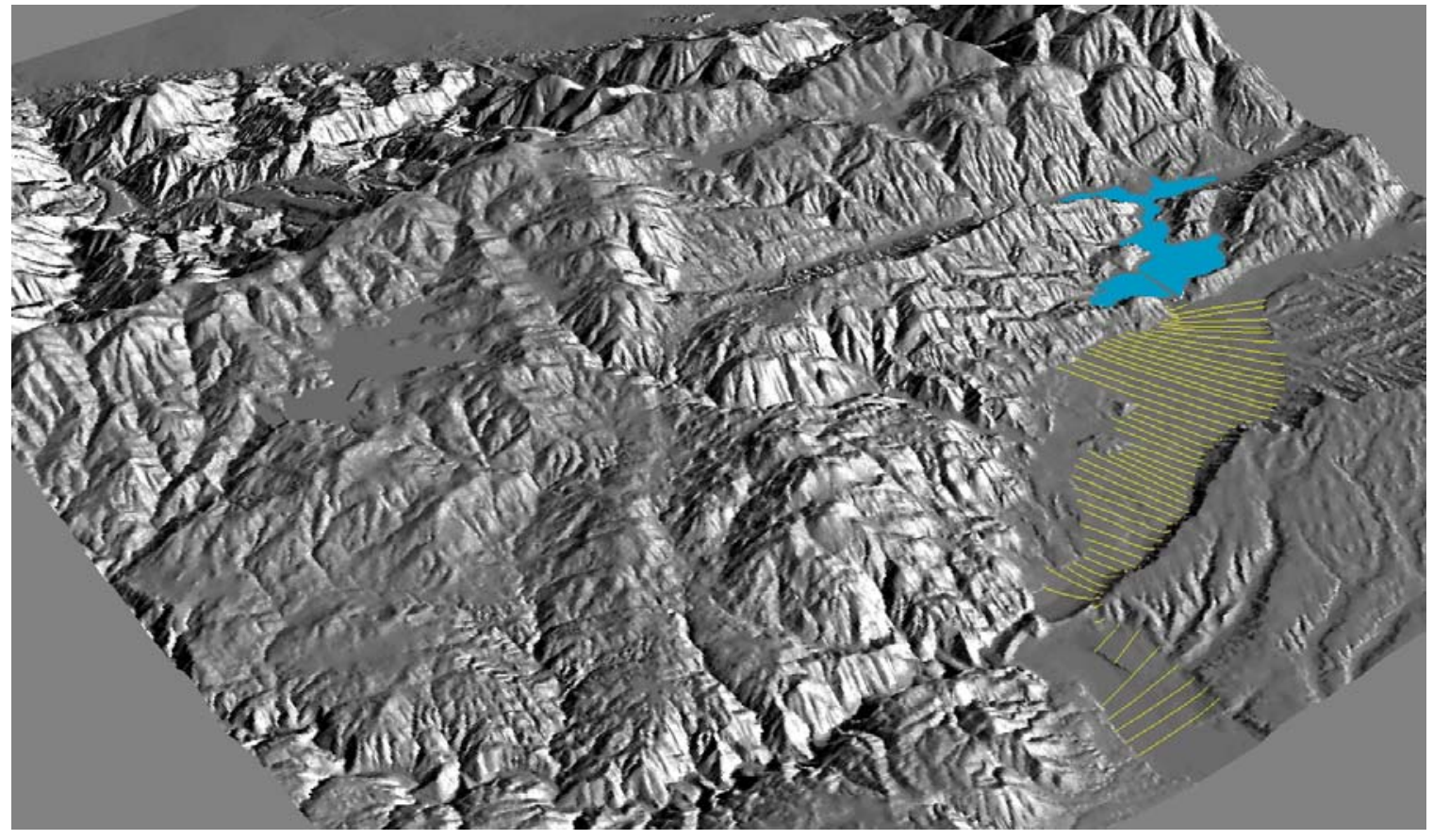

Figure 5-3. Higher angle 3D view of DEM and Silverwood Lake 


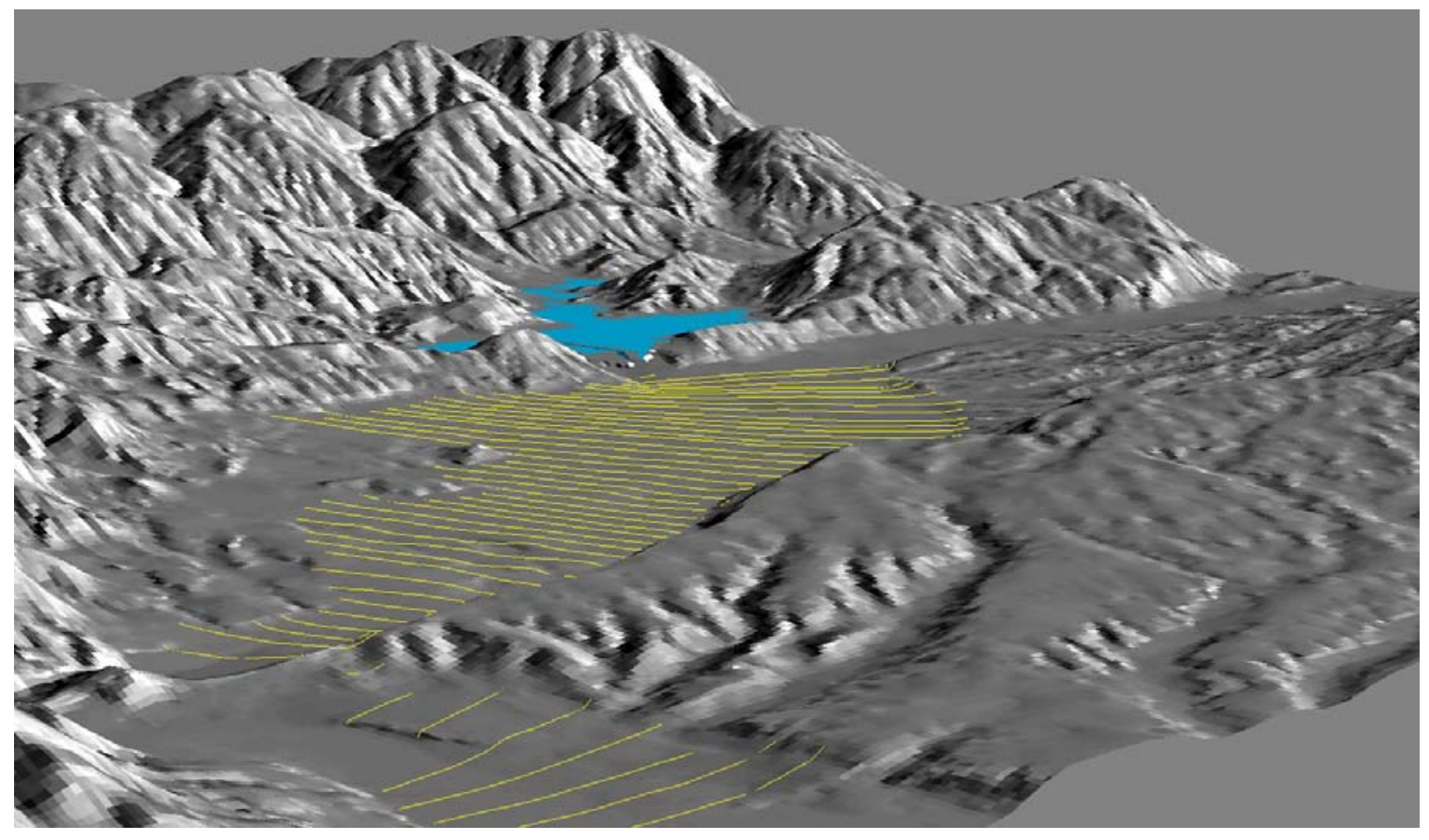

Figure 5-4. Large scale 3D view of XS cutlines

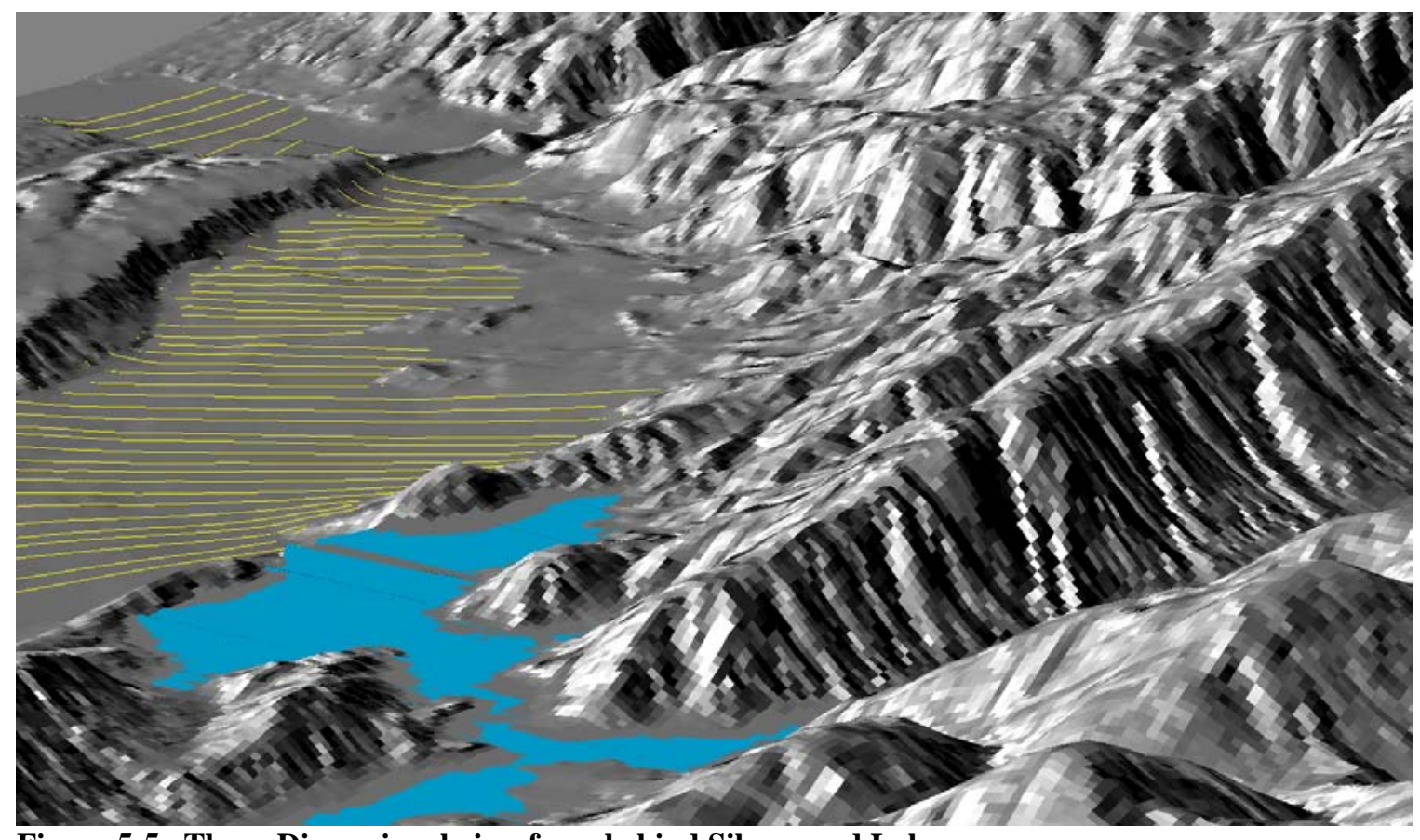

Figure 5-5. Three-Dimensional view from behind Silverwood Lake 


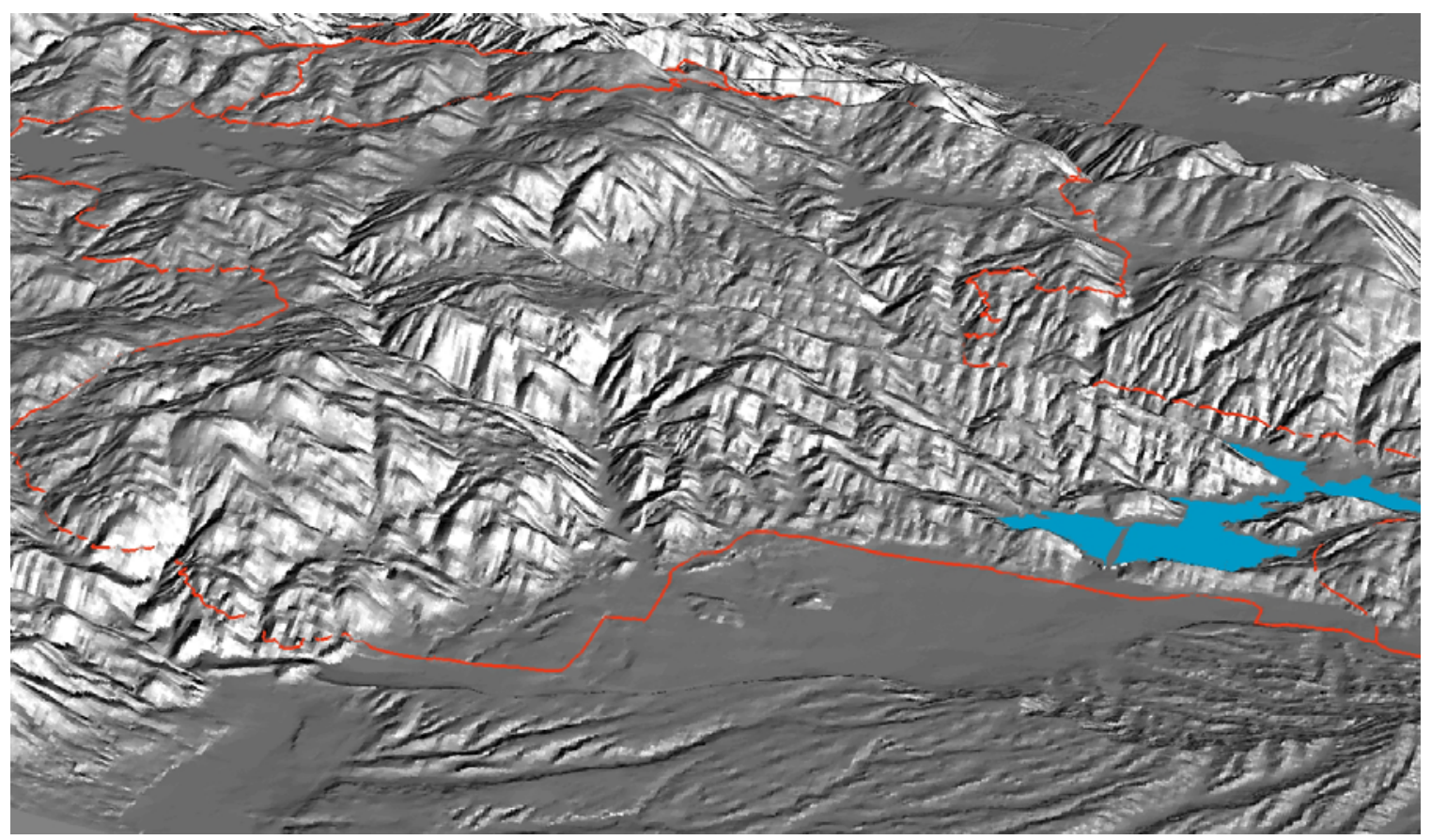

Figure 5-6. Three-Dimensional view of the area of concern with transportation overlaid

The analyst also created a shaded relief map for visualization purposes. This was created by overlaying the hillshade on the DEM, and experimenting with the transparency with the ESRI Effects Toolbar. The analyst created several graphics depicting the area of interest with different vector feature classes portrayed. These can be viewed in Figures 5-7 through 5-14 below. 


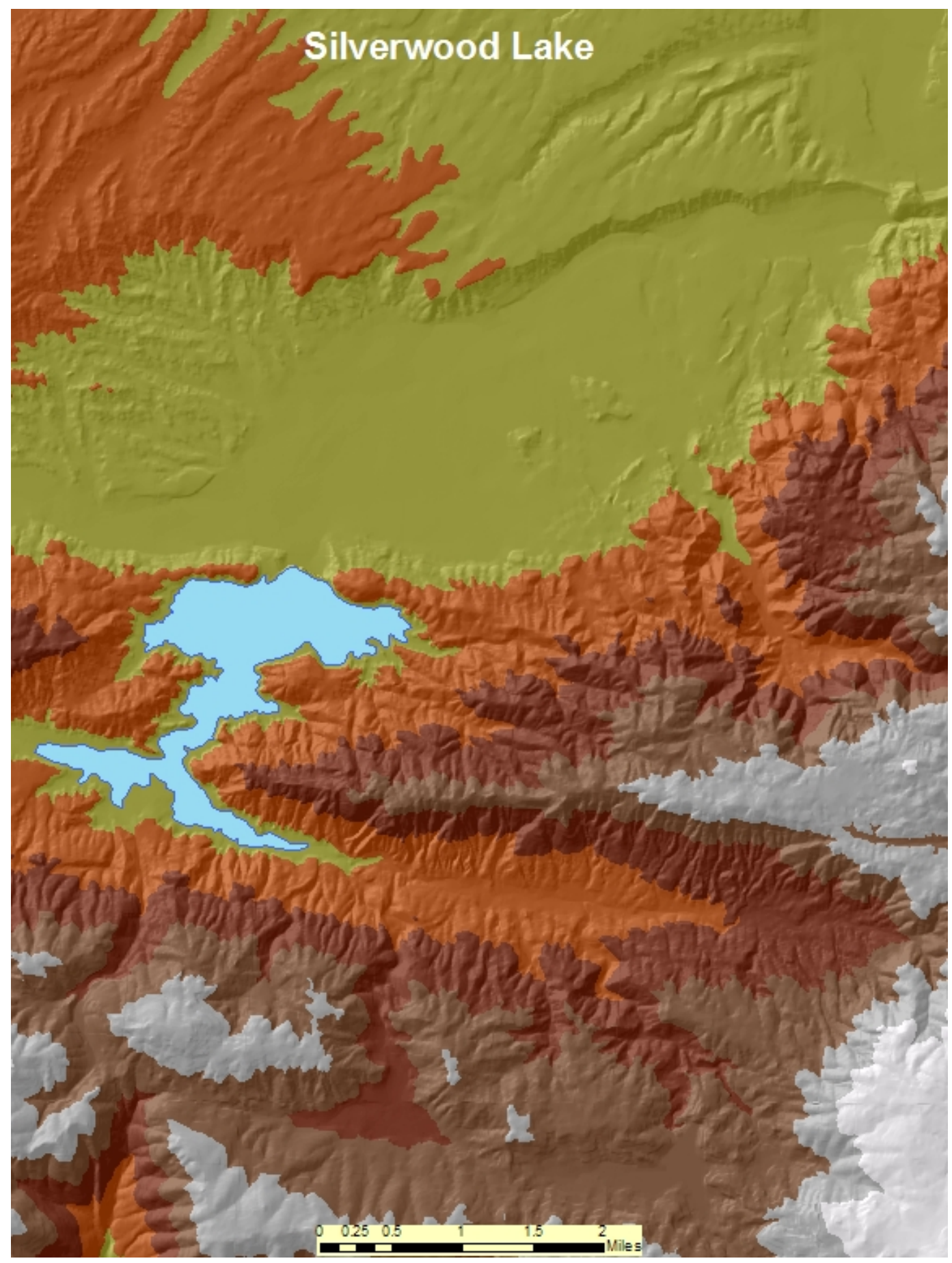

Figure 5-7. The processed DEM and overlaid hillshade featuring Silverwood Lake 


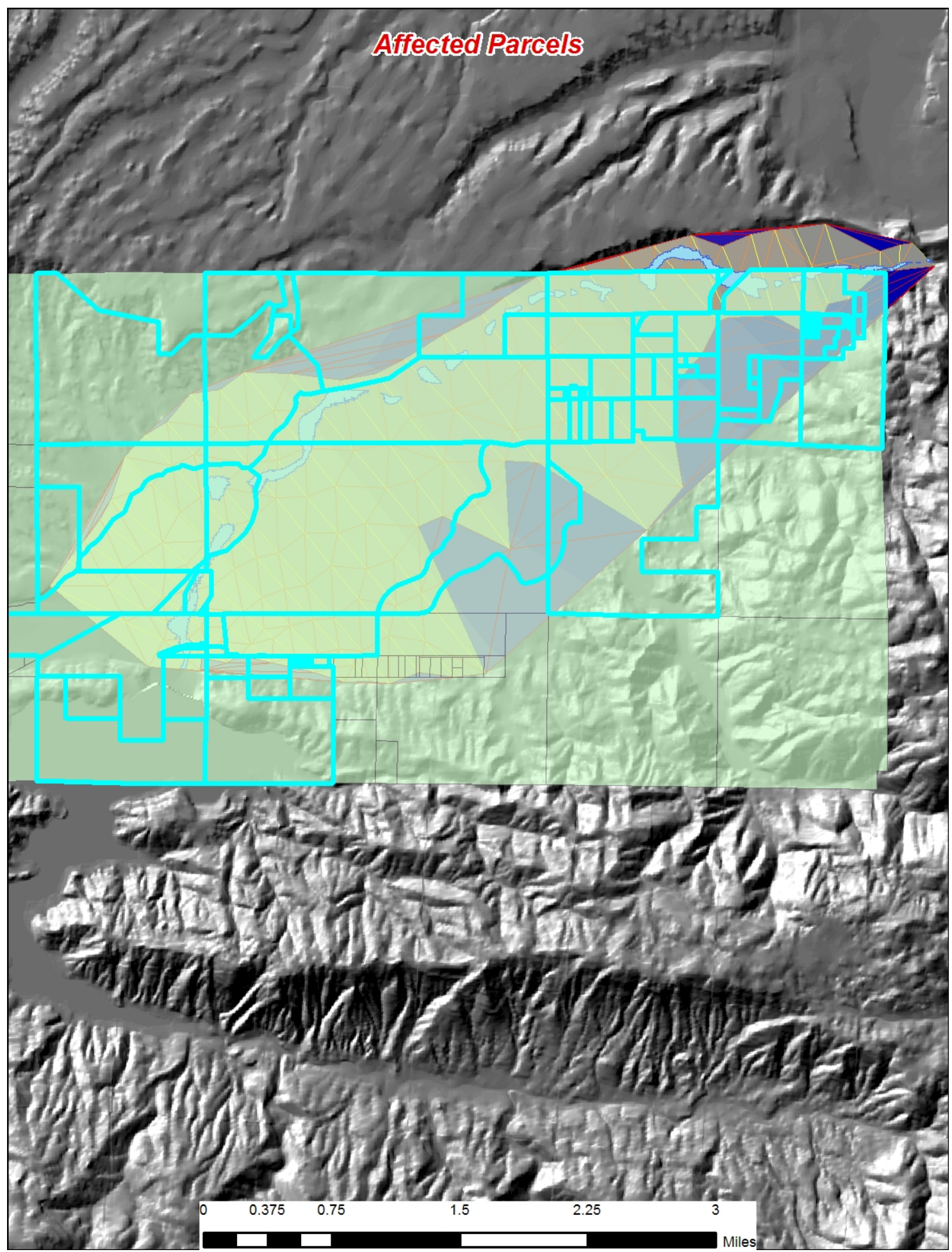

Figure 5-8. Area of interest showing parcels affected (highlighted in turquoise) 


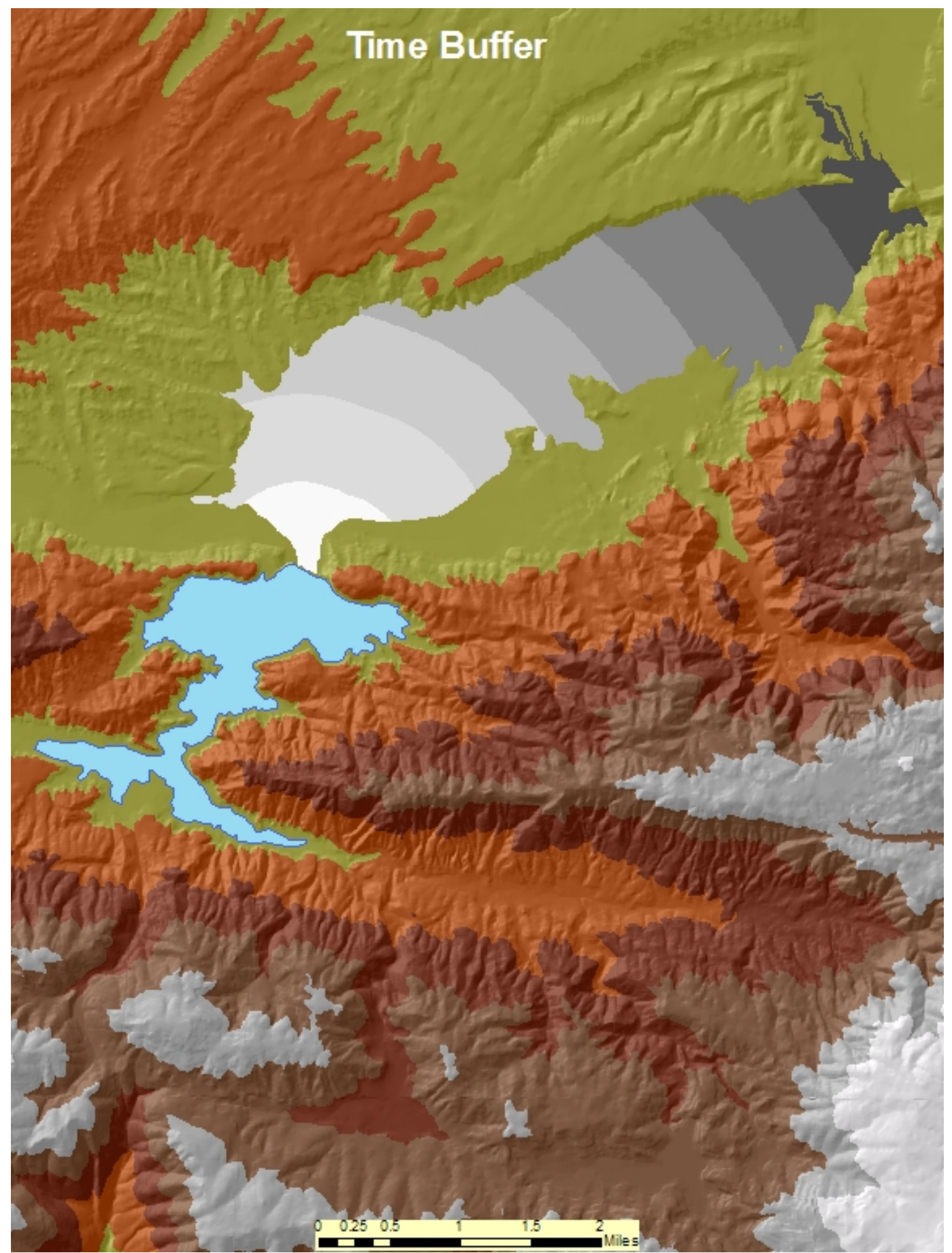

Figure 5-9. DEM and hillshade with 1000 meter buffers of the intersection of flooded area and buffers, which can be used as a time-series depiction of the dam burst 


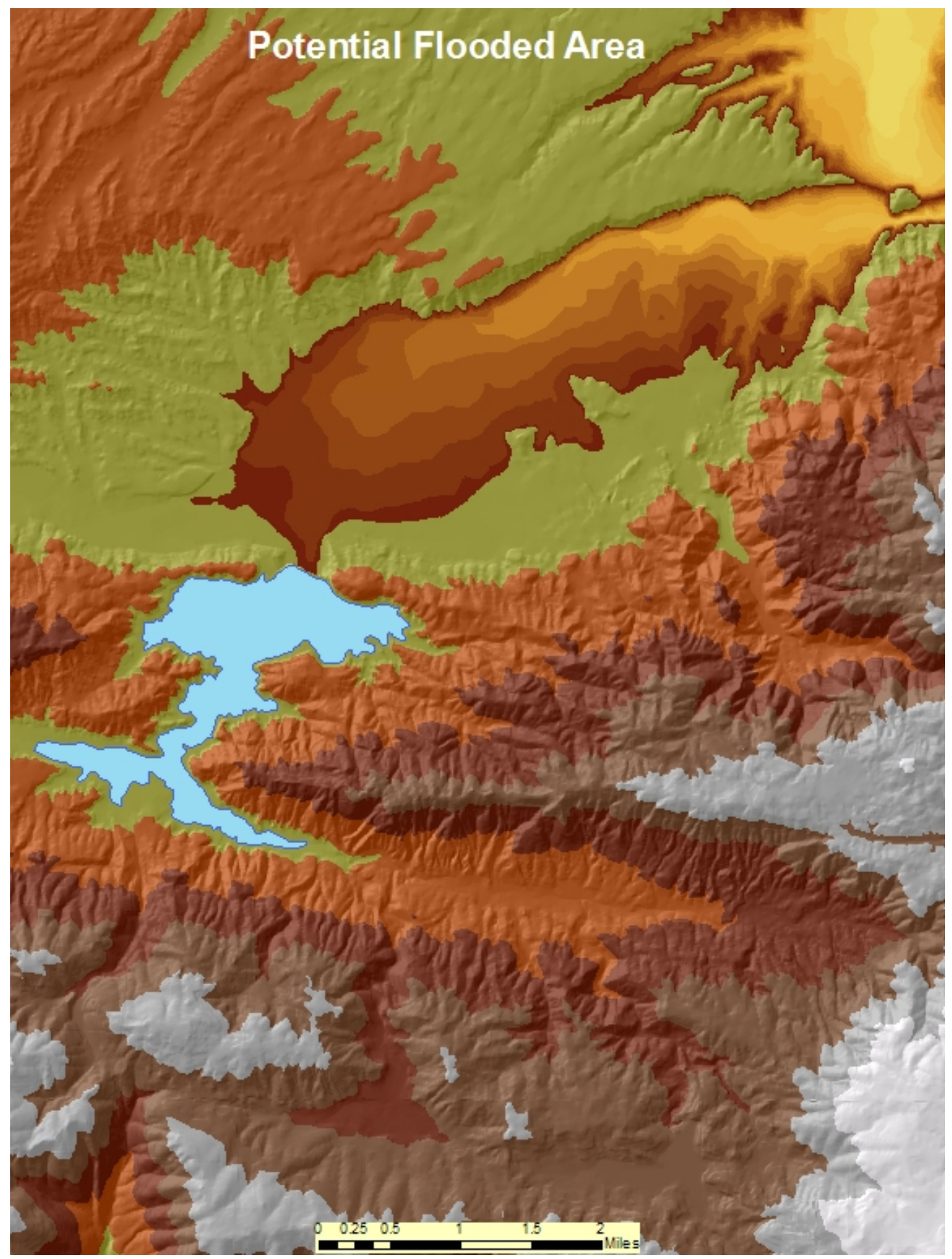

Figure 5-10. Depiction of the flooded area using ArcGIS 9.0 


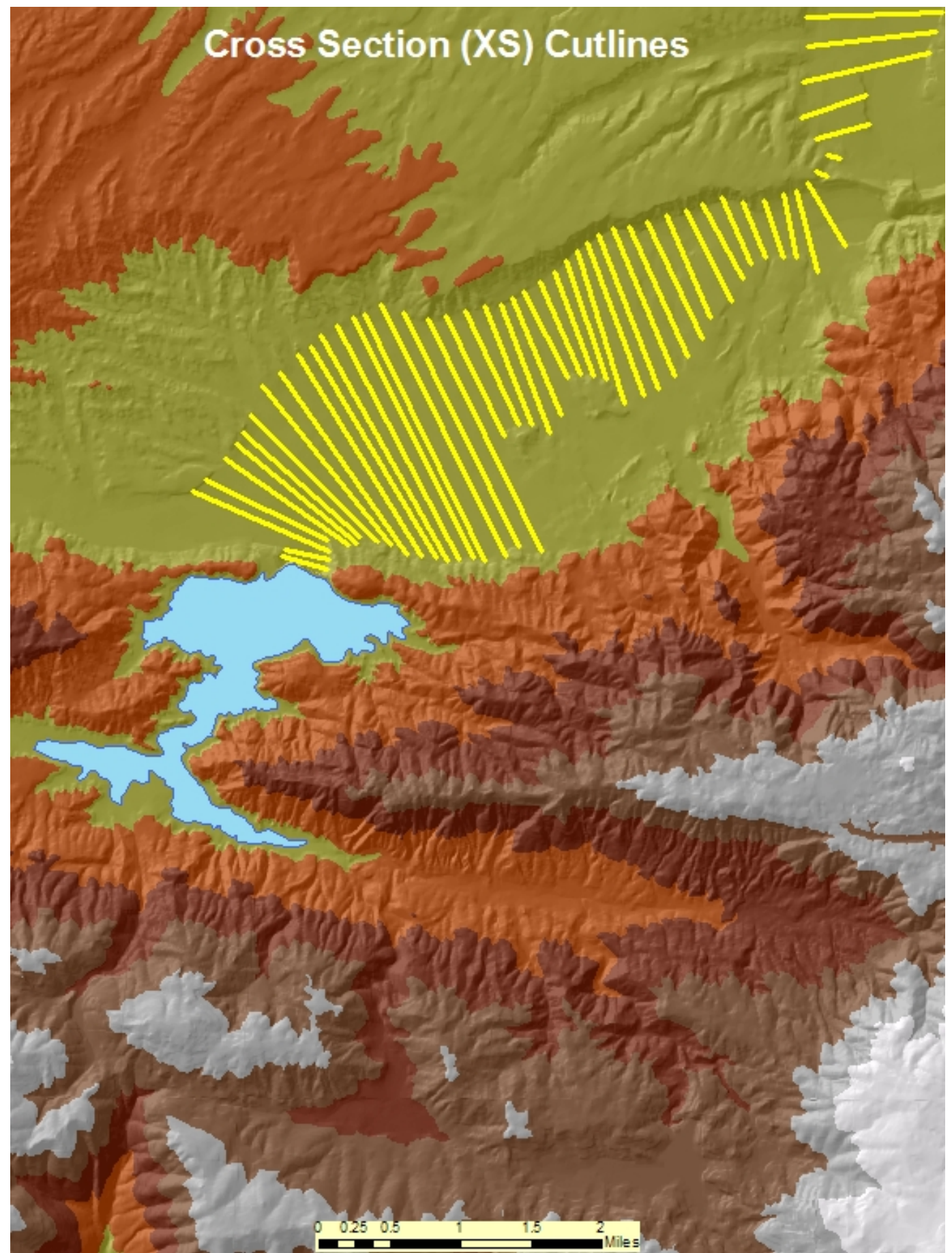

Figure 5-11. XS cutlines created in ArGIS using the same two reference data sets of rivers and hillshade.

The XS cutlines were then converted to 3D shapefiles, with the elevation values being derived from the DEM. This procedure emulates the same processes provided in the HEC-RAS software which is currently used by the USACE. This data was imported into ESRI’s ArcScene program for 3D representation. 


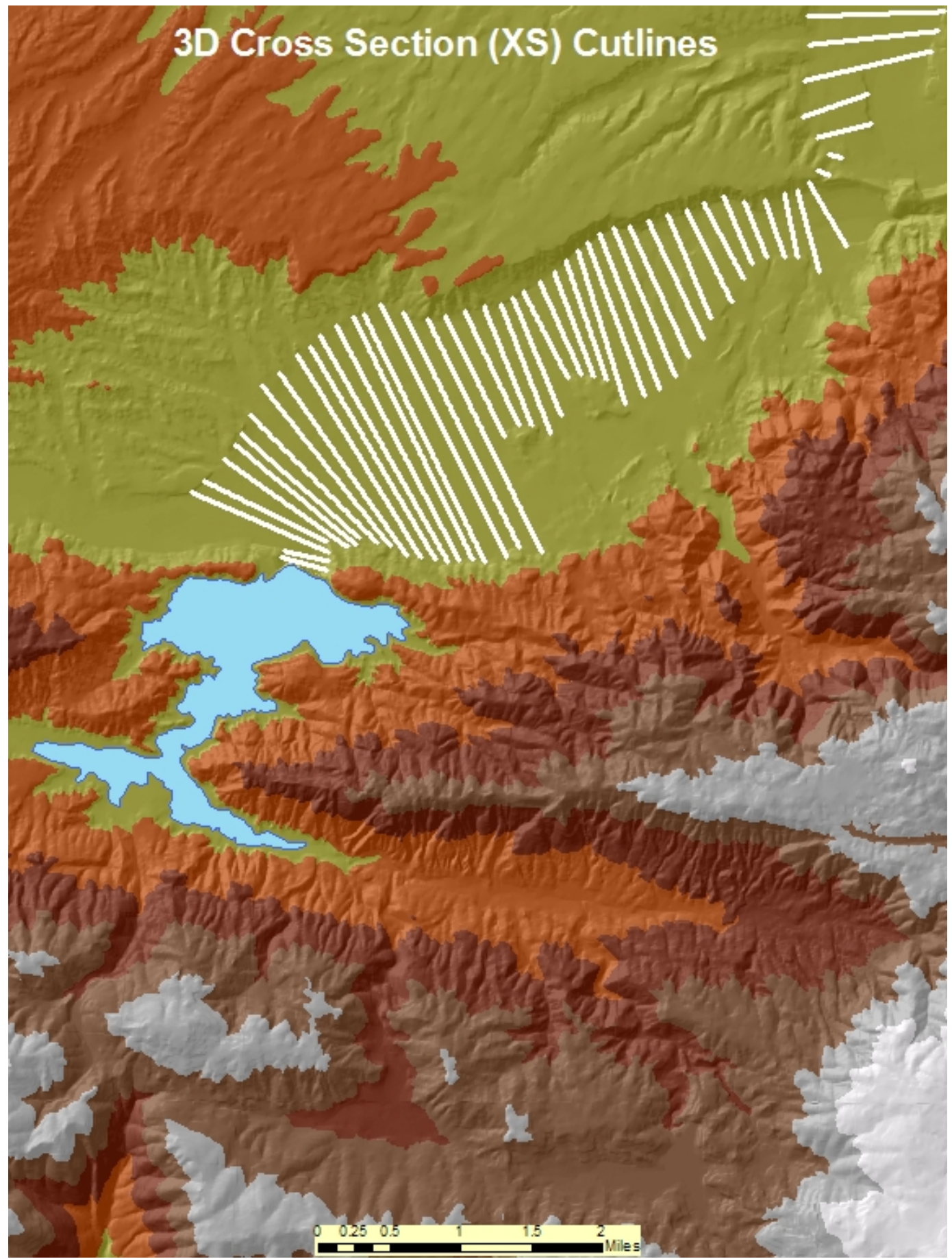

Figure 5-12. The XS cutlines converted to $3 \mathrm{D}$ feature class are here.

The 3D XS cutlines appear the same as the 2D XS cutlines seen in the previous graphic, but appear quite differently when displayed in ArcScene. Their elevations were derived from a 10-meter DEM. 


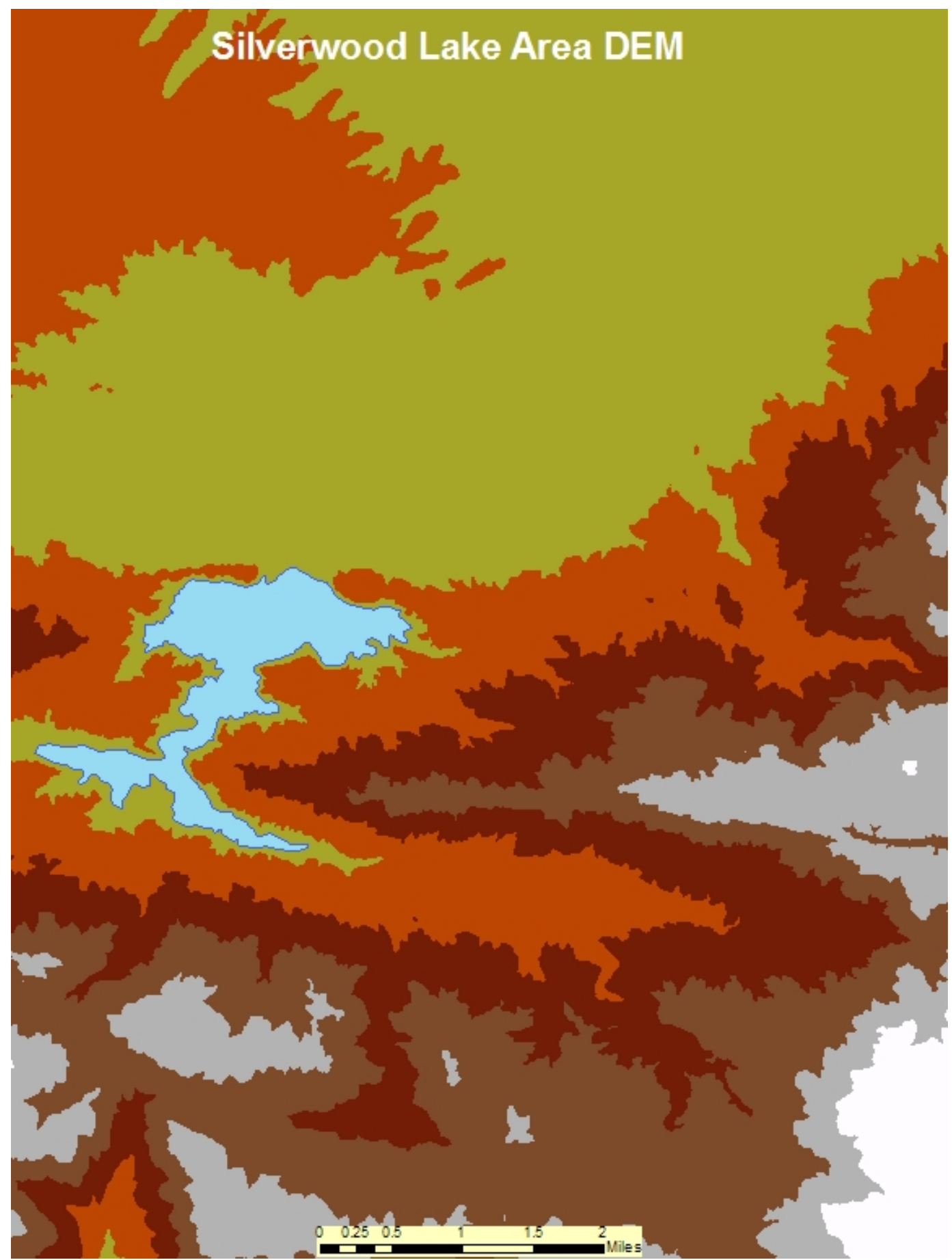

Figure 5-13. This graphic shows the DEM along with Silverwood Lake for reference.

The DEM was symbolized using an elevation symbology in ArcGIS. The analyst then overlaid the hillshade created from the working model for the 3D effect. Many iterations involving color scheme, transparency, and number of classes were considered before settling on this final product. 


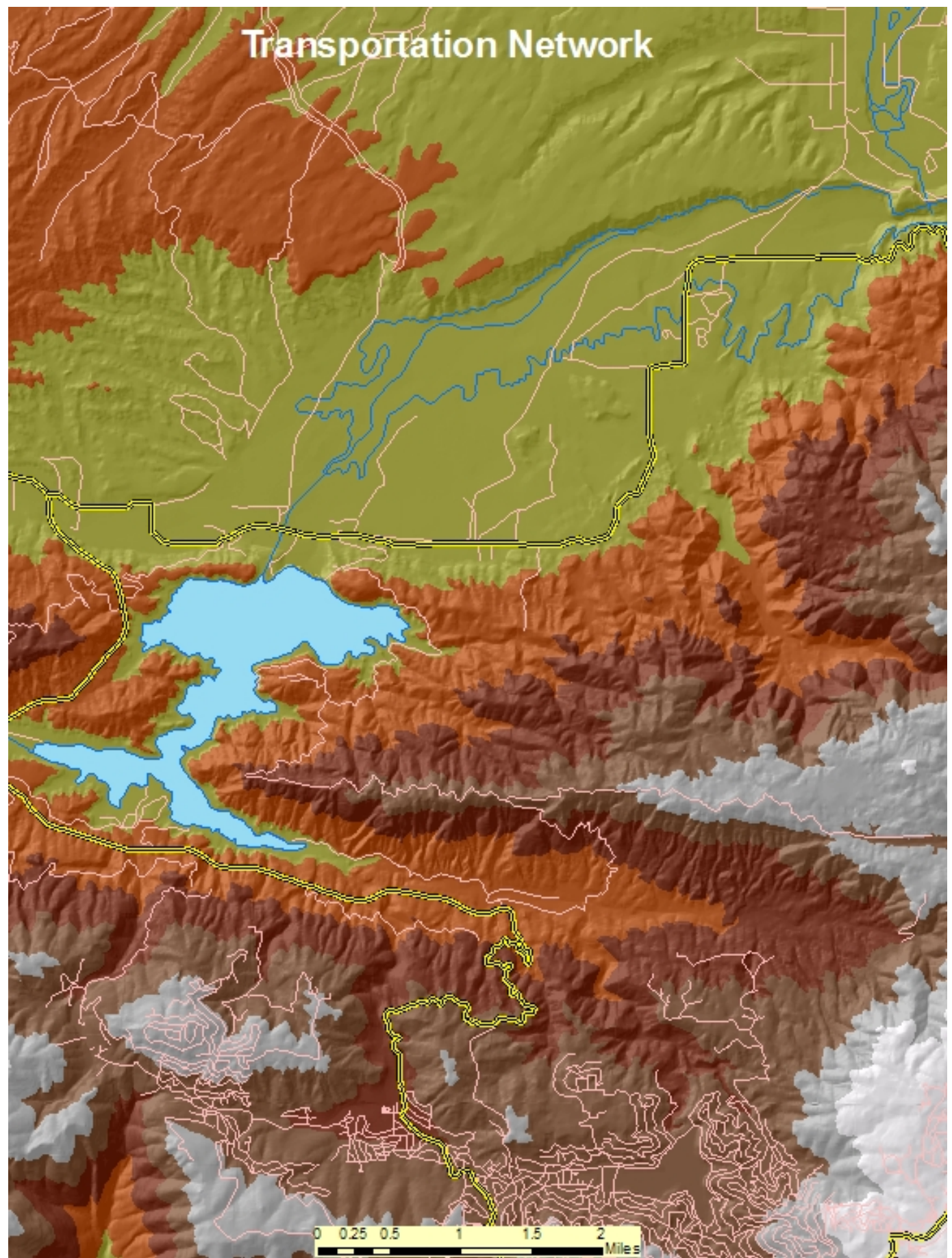

Figure 5-14. Silverwood Lake with surrounding transportation network

The analyst created a procedure to automate the creation of a shapefile to depict the area that would be flooded by a dam burst. This poster was the final project in the core curriculum Cartography class at the $\mathrm{U}$ of $\mathrm{R}$. This is shown as an interim step to the desired final products consolidated in Chapter 6. See Figure 5-15 below. 

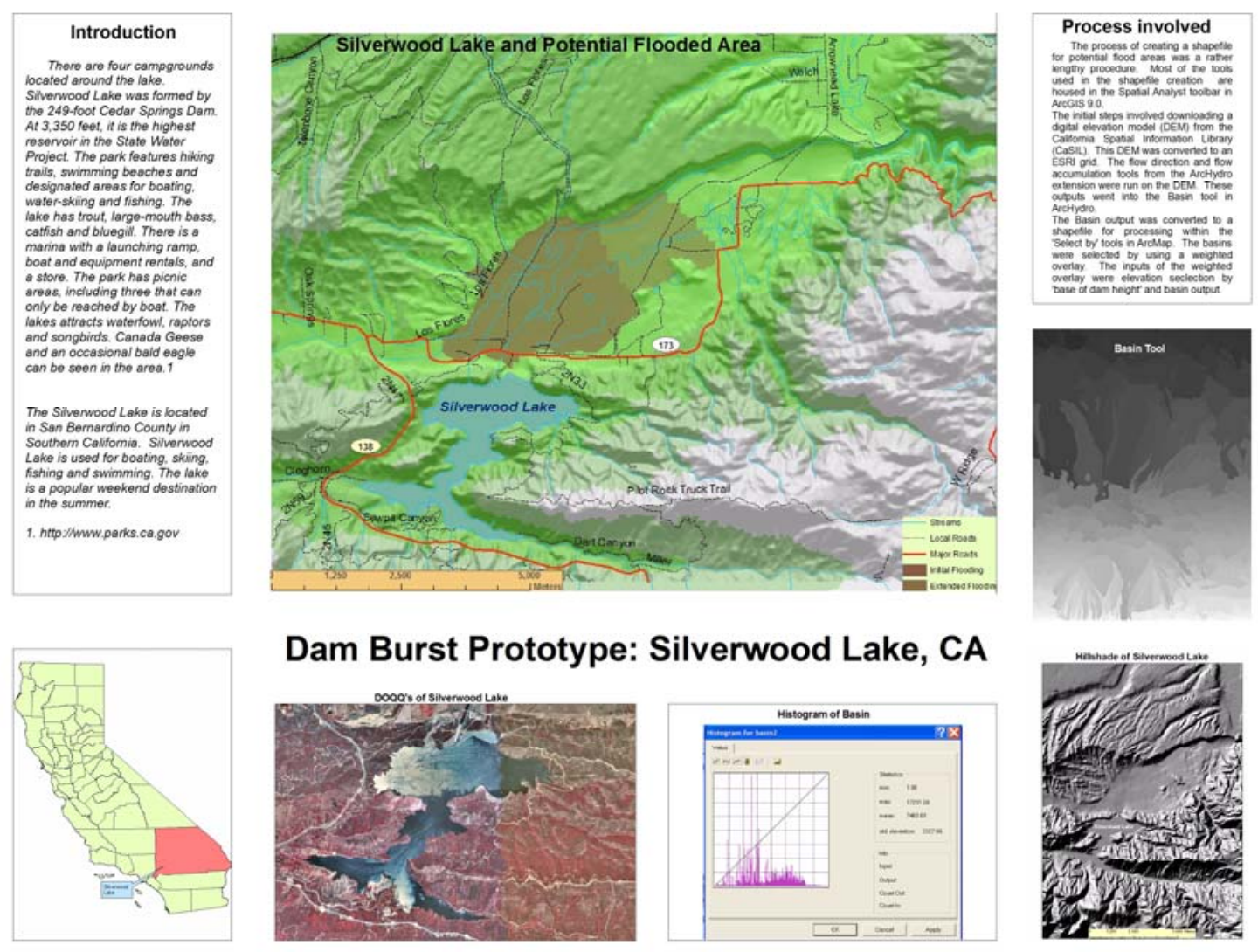

Figure 5-15. Poster display of Silverwood Lake 


\section{Comparison of Results and Conclusions}

The lake selected by the analyst (Silverwood Lake) is in a fairly isolated location. The number of houses and developments in the area turned out to be minimal. The MIP is designed as a prototype, so not all examples will be the same. The Mojave River flows north into the town of Hesperia. The analyst was concerned about the accuracy of the statistical analysis of other vector data sets, when the DEM appeared to show that the Mojave River stopped flowing abruptly. Upon physical inspection of the study area, the analyst noticed that another dam had been built. This second dam was built to protect the town of Hesperia in the event that Silverwood Lake's Mojave Dam was breached. The tabular analysis is included below based on the second dam being in place. The fact that many of the categories appear with 'zero' values illustrates that the flooded area is not densely populated. This ' 0 ' value, in effect, turns out to be a very positive statistic, in that crucial infrastructure are not affected. Also of note in the table are the Census Block Group numbers. The Block Group was the most detailed dataset acquired that showed the actual number of people located within it. Therefore, the numbers are for the entire Block Group, and not over the actual flooded area. In actuality, these people are still affected by road closure, though not directly due to flooding. In this case, road closure is defined as any road that is not safe to pass due to water covering all or part of it. It can also be defined as closed even if completely dry, if unable to reach it due to other lower parts of the road being covered with water. The analyst will continue to expand on this model to add more vital vector data sets to the list below. The results are in Table 6-1 below.

Table 6-1 Tabular Results

\begin{tabular}{|l|l|l|l|}
\hline Data Set & Number Affected & Stats & Comments \\
\hline Parcels & 79 & & Very large parcels \\
\hline Census Block Group & 3 & 878 people & Total \# in BlkGrp \\
\hline Major Roads & 1 & 6.7 miles & State Hwy 173 \\
\hline Secondary Roads & 6 & 38.4 miles & Arrowhead Rd \\
\hline Fire Stations & 0 & & Desolate area \\
\hline Airports & 0 & & Desolate area \\
\hline Hospitals & 0 & & Desolate area \\
\hline Police Stations & 0 & & Desolate area \\
\hline
\end{tabular}

The analyst concluded that any desired result can be derived from the use of HEC-RAS, HEC-GeoRAS and ArcGIS 9.0. The analyst also realized that the calculations performed in HEC-RAS are vital to modeling a realistic Floodplain Polygon. Future expansions of the dam burst model will definitely include the HEC-RAS software. The analyst will expand his knowledge on the input variables through research from Handbook of Applied Hydrology (Chow, 1964) and Kings Handbook of Hydraulics (Brater, et. al., 1996) and the HEC-RAS Help Manual. The results from the three procedures described in this document are presented below, starting with HEC-RAS graphics in Figures 6-1 through 6-3. 


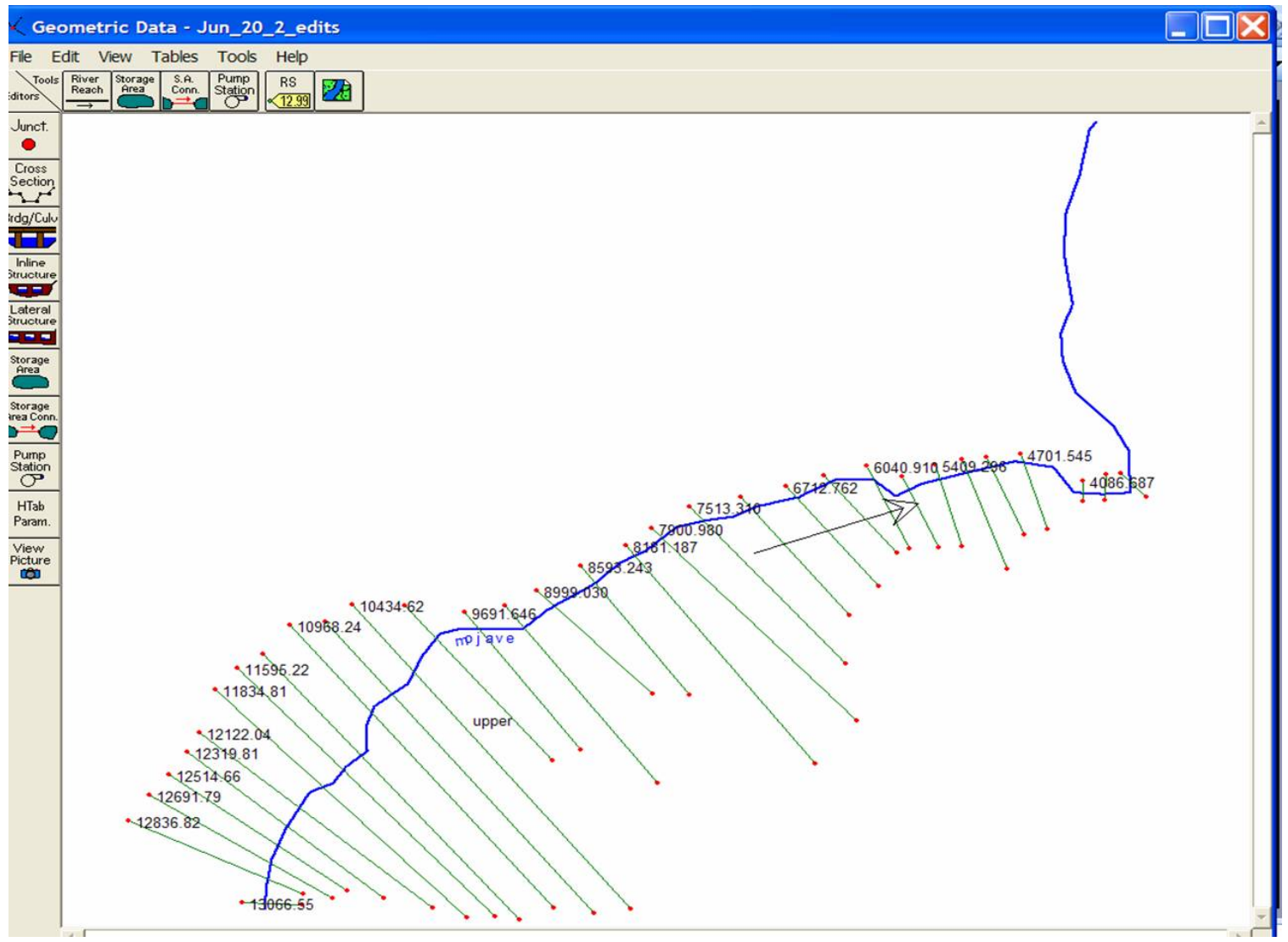

Figure 6-1. HEC-RAS geometry plot of XS cutlines and stream centerline 


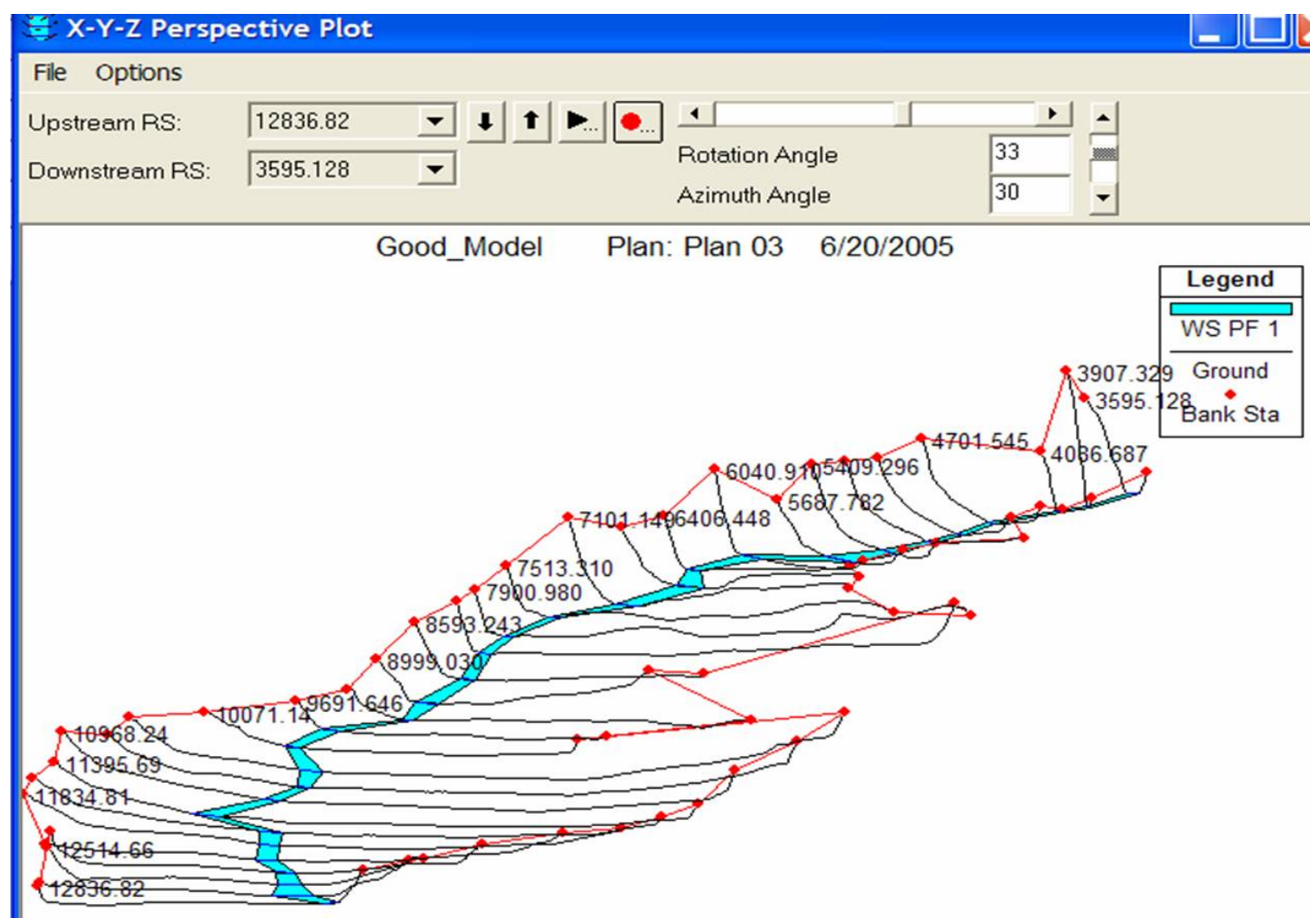

Figure 6-2. Profile view looking down from Cedar Springs Dam (HEC-RAS results)

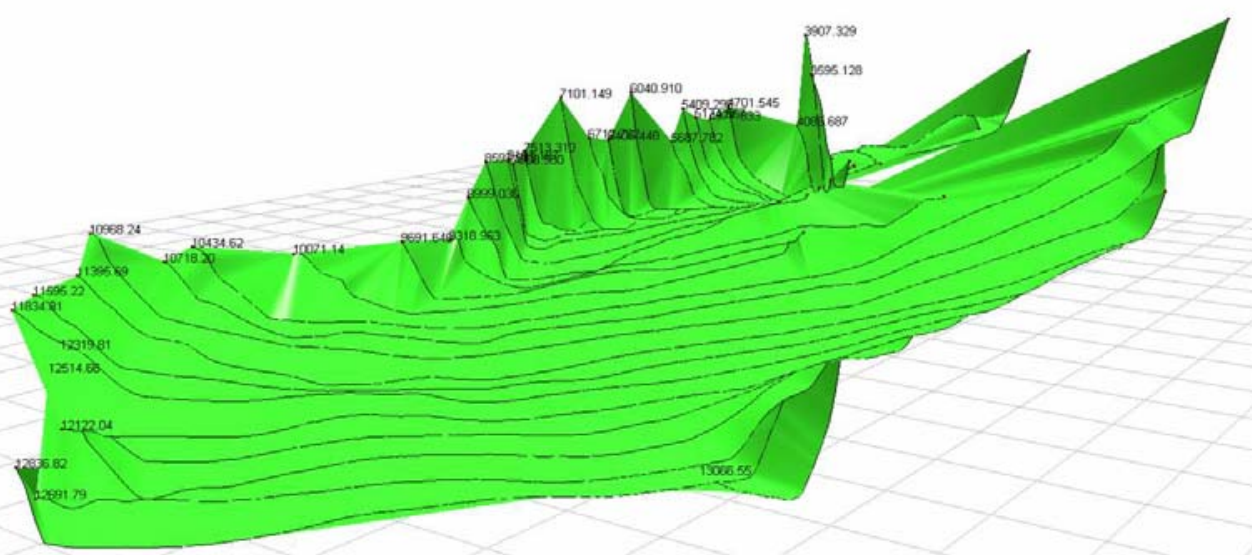

Figure 6-3. Perspective view using the fly-through tool in HEC-RAS 3.1.3 
The following three graphics were produced in the HEC-GeoRAS extension of ArcGIS 8.3.

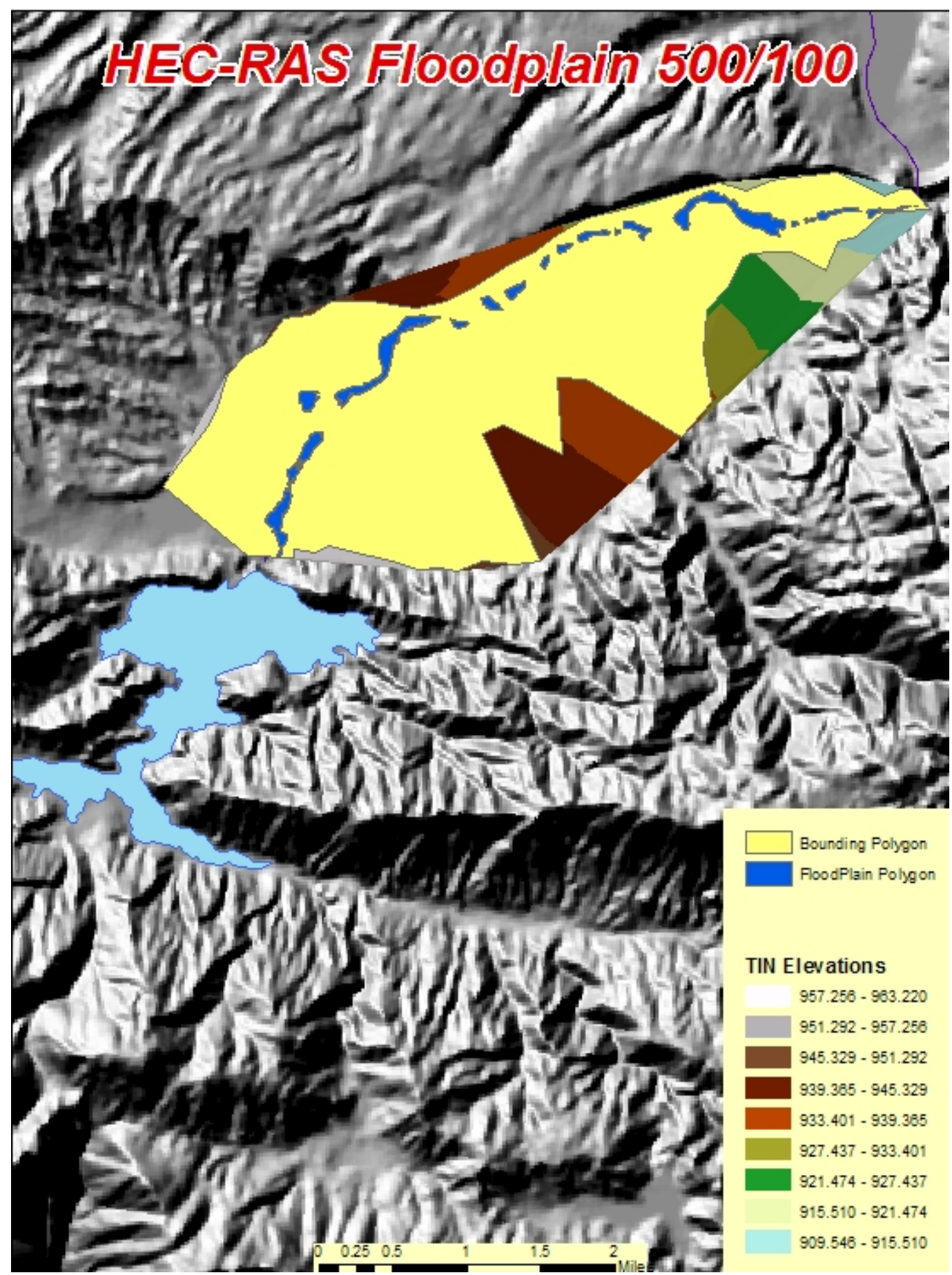

Figure 6-4. HEC-GeoRAS Initial Bounding polygon and Floodplain polygon 


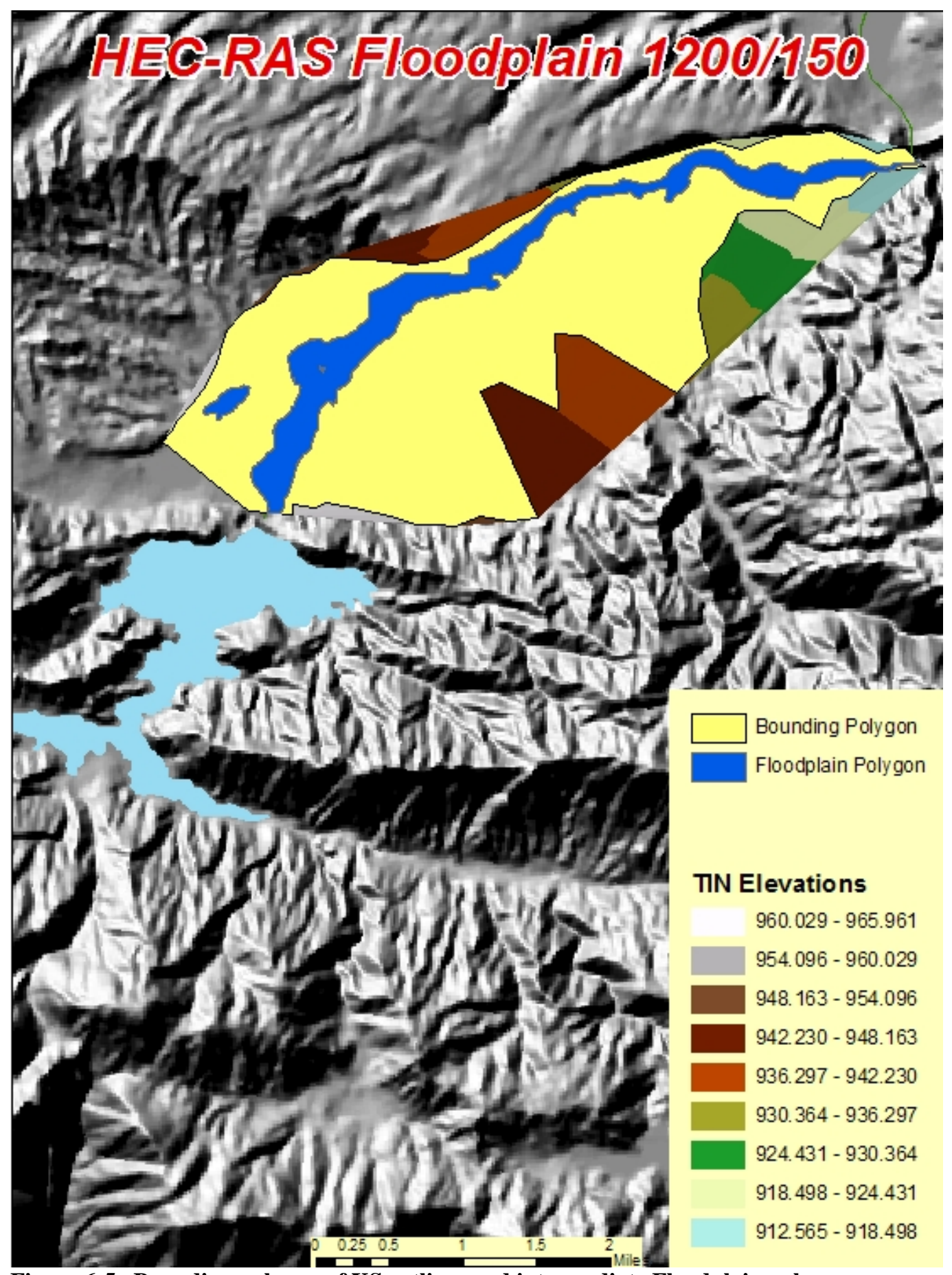

Figure 6-5. Bounding polygon of XS cutlines and intermediate Floodplain polygon 


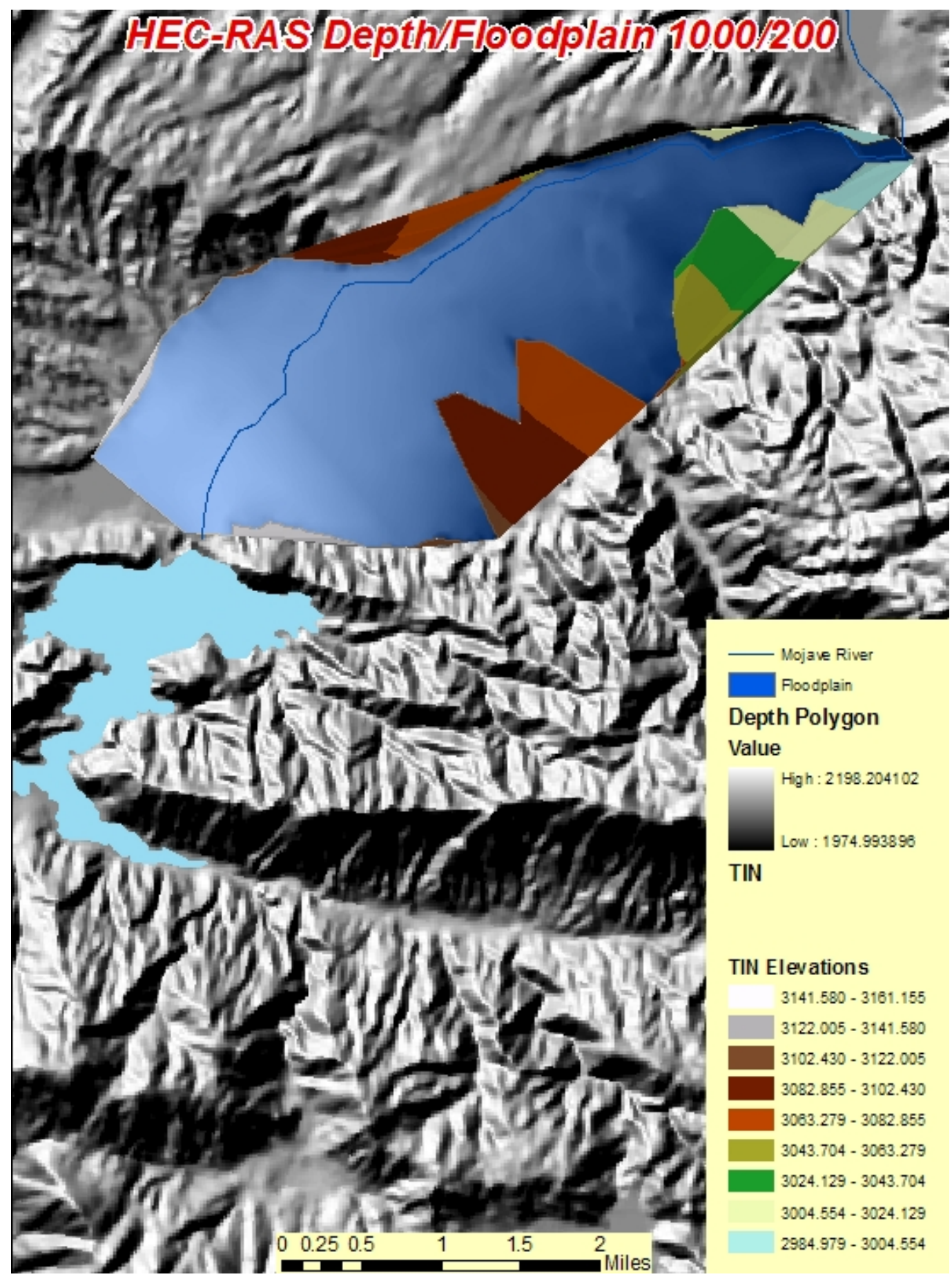

Figure 6-6. Fully extended Floodplain polygon with transparency enhanced

The following graphics in Figure 6-7 and Figure 6-8 previously presented in Chapter 5 were created in ArcGIS 9.0. They were created using the Spatial Analyst and 3D Analyst extensions. 


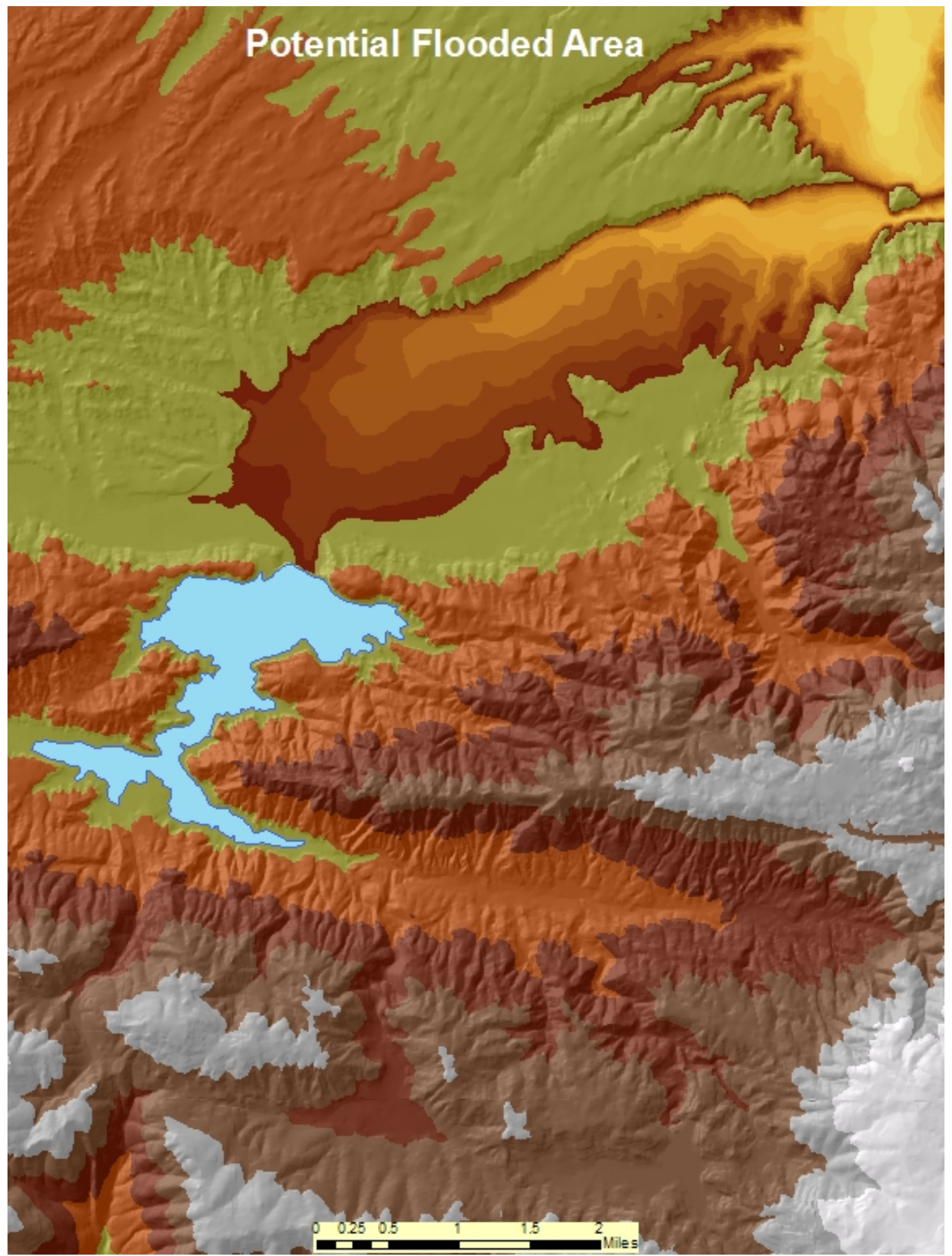

Figure 6-7. Depiction of the flooded area using ArcGIS 9.0 


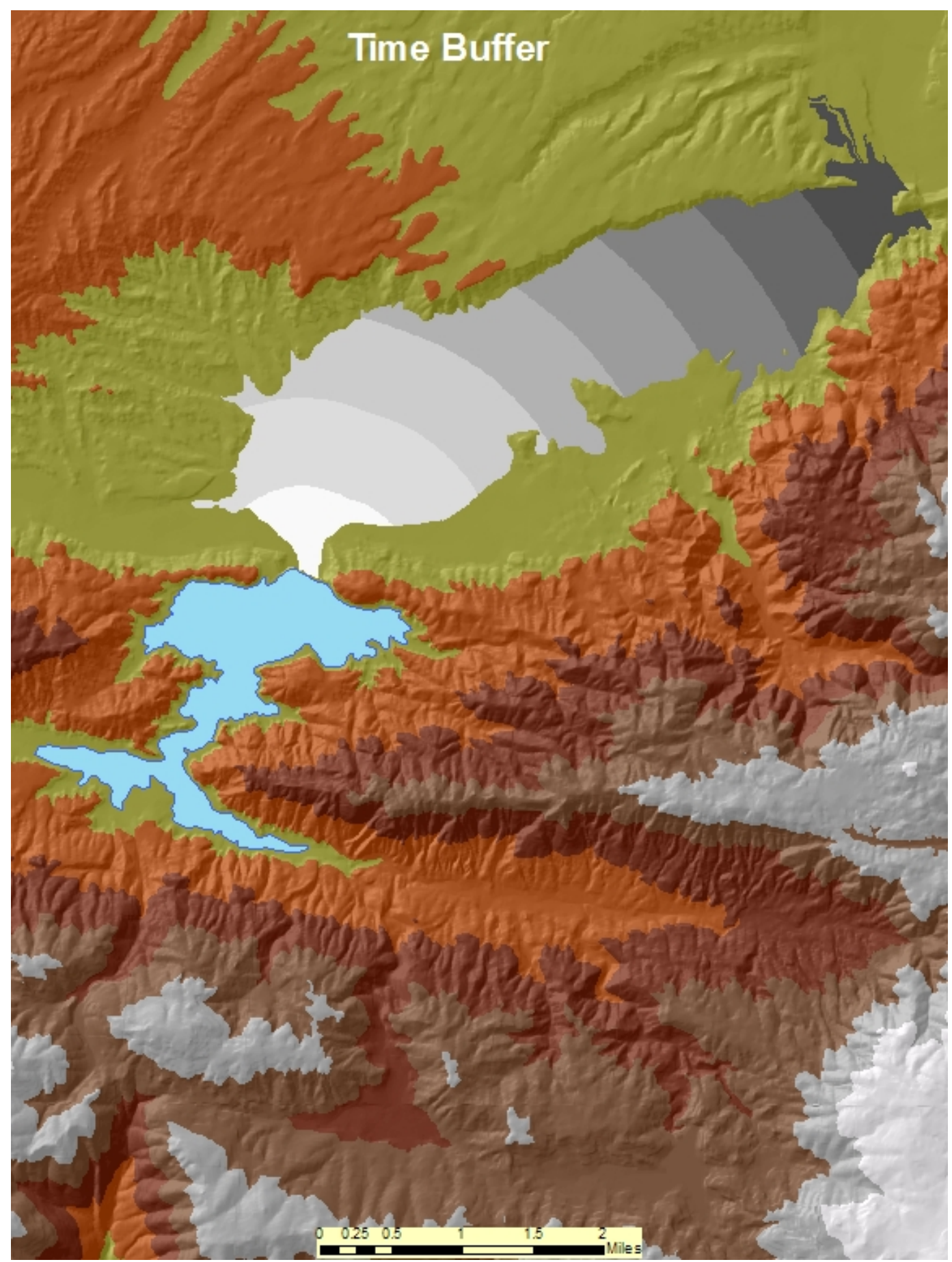

Figure 6-8. Time buffer flooded area depiction using ArcGIS 9.0 


\section{REFERENCES}

References cited:

California State Parks Home page

(http://search.parks.ca.gov/cgibin/MsmGo.exe?grab id=155\&EXTRA ARG=\&CFGNAME=MssFind\%2Ecfg\&host id=42 \&page id=8520448\&query=silverwood+lake\&hiword=lake+silverwood+)

U. S. Army Corps of Engineers, 2005. Tuttle Creek Dam Safety Assurance Program, http://www.nwk.usace.army.mil/projects/tcdam/index.htm 17 March 2005

Erdas, 1999. Erdas Field Guide, Fifth Edition. (Erdas: Atlanta, GA) page 29.

(HEC-RAS online Help, 2006)

Cameron T. Ackerman:

(Hydraulic Modeling of the Salt River, Arizona Using HECGeoRAS,17 May 2005)

http://gis.esri.com/library/userconf/proc00/professional/papers/PAP953/p953.htm

\section{BIBLIOGRAPHY}

\section{Websites visited to obtain data:}

California Spatial Information Library (CaSIL), http://gis.ca.gov/index.epl

GeoCommunity, http://data.geocomm.com

Utah Automated Geographic Reference Center (AGRC),

http://agrc.its.state.ut.us/agrc_sgid/sgidlib/statewide_shp.htm

Southern Nevada GIS, http://gisgate.co.clark.nv.us/gismo/Freedata.HTM

United States Army Corps of Engineers (USACE), http://www.hec.usace.army.mil/software/hec-ras/hecras-download.html

(Software download) HEC-RAS 3.1.3

Boss International, http://www.bossintl.com/products/download/item/DAMBRK.html\#3

(Software download) 
Leica Geosystems GIS and Mapping, http://gis.leica-geosystems.com/

(Software download) Erdas Imagine 8.7

MapMart Global Mapping Solutions, http://www.mapmart.com/

\section{Websites visited for research and reference information:}

Gannett Fleming; Dam Breach Analysis for High Hazard

http://www.gannettfleming.com/projectdetail.asp?ProjAspect=39123A

National Digital Orthophotograph Program (NDOP), http://www.ndop.gov/

National States Geographic Information Council (NSGIC), http://www.nsgic.org

United States Department of the Interior/Bureau of Reclamation, http://www.usbr.gov/pmts/hydraulics_lab/twahl/

Steve Pitman: GIS for Faster Analysis of Dam-break Flows http://www.crwr.utexas.edu/gis/gishydro04/Introduction/TermProjects/Pitman.ht $\underline{\mathrm{m}}$

California State Parks, http://www.parks.ca.gov/default.asp?page_id=650

University of Texas at Austin: GIS Hydro 2002

http://www.crwr.utexas.edu/gis/gishydro02/GISHydro2002.htm

Tuttle Creek Dam Safety Assurance Program, http://www.nwk.usace.army.mil/projects/tcdam/index.htm

United States Army Corps of Engineers (USACE)/Los Angeles District, http://www.spl.usace.army.mil/

United States Department of Homeland Security (DHS), http://www.dhs.gov/dhspublic 


\section{Appendix A: Tuttle Creek Dam Safety Exercise}

As mentioned in the Project Background section of this document, the analyst has extensive experience providing geospatial support while working with military and civilian disaster response exercises and special events, such as major sporting events. The practice of emergency response has become extremely prevalent the last four years, since the infamous September $11^{\text {th }}$, 2001 event. Following is the article outlining exercise procedures involved in the Tuttle Creek Dam Project outside Manhattan, Kansas. This exercise considers the possibility of a dam burst caused by an earthquake, rather than a terrorist event. Although these are two different disaster scenarios, they never the less share many similarities.

\section{Media Release}

US Army Corps of Engineers

601 E. 12th Street

Kansas City, Missouri 64106-2896 (816) 983-3487

Kansas City District

Contact: Eric Cramer

Date Oct 18, 2004

Tuttle Creek Dam Safety Exercise, Siren Testing and School Evacuation

MANHATTAN, Kan. - Preparation for a potential earthquake in the Manhattan area and testing of the Tuttle Creek Dam Failure Warning System will continue here on

Wednesday, October 20th with a Dam Safety Exercise. This exercise is being coordinated by the U.S. Army Corps of Engineers Kansas City District and involves 100 people from across the country from 20 different city, county, state and Federal agencies. This exercise will allow agencies to practice responding to an earthquake and its impacts on the community and on Tuttle Creek Dam.

This exercise will not involve activities in the field or the actual movement of personnel or equipment and is not open to the public. Agency representatives will be available to the media at 9:30 am and 11:00 am at the Manhattan Fire Department Headquarters at 2000 Denison Avenue.

As part of the dam safety exercise, at 1:00 pm the Tuttle Creek Dam Failure Warning System sirens will sound. Only the six new sirens will broadcast the voice messages and multiple siren tones. This test will be the final verification that the new sirens are fully operational. During this test, a voice message will indicate that "This is a test". The tornado warning tone will sound, followed by the civil defense tone, and then the dam safety evacuation tone will sound. After all tones have sounded, a voice message will indicate that "This has been a test". The evacuation tone is distinctly different than the other two tones. Residents should not take any action as a result of these tests. The Tuttle Creek Dam Failure Warning System will be tested monthly during routine tornado warning tests on the first Monday of each month. 
When the sirens sound, the 375 students of Eisenhower Middle School at 800 Walters Drive will practice evacuating by walking to the Meadowlark Hills Retirement Center west of Tuttle Creek Boulevard. As part of this evacuation, Tuttle Creek Boulevard will be closed while students cross the road at Northfield road.

The Kansas City District, U.S. Army Corps of Engineers constructed the six siren towers at Sojourner Truth Park, the City of Manhattan Water Treatment Facility, Northeast Community Park, Eisenhower Baseball Complex, the intersection of Casement and Barnes roads, and Tuttle Creek Outlet Park.

The Tuttle Creek Dam Failure Warning System and all associated exercises and testing have been cooperative efforts between the Corps of Engineers and local emergency management, emergency response and law enforcement officials.

The Dam Failure Warning System is designed to alert the community immediately downstream of Tuttle Creek Dam of the need to evacuate in the event of a potential dam failure caused by an earthquake.

Although the chances of an earthquake of this magnitude occurring near Manhattan are very small, the warning system will help protect the local community while the Corps of Engineers modifies Tuttle Creek Dam so that it meets current dam safety standards for earthquake effects. This construction on the dam will begin in 2005.

For more information about the Tuttle Creek Dam Failure Warning System, see the Corps Web site at http://www.nwk.usace.army.mil/projects/tcdam/index.htm or call Eric Cramer (816) 983-3487. 


\section{Appendix B: Cost Summary of MIP in terms of hours}

Table 6-2. Cost Summary of MIP in terms of hours

\begin{tabular}{|l|l|l|l|l|l|}
\hline Task & Task Description & Start Date & $\begin{array}{l}\text { Completion } \\
\text { Date }\end{array}$ & Analyst & Hours \\
\hline $\mathbf{1}$ & MIP Topic & 26 Aug 04 & 3 Sep 04 & Dean Erpenbach & $\mathbf{1 0}$ \\
\hline $\mathbf{2}$ & MIP Design & 3 Sep 04 & 31 Oct 04 & Dean Erpenbach & $\mathbf{1 2 4}$ \\
\hline $\mathbf{3}$ & Data Acquisition & 9 Jan 05 & 4 Mar 05 & Dean Erpenbach & $\mathbf{1 2 4}$ \\
\hline $\mathbf{4}$ & MIP Development & 21 Feb 05 & 11 July 05 & Dean Erpenbach & $\mathbf{3 0 0}$ \\
\hline $\mathbf{5}$ & $\begin{array}{l}\text { Final } \\
\text { Paper/Presentation }\end{array}$ & 3 June 05 & 29 July 05 & Dean Erpenbach & $\mathbf{1 2 0}$ \\
\hline $\mathbf{6}$ & $\begin{array}{l}\text { Training/Revisions } \\
\text { for NGA }\end{array}$ & 16 Aug 05 & 30 Aug 05 & Dean Erpenbach & $\mathbf{4 0}$ \\
\hline $\mathbf{7}$ & Total Hours & 26 Aug 04 & 30 Aug 05 & Dean Erpenbach & $\mathbf{7 0 8}$ \\
\hline
\end{tabular}




\section{Appendix C: Big Bear Lake}

The analyst chose Big Bear Lake, which is located in San Bernardino County, approximately forty-five miles northeast of Redlands, California. This close proximity means that many of the same data sets could be used in the model. The test of the model proved that by simply changing the file path names of the data sets, the model ran to completion. Many of the tools used for the terrain visualization model require significant computer processing time. For this reason, the analyst decided to include them in the working model. The graphics in Figures 2-6 through 2-11 were created upon model completion on the second lake, Big Bear. 


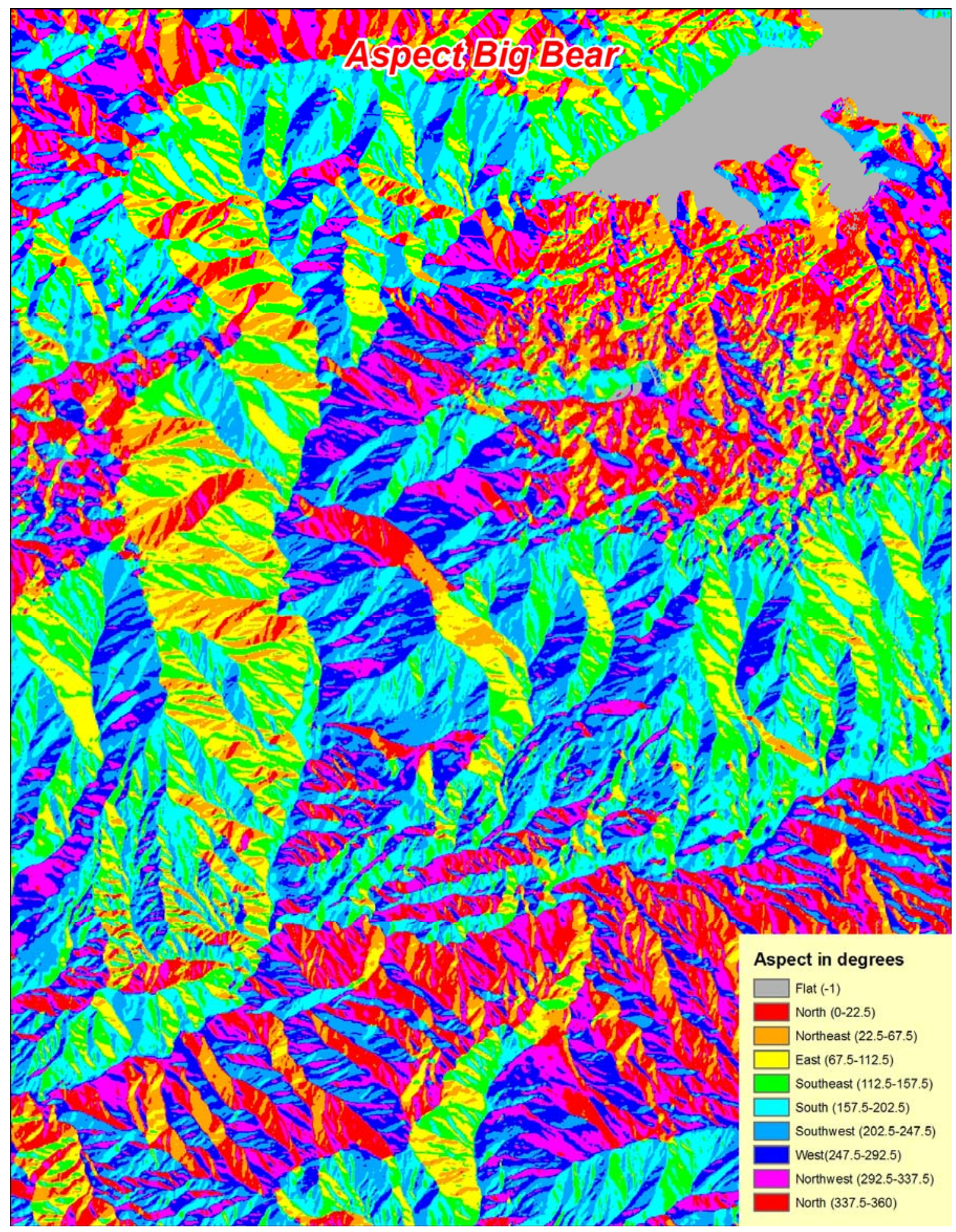

Figure C-1. Aspect of Big Bear Lake area 


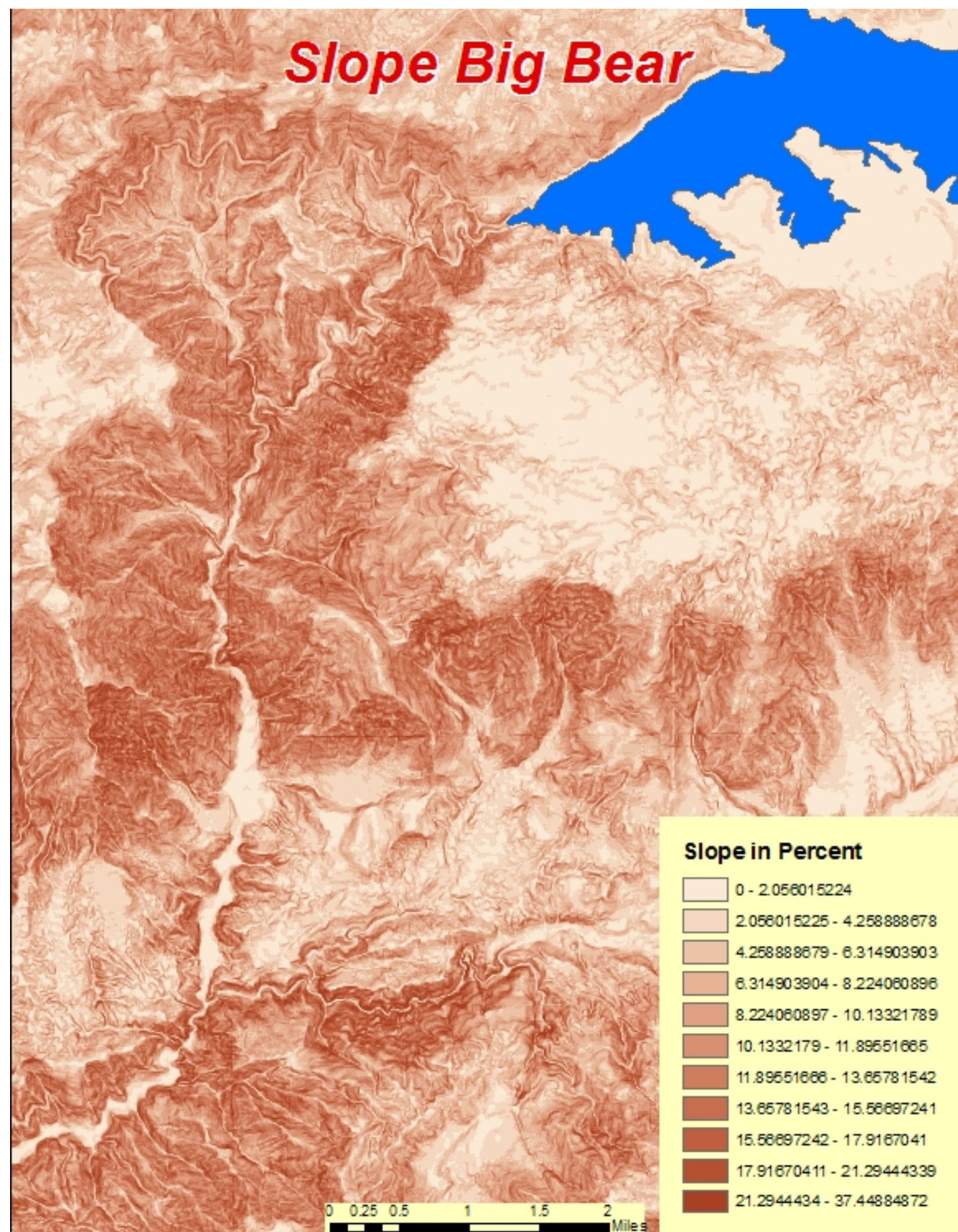

Figure C-2. Slope portrayal of Big Bear Lake area 


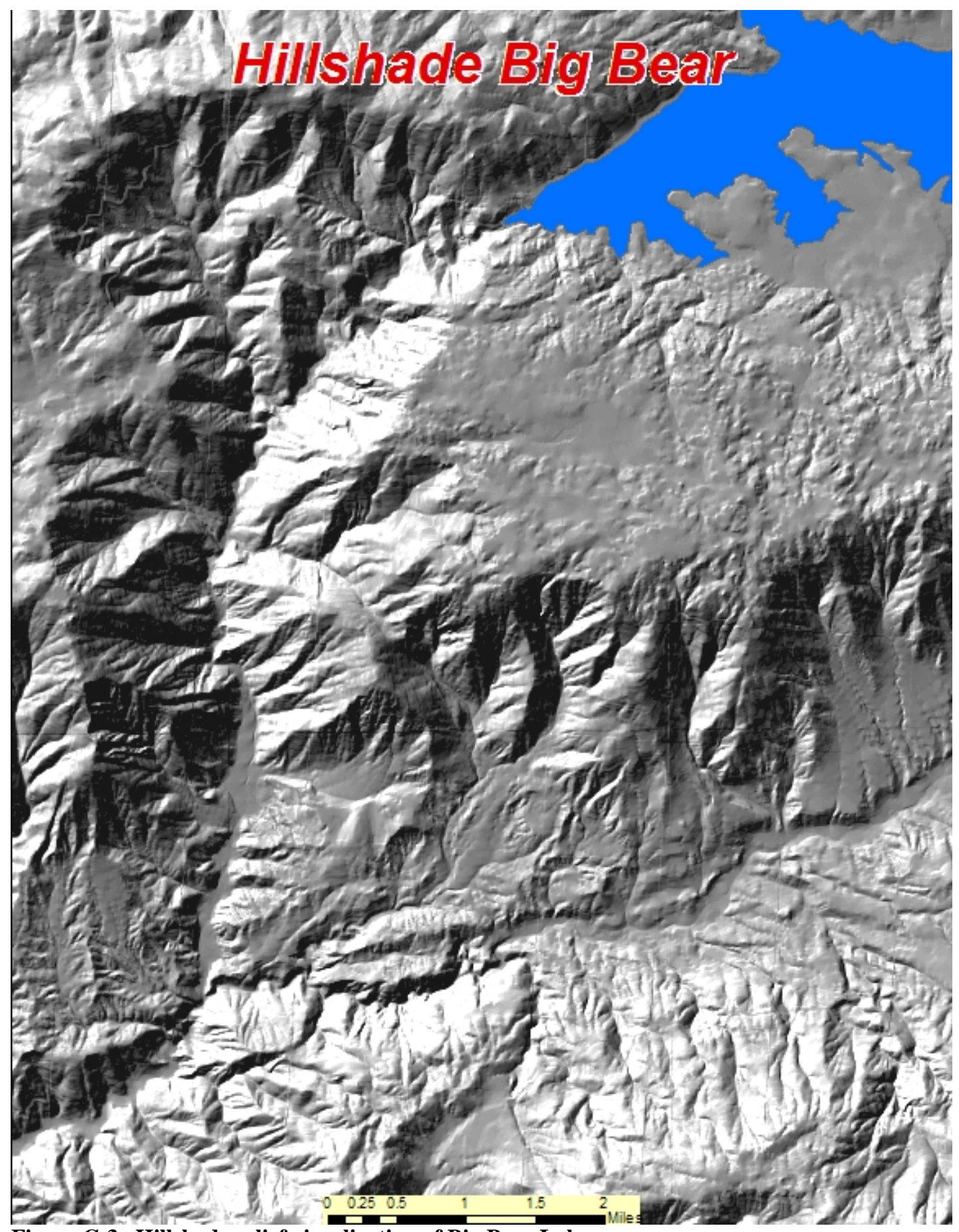

Figure C-3. Hillshade relief visualization of Big Bear Lake area 


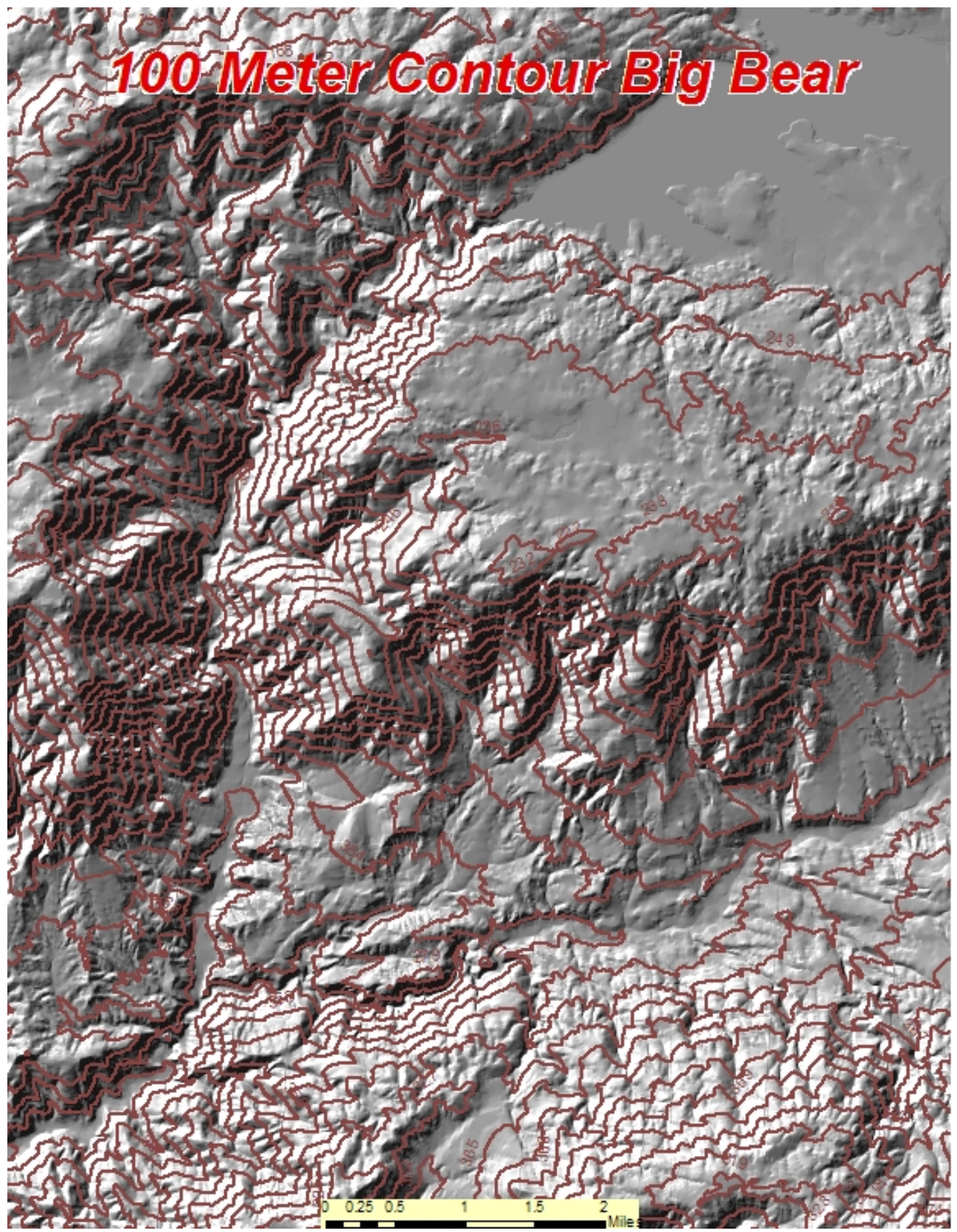

Figure C-4. 100 meter contours for Big Bear Lake area

The Flow Accumulation Tool performs calculations for surface runoff based on a continuous raster surface. The output from the Spatial Analyst extension tool, Flow Direction, is used for the continuous raster surface input in the Flow Accumulation tool. Areas with resulting high values can be categorized as high runoff or potential streams. (ESRI ArcGIS Desktop Help) This tool allows the analyst to visualize the natural flow of water. It becomes helpful when used with the other tools in the surface analysis model. 


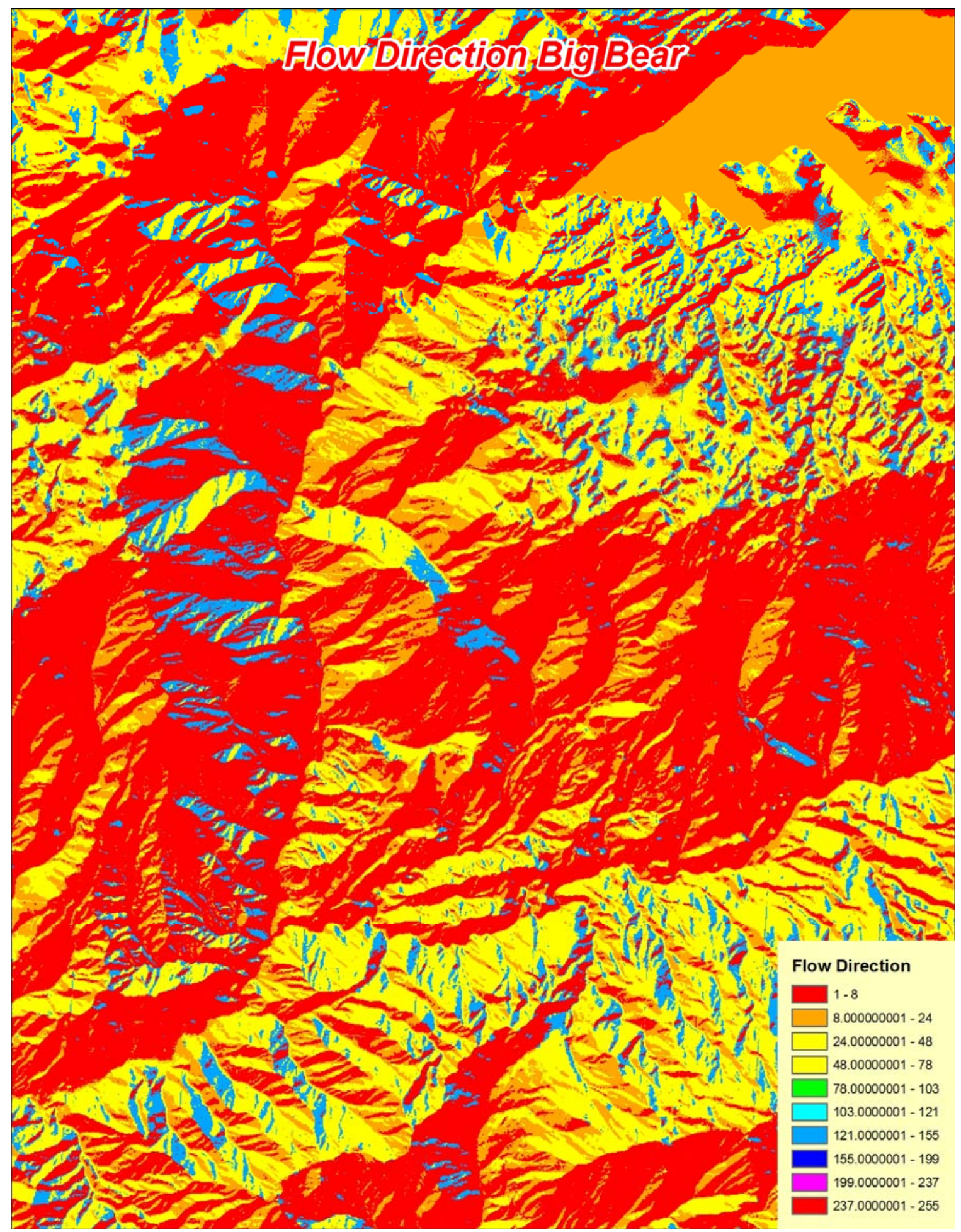

Figure C-5. Spatial Analyst's Flow Direction Tool for Big Bear Lake 


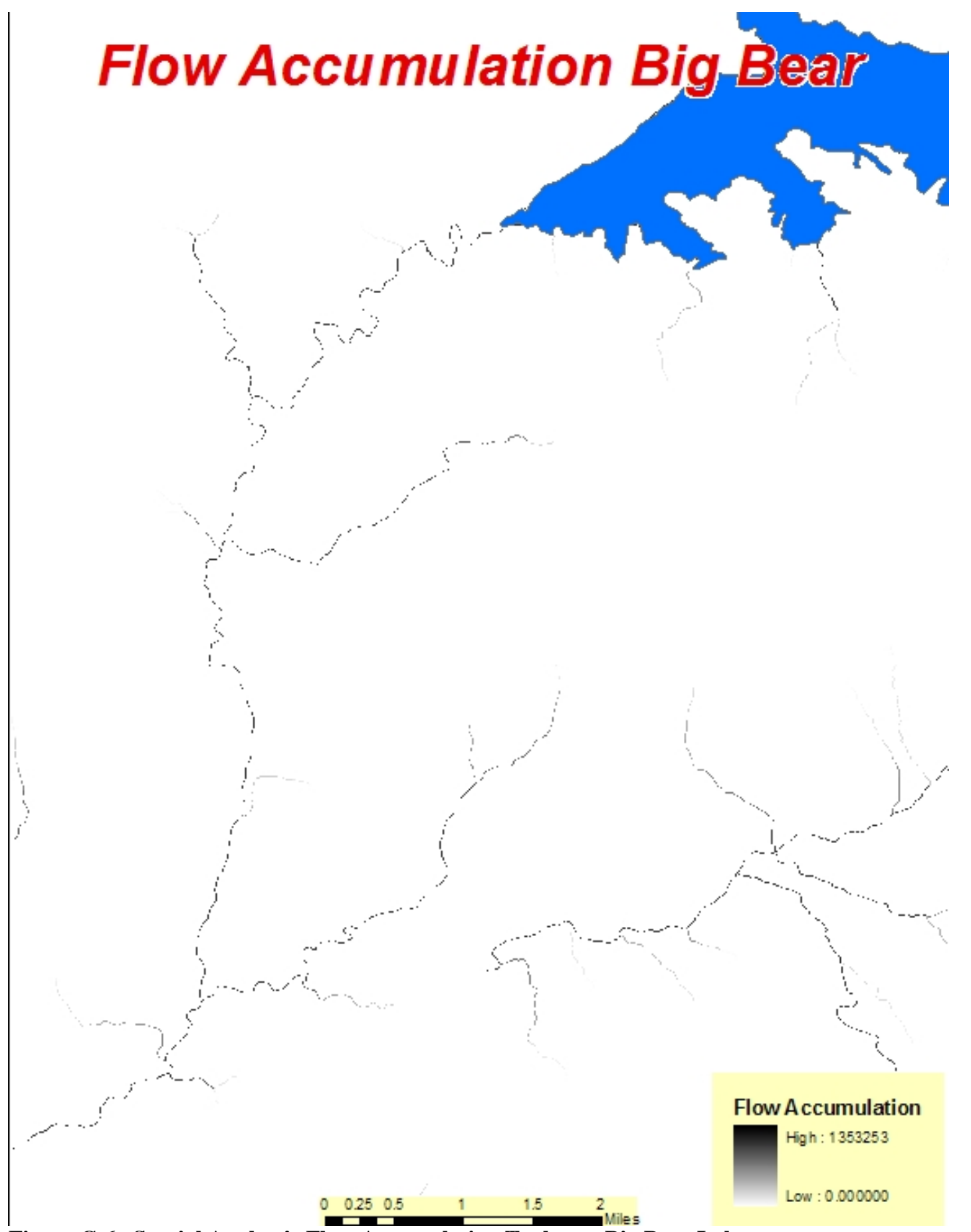

Figure C-6. Spatial Analyst’s Flow Accumulation Tool over Big Bear Lake 


\section{Appendix D: HEC-RAS Overview}

The following descriptions were taken from the HEC-RAS Help to give the user a consolidated description of the HEC-RAS software. The last two sections in this Appendix relate to the HEC-GeoRAS Software extension developed by ESRI and the USACE through a CRADA effort. These two sections make an easy transition into Appendix E which covers HEC-GeoRAS in a similar format. The main advantage of using HEC-GeoRAS is that it allows the user to work in the three-dimensional world, rather than the two-dimensional world that HEC-RAS uses.

\section{General Philosophy of the Modeling System}

HEC-RAS is an integrated system of software, designed for interactive use in a multitasking environment. The system is comprised of a graphical user interface (GUI), separate hydraulic analysis components, data storage and management capabilities, graphics and reporting facilities.

The HEC-RAS system will ultimately contain three one-dimensional hydraulic analysis components for: (1) steady flow water surface profile computations; (2) unsteady flow simulation; and (3) movable boundary sediment transport computations. A key element is that all three components will use a common geometric data representation and common geometric and hydraulic computation routines. In addition to the three hydraulic analysis components, the system contains several hydraulic design features that can be invoked once the basic water surface profiles are computed.

New features and additional capabilities will be added in future releases.

The current version of HEC-RAS supports Steady and Unsteady flow water surface profile calculations. (HEC-RAS online Help, 2006)

\section{Data Storage and Management}

Data storage is accomplished through the use of "flat" files (ASCII and binary), as well as the HEC-DSS. User input data are stored in flat files under separate categories of project, plan, geometry, steady flow, unsteady flow, and sediment data. Output data is predominantly stored in separate binary files. Data can be transferred between HEC-RAS and other programs by utilizing the HEC-DSS.

Data management is accomplished through the user interface. The modeler is requested to enter a single filename for the project being developed. Once the project filename is entered, all other files are automatically created and named by the interface as needed. The interface provides for renaming, moving, and deletion of files on a project-by-project basis. (HEC-RAS online Help, 2006)

\section{Graphics and Reporting}

Graphics include X-Y plots of the river system schematic, cross-sections, profiles, rating curves, hydrographs, and many other hydraulic variables. A three-dimensional plot of 
multiple cross-sections is also provided. Tabular output is available. Users can select from pre-defined tables or develop their own customized tables. All graphical and tabular output can be displayed on the screen, sent directly to a printer (or plotter), or passed through the Windows Clipboard to other software, such as a word-processor or spreadsheet.

Reporting facilities allow for printed output of input data as well as output data. Reports can be customized as to the amount and type of information desired. (HEC-RAS online Help, 2006)

\section{Defining A Plan}

The first step in performing a simulation is to put together a Plan. The Plan defines which geometry and flow data are to be used, as well as provide a description and short identifier for the run. Also included in the plan information are the selected flow regime and the simulation options.

Before a Plan is defined, the user should select which geometry and flow data will be used in the plan. To select a geometry or flow file, press the down arrow button next to the desired data type. When this button is pressed, a list will appear displaying all of the available files of that type that are currently available for the project. Select the geometry and flow files that you want to use for the current plan.

To establish a Plan, select New Plan from the File menu on the steady flow analysis window. When New Plan is selected, a window will appear prompting you to enter a title for the plan. After you enter the title, press the $\mathbf{O K}$ button to close the window and accept the title. The user will also be prompted to enter a short identifier for the plan. The short identifier is limited to 12 characters. It is very important to enter a short identifier that is descriptive of the plan. When viewing multiple plan output from the graphics and tables, the Short ID will be used to identify each plan.

The last step is to select the desired flow regime for which the model will perform calculations. The user can select between subcritical, supercritical, or mixed flow regime calculations. (HEC-RAS online Help, 2006)

\section{Starting the Computations}

Once all of the data have been entered, and a Plan has been defined, the steady flow computations can be performed by pressing the Compute button at the bottom of the steady flow simulation window. Once the compute button is pressed, a separate window will appear showing you the progress of the computations. The information that appears in the window is only there as an indicator of the programs progress during the computations. This window is not intended to be used for viewing any output. When the computations have been completed, the user can close the computations window by clicking the close button at the bottom of the window. If the computations ended with a message stating "Finished Steady Flow Simulation," the user can then begin to review the output. (HEC-RAS online Help, 2006) 


\section{Using GIS Data With HEC-RAS}

HEC-RAS has the ability to import three-dimensional (3D) river schematic and cross section data created in a GIS or CADD system. While the HEC-RAS software only utilizes two-dimensional data during the computations, the three-dimensional information is used in the program for display purposes. After the user has completed a hydraulic analysis, the computed water surface profiles can be exported back to the GIS or CADD system for development and display of a flood inundation map.

The importing and exporting of GIS or CADD data is accomplished through the use of formatted ASCII text files. The text files provide a generic way of exchanging data between GIS/CADD systems and HEC-RAS, without adopting any single GIS/CADD system. Appendix B of this manual provides a detailed description and examples of the file formats used for importing and exporting GIS or CADD data.

The HEC has developed an ArcView GIS extension called GeoRAS, that was specifically designed to process geospatial data for use with HEC-RAS. The GeoRAS software allows a user to write geometric data to a file in the required format for HEC-RAS. Additionally, the users can read the HEC-RAS results into GeoRAS and perform the flood inundation mapping. This software is not part of the HEC-RAS program. The software and a user's manual are provided as a separate program to be used with ArcView. Also, the Intergraph Corporation has adding the capability to exchange data with HEC-RAS in their Software package called Storm and Sewer Works (Intergraph, 1999)

This chapter discusses how to import GIS or CADD data into HEC-RAS; what additional information will need to be added to complete the data; and how to export the results back to the GIS or CADD system. (HEC-RAS online Help, 2006)

\section{HEC-RAS Appendix B}

\section{HEC-RAS Import/Export Files for Geospatial Data}

At version 2.0, HEC-RAS has introduced three-dimensional (3D) geometry for the description of river networks and cross-sections. This capability makes it possible to import channel geometry from CADD or GIS programs without conversion from realworld coordinates to station-elevation descriptions for the cross sections, as HEC-2 required. Similarly, water-surface elevations calculated at cross sections can be exported to CADD or GIS programs, where they can be used to create model water surfaces for inundation mapping. (HEC-RAS online Help, 2006) 


\section{Appendix E: HEC-GeoRAS Overview}

This section gives a brief overview of the HEC-GeoRAS extension for ESRI's ArcGIS software program. The analyst provides a paragraph on the general usage, and then cites an article from an actual example of usage of the HEC-GeoRAS extension. The analyst follows with some excerpts of the online help dealing with the particular tools incorporated into the analyst's Major Individual Project (MIP).

HEC-GeoRAS is a set of procedures, tools, and utilities for processing geospatial data in ArcGIS using a graphical user interface (GUI). The interface allows the preparation of geometric data for import into HEC-RAS and processes simulation results

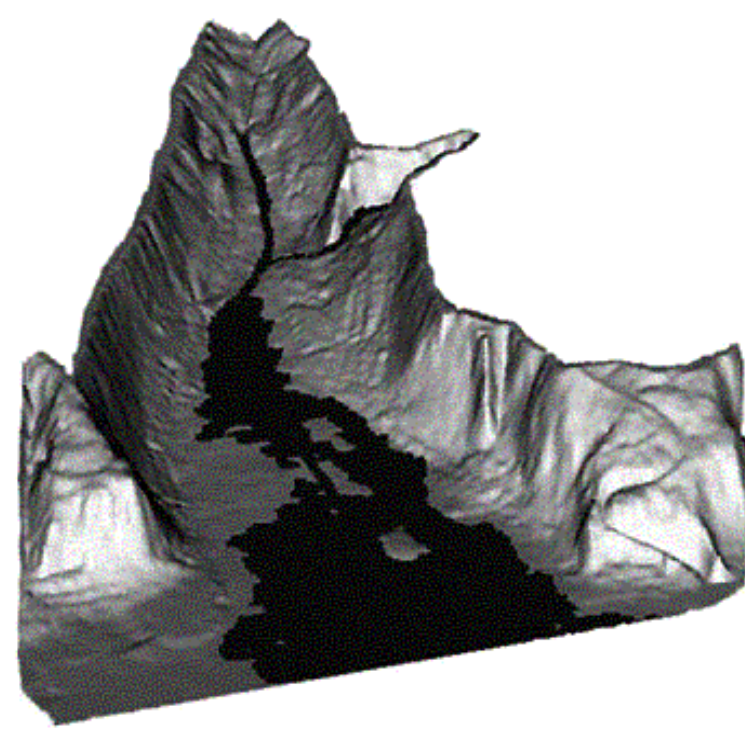
exported from HEC-RAS. To create the import file, the user must have an existing digital terrain model (DTM) of the river system in the ArcInfo TIN format. The user creates a series of line themes pertinent to developing geometric data for HEC-RAS. The themes created are the Stream Centerline, Flow Path Centerlines (optional), Main Channel Banks (optional), and Cross Section Cut Lines referred to as the RAS Themes.

Additional RAS Themes may be created/used to extract additional geometric data for import in HEC-RAS. These themes include Land Use, Levee Alignment, Ineffective Flow Areas, and

Storage Areas.

Water surface profile data and velocity data exported from HEC-RAS simulations may be processed by HEC-GeoRAS for GIS analysis for floodplain mapping, flood damage computations, ecosystem restoration, and flood warning response and preparedness. (http://www.hec.usace.army.mil/software/hec-ras/hec-georas.html)

GeoRAS requires the use of a digital terrain model (DTM) in the form of a triangulated irregular network (TIN). The TIN is used for extracting station-elevation data along cross sections, but may also be useful for visualizing the terrain. Due to the fact that the terrain for the Tres Rios study area had braided river channel with little relief, visualization of the TIN was not practical for identifying connected conveyance areas. However, registered digital aerial photography at a 1:2,400 scale were available for the study area and were used to identify the stream network and floodplain.

Several RAS Themes were created in the process of developing the geometric data file for import to HEC-RAS. ArcView themes defining the stream network, main channel conveyance, flow paths, cross-section locations, and levees were developed. A land use theme was available for the study area, and was used to estimate roughness coefficients. 
These themes were then used, together with the TIN, to develop geometric data for import into HEC-RAS.

Cameron T. Ackerman:

(Hydraulic Modeling of the Salt River, Arizona Using HECGeoRAS,17 May 2005)

http://gis.esri.com/library/userconf/proc00/professional/papers/PAP953/p953.htm

\section{Cross-sectional cut lines}

The location of cross sections is defined by the cross-sectional cut lines theme. They are digitized from the left to right overbank (when facing downstream). Cut lines should be created perpendicular to flow. Geometric data is extracted using the cross-sectional cut line theme. The data is then appended to the cut lines theme table.

\section{Terrain TIN}

Elevation data is extracted from the Terrain TIN, but it is also used to locate the floodplain. For the Tres Rios area, a digital orthophoto was available to use a reference for locating the floodplain. Note the waste water treatment plant in the Northeast portion of the photo.

The Terrain TIN was modified for the alternative scenario to reflect proposed channel modifications.

Cameron T. Ackerman:

(Hydraulic Modeling of the Salt River, Arizona Using HECGeoRAS,17 May 2005)

http://gis.esri.com/library/userconf/proc00/professional/papers/PAP953/p953.htm

\section{Stream centerline}

The stream centerline was digitized, using the orthophoto for reference, from upstream to downstream. The stream centerline is used to calculate the river stationing at each cross section.

Data were extracted through automated procedure in GeoRAS. The data were appended to the cross-sectional cut line theme before being written to a file for import into HECRAS. The cross-sectional cut line theme table is shown in Figure 2. Mannings $n$ values and levee information is stored in separate tables that are linked to the cross section ID (XS_ID) field. The geometric import file is an ASCII file, having a data exchange file format developed by HEC that contains a header information, stream centerline data, and cross-sectional data.

Cameron T. Ackerman:

(Hydraulic Modeling of the Salt River, Arizona Using HECGeoRAS,17 May 2005) http://gis.esri.com/library/userconf/proc00/professional/papers/PAP953/p953.htm

HEC-GeoRAS is an ArcGIS application specifically designed to process geospatial data for use with the Hydrological Engineering Center River Analysis System (HEC-RAS). The application allows users with limited GIS experience to create an HEC-RAS import file containing geometric attribute data from an existing digital terrain model (DTM) and 
complementary data sets. (http://www.hec.usace.army.mil/software/hec-ras/hecgeoras.html)

\section{Create Stream Centerline}

The Stream Centerline layer should be created first. Click RAS Geometry. Point to Create RAS Layers, and click Stream Centerline.

A dialog will show up with an editable layer name.

Click OK to add the Stream Centerline layer to the map. A message will inform you that the layer needs to be completed by digitizing new features. To start adding features to the Stream Centerline layer, click Editor, and point to Start Editing.

Select Create New Feature from the dropdown list to set the task. Select the feature layer from the dropdown list to set the target. Move the cursor over to the map and digitize river reaches one by one, from upstream to downstream using the mouse. Each reach is represented by one line having a series of vertices. To start a line use the mouse to left click, using left clicks to add vertices, and double-click to end a line. After creating the river network, click Editor and point to Stop Editing. A dialog will appear asking you to save the edits. Click Yes.

You should also define the spatial reference of the map before adding the layer. Failure to do so will result in a layer without spatial reference. Spatial reference can be set by either setting the properties of map, or by simply adding a terrain layer with a defined spatial reference. (http://www.hec.usace.army.mil/software/hec-ras/hec-georas.html)

\section{Create XS Cut Lines}

Click RAS Geometry. Point to Create RAS Layers, and click XS Cut Lines.

Click OK to add the XS Cut Lines layer to the map. A message will inform you that the layer needs to be completed by digitizing new features. To start adding features to the XS Cut Lines layer, click Editor, and point to Start Editing.

Select Create New Feature from the dropdown list to set the task. Select the feature layer from the dropdown list to set the target. Move the cursor over to the map and digitize features where cross-sectional data should be extracted from the Terrain TIN. Each cross-sectional cut line should be drawn from the left overbank to the right overbank, when facing downstream. Cross-sectional cut lines are multi-segment lines that should be drawn perpendicular to the flow path lines. Cut lines must cross the main channel only once and no two cross sections may intersect. Each feature is represented by one line having a series of vertices. To start a line use the mouse to left click, using left clicks to add vertices, and double-click to end a line. After creating the features, click Editor and point to Stop Editing. A dialog will appear asking you to save the edits. Click Yes. 
You should also define the spatial reference of the map before adding the layer. Failure to do so will result in a layer without spatial reference. Spatial reference can be set by either setting the properties of map, or by simply adding a terrain layer with a defined spatial reference. (http://www.hec.usace.army.mil/software/hec-ras/hec-georas.html)

\section{Read RAS GIS Export File}

Click Floodplain Mapping and point to Read RAS GIS Export File.

HEC-GeoRAS will read the export file and begin creating preliminary data sets. Following feature classes are created:

- $\quad$ Cross section cut lines

- Bounding polygon layer defining the maximum extent of flow

No user input is needed to create these feature classes. These layers are used to create floodplain datasets. For each new analysis, a new directory is needed. This is specified in the Layer Setup. A new personal geodatabase is created under this directory. The geodatabase is named after the Analysis name. The name of dataset in the geodatabase by default is RASResults. This name is hardwired in GeoRAS. After a successful reading of the RAS export data, the RASResults dataset contains two layers - Cross Section Cut Lines and Flow Boundary polygon. Both these layers are added to a new map named RASResults. (http://www.hec.usace.army.mil/software/hec-ras/hec-georas.html)

\section{Water Surface Generation}

All GIS Layers developed during RAS post-processing are based on the content of the RAS GIS Export File and the Terrain TIN/DEM. For data consistency, the same Terrain TIN/DEM used for generation of the RAS GIS Import File should be used for postprocessing.

Once the RAS GIS Export File has been read, the user can begin creating inundation data sets. The first step is to create water surface TIN for each water surface profile. Click Floodplain Mapping and point to Water Surface Generation.

The dialog lists all water surface profiles. Multiple water surface profiles may be selected by holding the SHIFT key down during selection. Press OK to build water surface TINs.

One water surface TIN will be created for each selected water surface profile. The TIN is created based on the water surface elevation at each cross section and the flow boundary data extracted from the RAS GIS Export File. Prefixing 'WS' to the water surface profile name derives the name of water surface TIN. It is saved in the output directory specified in the Layer Setup. Be aware that if a water surface TIN with the same name already 
exists in that directory, GeoRAS will not regenerate the TIN. Instead, it will use the existing water surface TIN for further analysis.

After a water surface TIN is created, it is added to the map. The default name for the map is RASResults. One example is given below (http://www.hec.usace.army.mil/software/hec-ras/hec-georas.html).

\section{Floodplain Delineation by GRID Intersection}

The floodplain may then be delineated for each water surface profile for which a water surface TIN exists. Click Floodplain Mapping, point to Floodplain Delineation, and click GRID Intersection.

The dialog lists all water surface profiles available. Multiple water surface profiles may be selected by holding the SHIFT key down during selection. Press OK to build floodplain polygon feature classes.

One floodplain polygon will be created for each water surface TIN. Each floodplain polygon results from intersecting the water surface and terrain surface.

The floodplain delineation procedure converts the water surface TIN and Terrain TIN to lattices (grids) with the same cell size and origin. A depth grid is then created with values where the water surface grid is higher than the terrain grid. Each depth grid is named as a concatenation of 'gd' and the water surface profile name; and it is saved into the output directory specified in the Layer Setup. The depth grid is then converted into a floodplain polygon feature class that is also saved in the personal geodatabase. After the floodplain delineation, depth grid and feature class are created and added to the map The figure below presents an example about those created floodplain delineation depth grid and feature class. (Hec-GeoRAS online help: 12 June 2006) 